TRABALHO DE GRADUAÇÃO

\title{
PROJETO DE UM AMPLIFICADOR DE BAIXO RUÍDO EM TECNOLOGIA CMOS COM AUXÍLIO DE ALGORITMOS EVOLUCIONÁRIOS
}

\author{
Bernardo Menezes Leitão Tavares \\ Rodrigo Ramos Gonçalves
}

\section{UNIVERSIDADE DE BRASÍLIA}



Faculdade de Tecnologia

\title{
TRABALHO DE GRADUAÇÃO
}

\section{PROJETO DE UM AMPLIFICADOR DE BAIXO RUÍDO EM TECNOLOGIA CMOS COM AUXÍLIO DE ALGORITMOS EVOLUCIONÁRIOS}

\author{
Bernardo Menezes Leitão Tavares \\ Rodrigo Ramos Gonçalves
}

\begin{abstract}
Relatório submetido ao Departamento de Engenharia Elétrica
da Faculdade de Tecnologia da Universidade de Brasília como requisito parcial para obtenção do grau de Engenheiro Eletricista.
\end{abstract}

\section{Banca Examinadora}

Prof. Dr. Paulo Henrique Portela, UnB/ ENE (Orientador)

Prof. Dr. Alexandre Ricardo Soares Romariz, UnB/ ENE

Prof. MSc. Charles dos Santos Costa, UCG/ ENG 


\section{FICHA CATALOGRÁFICA}

GONÇALVES, RODRIGO RAMOS

TAVARES, BERNARDO MENEZES L.

Projeto de um Amplificador de Baixo Ruído em Tecnologia CMOS com auxílio de

Algoritmos Evolucionários. [Distrito Federal] 2006.

xvii, ?? 134p.(ENE/FT/UnB, Engenheiro Eletricista, 2006)

Monografia de Graduação - Universidade de Brasília.

Faculdade de Tecnologia.

Departamento de Engenharia Elétrica.
1. Amplificadores
2. Microondas
3. CMOS
4. Algoritmos Evolucionários
I. ENE/FT/UnB
II. Título (série)

\section{REFERÊNCIA BIBLIOGRÁFICA}

Gonçalves, R. R. ;Tavares, B. M. L. (12006). Projeto de um Amplificador de Baixo Ruído em Tecnologia CMOS com auxílio de Algoritmos Evolucionários. Monografia de Graduação, Publicação ENE 02/2006, Departamento de Engenharia Elétrica, Universidade de Brasília, Brasília, DF, 134p.

\section{CESSÃO DE DIREITOS}

NOMES DOS AUTORES:

Bernardo Menezes Leitão Tavares

Rodrigo Ramos Gonçalves

TÍTULO: Projeto de um Amplificador de Baixo Ruído em Tecnologia CMOS com auxílio de Algoritmos Evolucionários.

GRAU / ANO: Engenheiro Eletricista / 2006

É concedida à Universidade de Brasília permissão para reproduzir cópias deste projeto final de graduação e para emprestar ou vender tais cópias somente para propósitos acadêmicos e científicos. O autor reserva outros direitos de publicação e nenhuma parte deste projeto final de graduação pode ser reproduzida sem a autorização por escrito do autor.

Bernardo Menezes Leitão Tavares

tavaresbernardo@gmail.com

Brasília - DF - Brasil.

Rodrigo Ramos Gonçalves

rodrigo.ram@gmail.com

Brasília - DF - Brasil. 


\section{Dedicatórias}

À minha família, aos meus amigos e à Priscylla. $\quad$ À minha família, aos amigos e especialmente à Maria Clara. 


\section{RESUMO}

É apresentado neste trabalho, um estudo sobre a tecnologia MOS, a teoria eletromagnética e algoritmos evolucionários. A tecnologia MOS vem mostrando uma constante evolução desde sua criação, o que tem resultado na ampliação de sua utilização pelos mais diversos campos. Conforme essa evolução ocorre, dispositivos operando em alta frequência se tornam uma realidade dentro desta tecnologia e para sua implantação um estudo das teorias eletromagnéticas se faz necessário. Pois assim, há um melhor entendimento da dinâmica envolvida entre circutos eletrônicos e sinais de alta frequência. $\mathrm{O}$ estudo sobre algoritmos evolucionários é feito com o intuito de desenvolver uma ferramenta de auxílio para projetos de circuitos elétricos, focado em dispositivos de alta frequência.

Nesse trabalho é feita a implementação de uma ferramenta para otimização de circuitos elétricos. Este otimizador foi agregado a um programa de simulação de circuitos de código aberto. Esta ferramenta é utilizada com a intenção de obter resultados que vão além dos resultados obtidos pelo projetista. O projeto de um amplificador de baixo ruído é executado e posteriormente otimizado utilizando este programa. Esse tipo de amplificador é de fundamental importância dentro de sistemas de comunicações, por se tratar, geralmente, do primeiro estágio após a antena, seu papel é amplificar sinais bastante atenuados sem adicionar muito ruído ao mesmo.

Os resultados encontrados mostram que a utilização de algoritmos evolucionários se torna uma importante ferramenta de projeto. Pois os resultados apresentados com a otimização se mostraram muito bons. Além dos bons resultados, a praticidade para sua obtenção também chamou atenção.

\section{ABSTRACT}

In this work is shown a study about MOS technology, eletromagnetic theory and evolutionary algorithms. The MOS Technology have been showing a constant evolution since it was created, wich is resulting in the large growth of its use in a lot of different fields. With this evolution, devices operating in high frequencies using this technology are becoming more achievable and for that, the study of eletromagnetic theories is necessary. Using all this knowledge together the dynamics between eletronic circuits and high frequency signals are more easy to understand. The study of evolutionary algorithms is made with the intention to develop an aid tool for eletric circuits projects, with the focus in microwave devices.

This work implements a tool for optimization of eletric circuits. This optimizer was inserted in a open-source circuit simulator. The use of such tool is to provide results that fall far better from the ones obtained by the projector. The project of an low noise amplifier is made and optimized in this work using the circuit optimizer. This kind of amplifier represents great importance in telecomunication's systems, because it is, generally, the first stage after the antenna and his role is to provide gain to very attenuated signals without add much noise to them. 
The results found show that the utilization of evolutionary algorithms have become an important aid to the project. Therefore the results obtained with the optimization were found to be very good. Besides the good results, the practicality of what was attain also was impressive. 



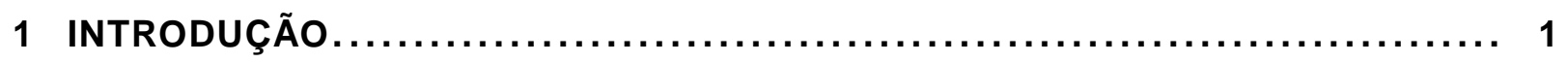

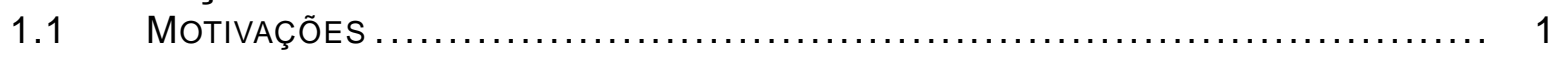

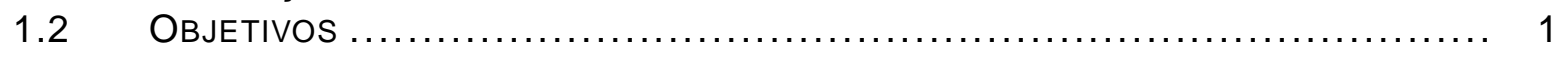

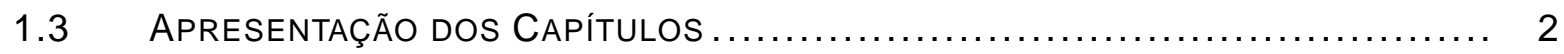

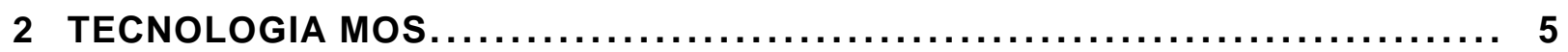

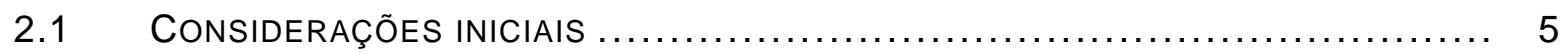

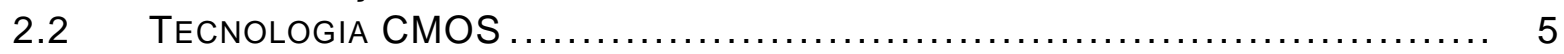

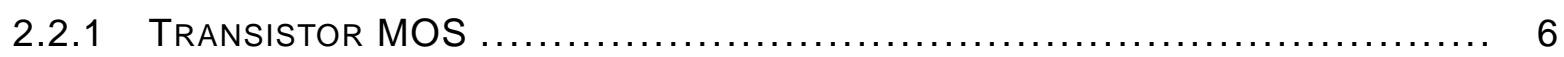

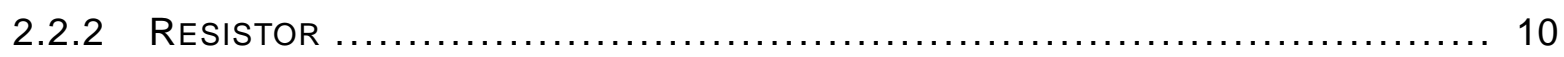

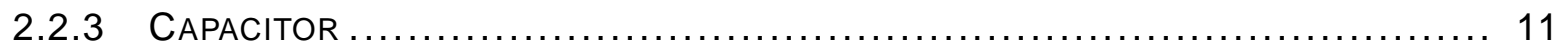

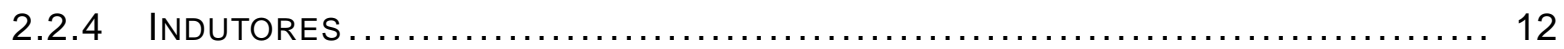

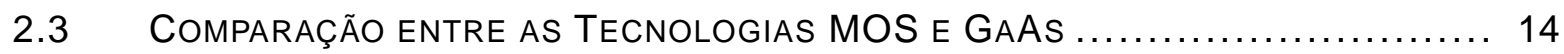

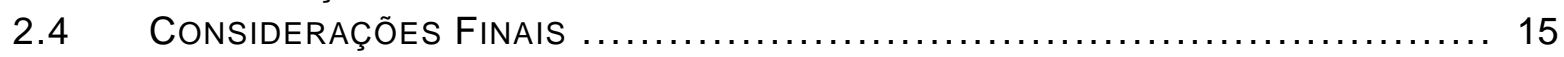

3 TEORIA DE MICROONDAS APLICADA À SÍNTESE DE AMPLIFICADORES CLASSE

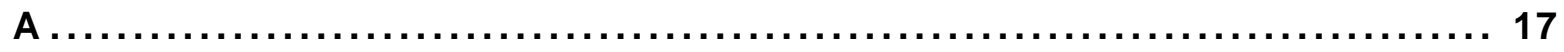

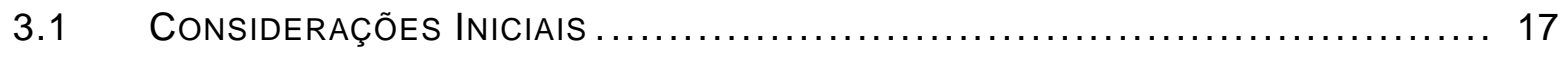

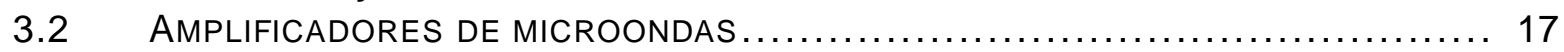

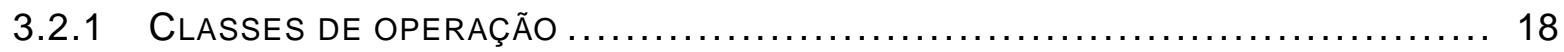

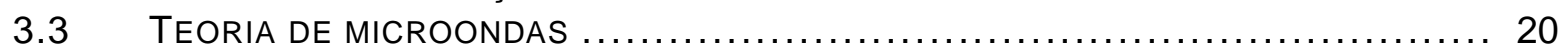

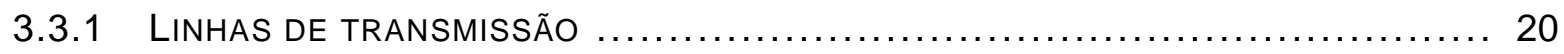

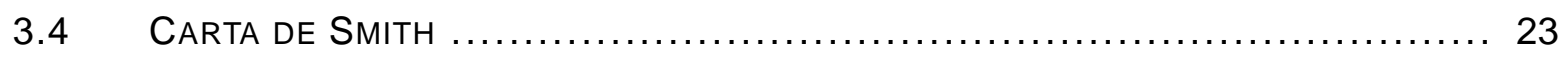

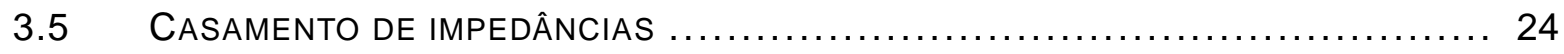

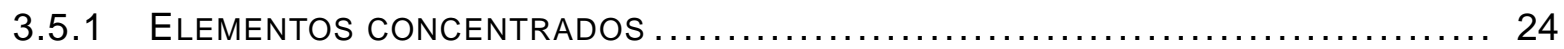

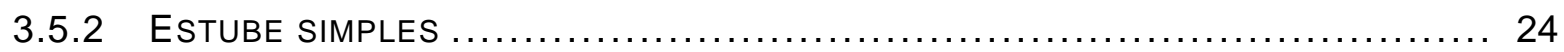

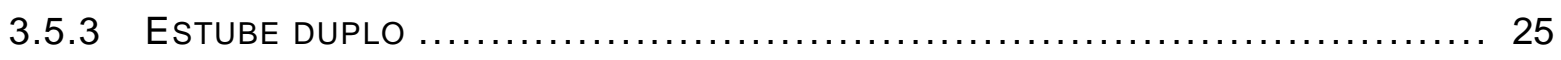

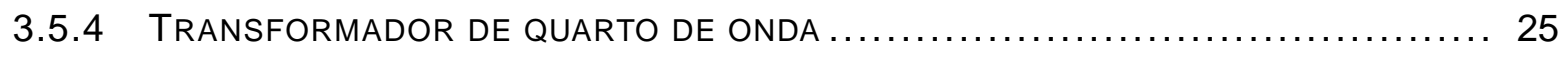

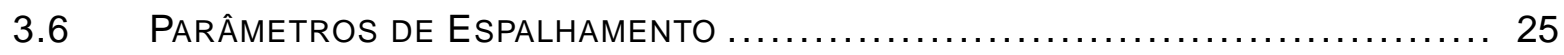

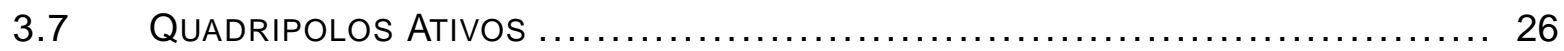

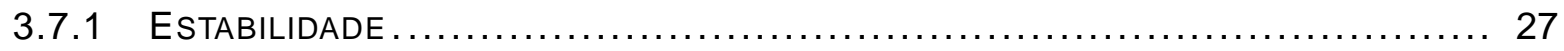

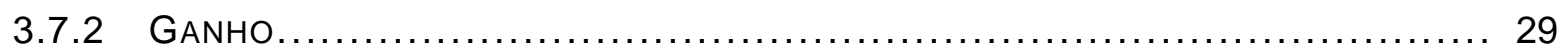

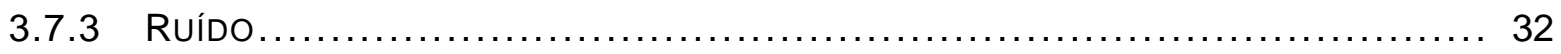

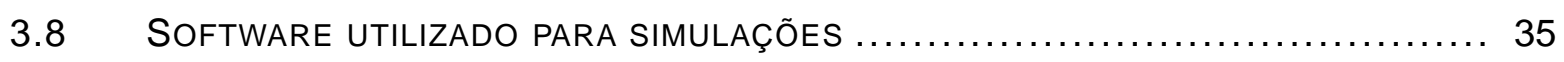

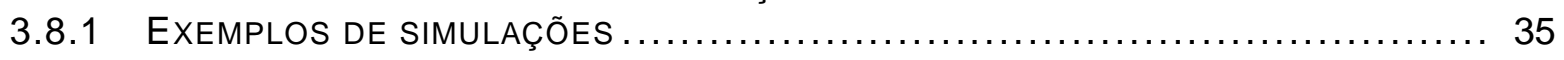

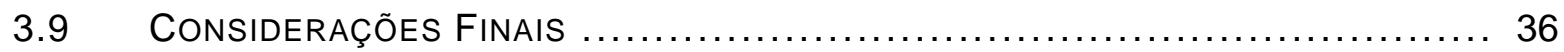

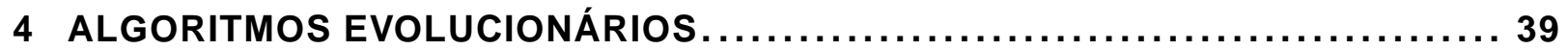

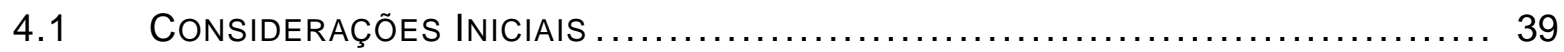

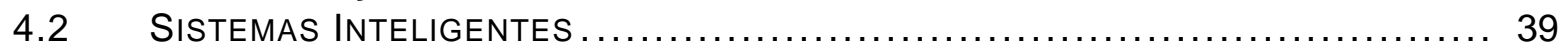

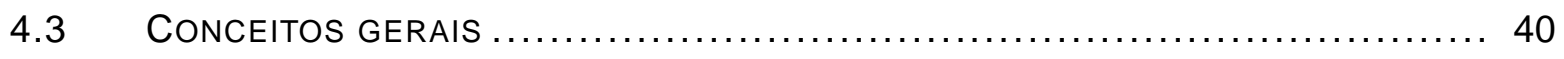

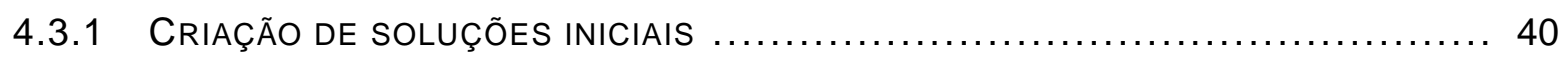

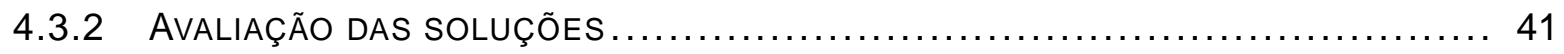

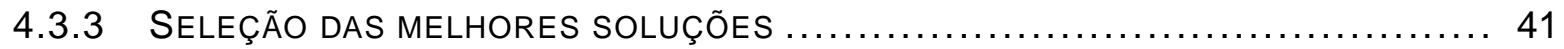

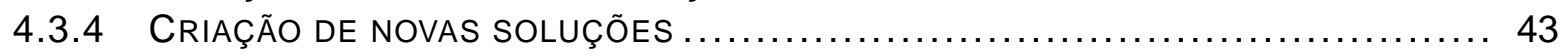

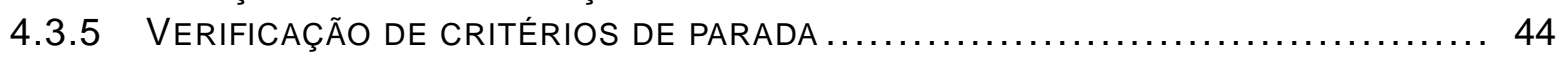

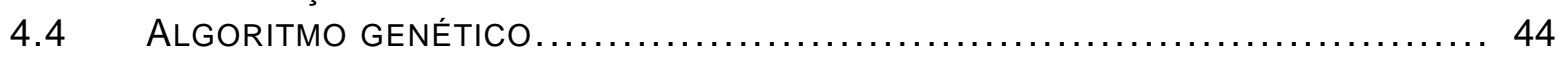




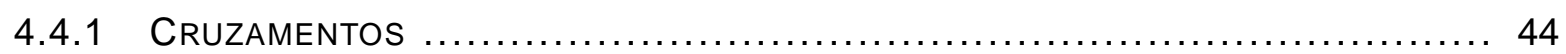

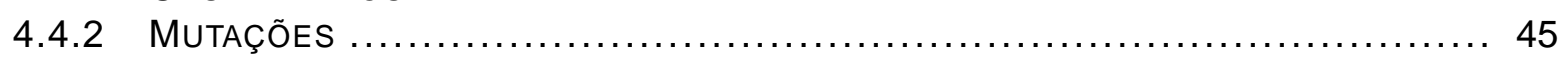

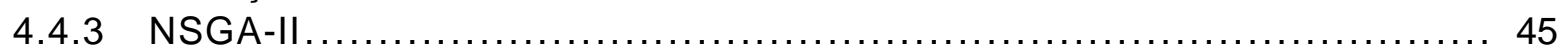

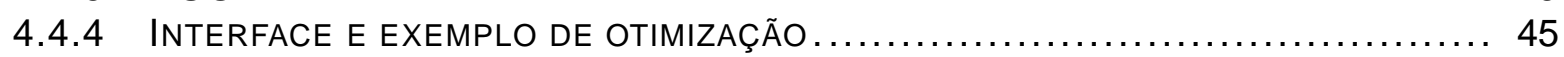

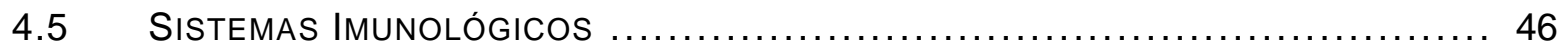

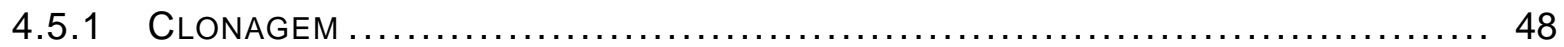

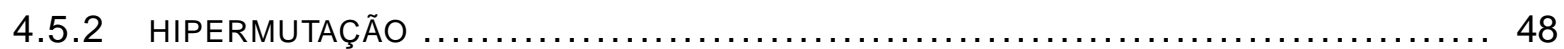

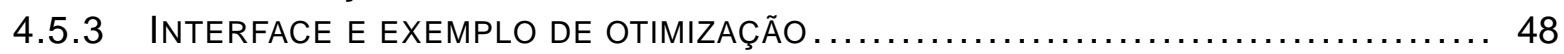

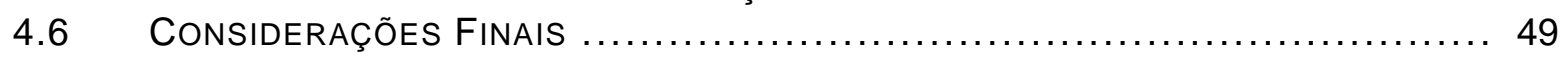

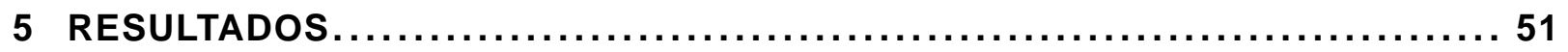

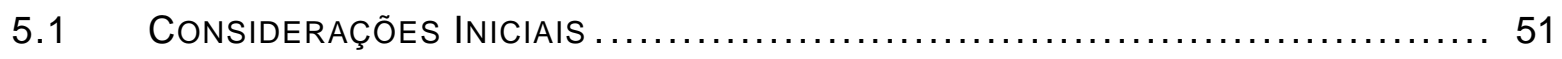

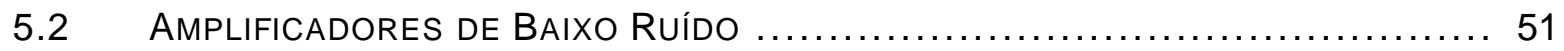

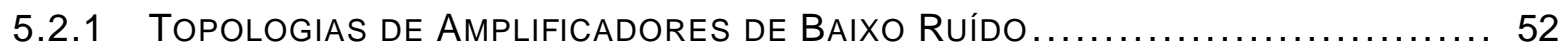

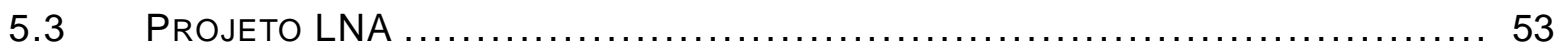

5.3.1 OTIMIZAÇÃO DA FIGURA DE RUÍDO, CARACTERIZAÇÃO DO TRANSISTOR E PRO-

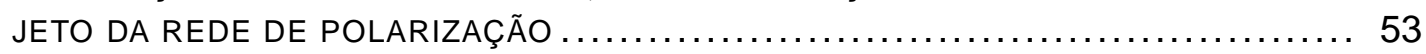

5.3.2 ESTIMATIVA DAS CAPACITÂNCIAS PARASITAS E CÁlCULO DAS INDUTÂNCIAS DO

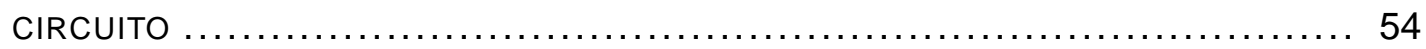

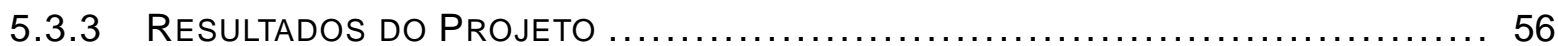

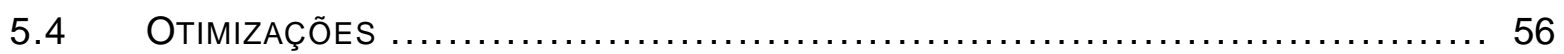

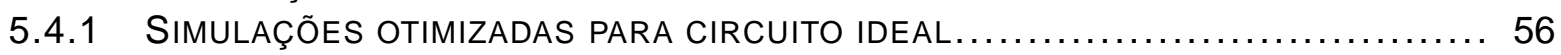

5.4 .2 SIMULAÇÕES OTIMIZADAS PARA CIRCUITO COM PARASITAS $\ldots \ldots \ldots \ldots \ldots \ldots \ldots \ldots$

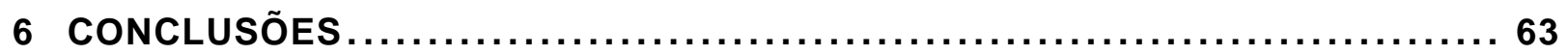

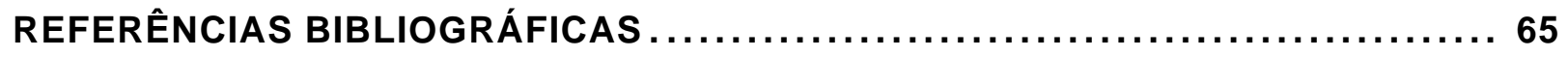

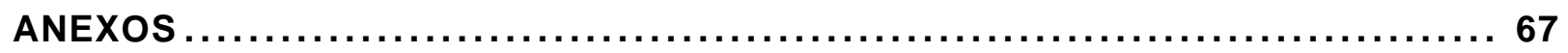

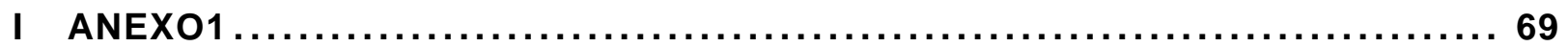




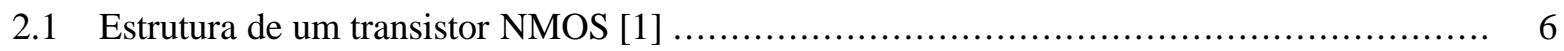

2.2 Modelo para representação de um transistor.................................................... 8

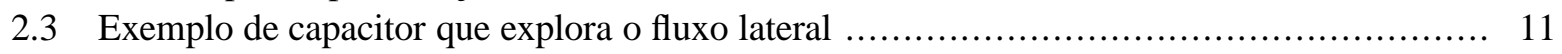

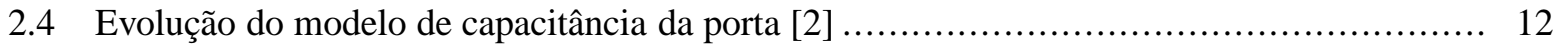

2.5 Exemplos de geometria de indutores planares [2] ..................................... 13

2.6 Modelo equivalente de um indutor planar na tecnologia CMOS (elementos parasitas)[2] ..... 13

2.7 Representação dos parasitas na estrutura planar [2] ....................................... 14

3.1 Representação de linhas de transmissão ................................................. 21

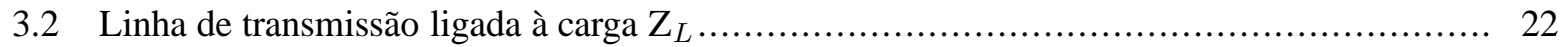

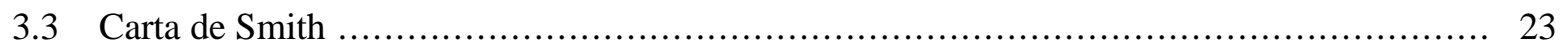

3.4 Potências em quadripolos ativos .......................................................... 29

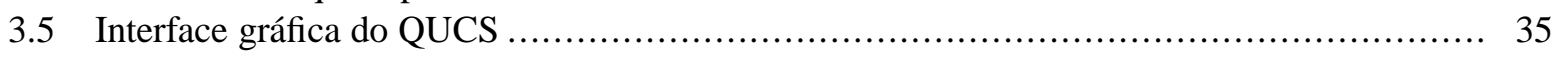

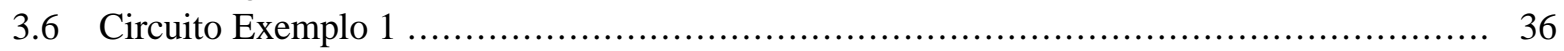

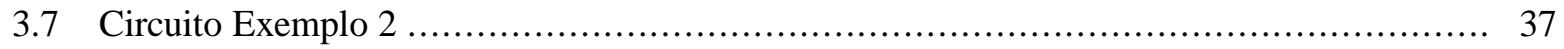

4.1 Fluxo de execução de um algoritmo evolucionário.................................... 40

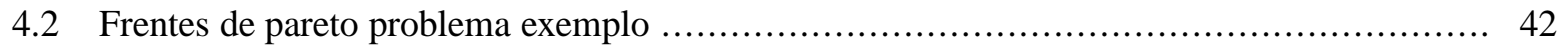

4.3 Interface implementada para a utilização do algoritmo NSGA-II $\ldots \ldots \ldots \ldots \ldots \ldots \ldots \ldots \ldots \ldots . \ldots \ldots$

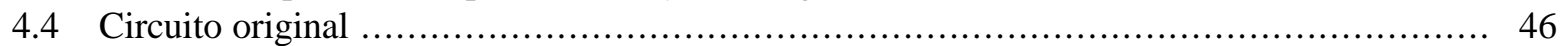

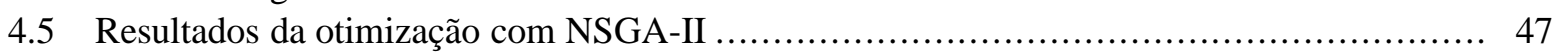

4.6 Interface implementada para a utilização do sistema imunológico......................... 48

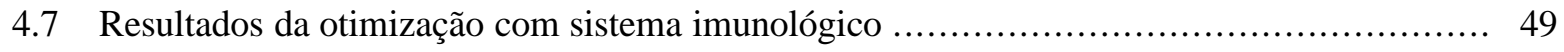

5.1 Corrupção do sinal devido à intermodulação de duas interferências [3] ....................... 52

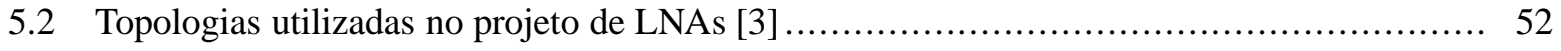

5.3 Configuração cascode com degeneração indutiva na fonte [3] ............................ 53

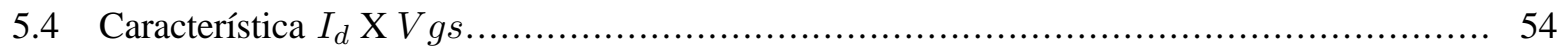

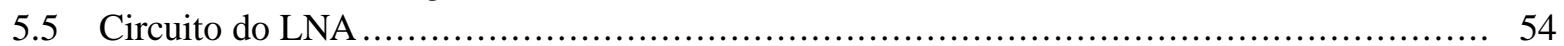

5.6 Modelo - Transistor MOS - Capacitâncias parasitas .................................... 54

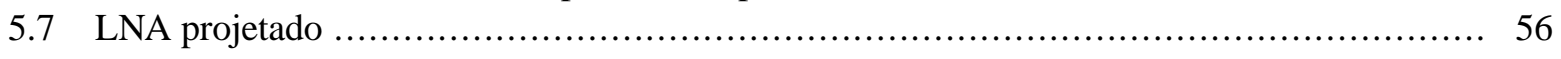

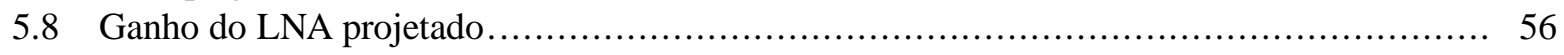

5.9 Circuito utilizado para transformação de impedância ..................................... 57

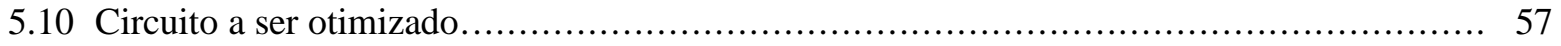

5.11 Otimização - Ganho em potência/Banda do Amplificador ..................................... 59

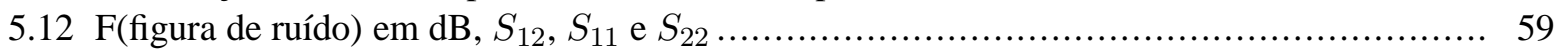

5.13 Comportamento do amplificador levando em consideração as frequências adjacentes ........ 59

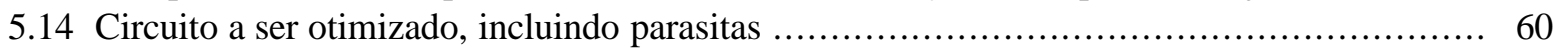

5.15 Otimização - Ganho em potência/Banda do Amplificador ................................. 61

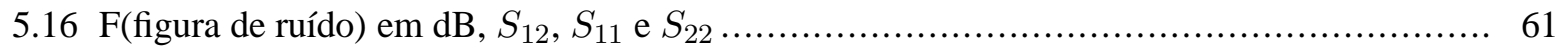

5.17 Comportamento do amplificador, incluindo parasitas, levando em consideração as frequências adjacentes 

2.1 Parâmetros de caracterização de transistores - Level 1 ..................................... 7

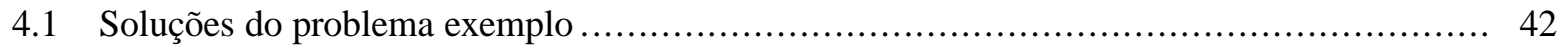

4.2 Ordenamento das soluções do problema exemplo........................................ 43

I.1 Parâmetros de caracterização de transistores - Level 1 .................................... 69 



\section{Siglas}

\begin{tabular}{ll}
$S i$ & Silício \\
$G a A s$ & Arseneto de gálio \\
$S_{i} O_{2}$ & Oxido de silício \\
$T_{o x}$ & Espessura do óxido de silício \\
$I_{d}$ & Corrente no dreno \\
$\mu$ & Mobilidade \\
$C_{o x}^{\prime}$ & Capacitância do óxido por $m^{2}$ \\
$W$ & Comprimento do canal \\
$L$ & Largura do canal \\
$V_{g s}$ & Tensão entre porta e fonte \\
$V_{t}$ & Tensão de limiar \\
$V_{d s}$ & Tensão entre fonte e dreno \\
$\lambda$ & Parâmetro de modulação da largura do canal \\
$\epsilon_{0}$ & Constante diéletrica do ar \\
$\epsilon_{r o x}$ & Constante relativa do óxido \\
$C_{g d}$ & Capacitância entre porta e dreno \\
$C_{g s}$ & Capacitância entre porta e fonte \\
$C_{g d}$ & Capacitância entre porta e corpo \\
$g m$ & Transcondutância \\
$\omega_{\tau}$ & Frequência de ganho de corrente unitário \\
$\omega_{m a x}$ & Frequência de ganho de potência unitário \\
$T C$ & Temperature coefficient \\
$r_{d s}$ & Resistência entre dreno e fonte \\
$R_{s}$ & Resistência série (parasita - indutor MOS) \\
$C_{l}$ & Capacitância com substrato (parasita - indutor MOS) \\
$C_{p}$ & Capacitância paralela (parasita - indutir - MOS) \\
$M M I C$ & Monolitic Microwave Integrated Circuit \\
$\Gamma$ & Coeficiente de reflexão \\
$F$ & Figura de ruído \\
$\sigma$ & Condutividade elétrica \\
$\delta$ & Espessura condutiva (Efeito Skin) \\
$t$ & Espessura \\
$l$ & largura \\
& \\
\hline &
\end{tabular}





\subsection{MOTIVAÇÕES}

A evolução das tecnologias de telecomunicações trouxe-nos até a era da informação. No cenário atual, a demanda por fluxo de dados e, por conseguinte, por banda cresce de maneira cada vez mais acentuada. Dentro desse escopo, tecnologias como Bluetooth, Wi-Fi, WiMAX, entre outras despontam aliando esta necessidade de transmissão/recepção de dados à facilidade da mobilidade.

As tecnologias desenvolvidas combinando acesso/mobilidade exigem circuitos robustos para que seu funcionamento atinja os patamares de transmissão/recepção que os viabilize. Portanto, o projeto de elementos que formam o sistema de transmissão/recepção torna-se mais complexo, devido ao alto grau de desempenho de banda, baixa potência, empacotamento em um pequeno espaço, que devem ser atendidos.

Aliado aos fatos apresentados, tem-se o uso cada vez maior das freqüências na faixa de microondas. Com o aumento da freqüência de operação dos dispositivos, uma série de novos fatores devem ser considerados. Neste ponto, o estudo da teoria eletromagnética faz-se tão necessária quanto o estudo da eletrônica, para entendimento de todas as variáveis em jogo. Com essa fusão, entre eletrônica e eletromagnetismo, a síntese de dispositivos mostra-se ainda mais desafiadora devido ao aumento de exigências de projeto, o que obriga o projetista muitas vezes a trabalhar com o limite da tecnologia.

As tecnologias como Bluetooth, Wi-Fi e WiMAX têm criado um grande mercado. Portanto, o projeto de circuitos que funcionem para uma destas tecnologias torna-se uma excelente área de atuação. As faixas de frequência exploradas comercialmente, ou ainda em fase de teste (caso do WiMAX), no Brasil são: 2,4 GHz para Bluetooth, 2,4 e 5,5 GHz para Wi-Fi e 3,5 GHz para WiMAX, conforme resolução da Anatel.

\subsection{OBJETIVOS}

Este trabalho busca projetar um amplificador de baixo ruído, na faixa de microondas, com o auxílio de uma ferramenta computacional baseada em sistemas evolucionários. Com esse intuito, o programa QUCS, 
software livre de simulação de circuitos, foi utilizado. A ferramenta para projeto elétrico do dispositivo, que atuará na faixa 2,4 GHz, consistirá no programa já citado em conjunto com softwares de otimização, algoritmo genético e imunológico, sendo que esses algoritmos serão incorporados ao código do programa de forma a configurar um adendo.

O projeto de amplificador de baixo ruído a ser executado deverá incluir tanto aspectos de projeto advindos da eletrônica quanto elementos de análise advindos da teoria eletromagnética. Esse projeto será simulado e analisado, utilizando-se o software livre. A partir da base de dados do projeto, será feita a otimização do circuito, com o intuito de conseguir um melhor desempenho do mesmo.

Com esta ação, visa-se validar a ferramenta como facilitadora no projeto de circuitos destinados às tecnologias Bluetooth, Wi-Fi e WiMAX. Como objetivo final, busca-se a obtenção de estruturas que não seriam descritas pelas tradicionais metodologias de projetos de amplificadores de baixo ruído.

A fim de desenvolver esta ferramenta e o projeto do amplificador, foram feitos estudos sobre tecnologia de fabricação, eletrônica, programação, modelos de representação de transistores e teoria eletromagnética. Essas teorias foram os alicerces sobre os quais este trabalho apoiou-se para gerar os resultados apresentados adiante.

\subsection{APRESENTAÇÃO DOS CAPÍTULOS}

Nos próximos capítulos serão abordadas teorias e metodologias que resultam no projeto de um amplificador em baixo ruído na faixa de 2,4 GHz. No capítulo 2, é feita uma apresentação sobre a tecnologia CMOS, a qual servirá de base para o projeto. Nesse capítulo são apresentadas as principais estruturas elétricas e suas características para a tecnologia.

No capítulo 3, é feita uma introdução da teoria eletromagnética necessária para a síntese de amplificadores. Nesse ponto, é feito um estudo, e são introduzidos conceitos para análise da desempenho do circuito como potência, ruído e estabilidade. O software utilizado para simulações computacionais é, então, mostrado.

No capítulo 4, é apresentada a teoria de algoritmos evolucionários. São abordadas noções básicas que envolvem esse tipo de algoritmo. São introduzidos os conceitos de algoritmos genéticos e de sistemas imunológicos. A implementação destes algoritmos é mostrada e sua utilização exemplificada.

No capítulo 5, é apresentado o projeto para o amplificador de baixo ruído na faixa de 2,4 GHz. Além 
do projeto, são mostrados os resultados da otimização desse circuito com o auxílio de softwares baseados em processos evolucionários. Nesse ponto, são também inseridos os parasitas presentes na tecnologia, e realizada posterior otimização desse circuito. 



\subsection{CONSIDERAÇÕES INICIAIS}

Neste capítulo, será feito um estudo sobre a tecnologias MOS. Com este texto busca-se o entendimento das potencialidades e limitações de tecnologia, a partir da análise dos elementos de circuito: transistor, resistor, capacitor e indutor. Além disso, será feita uma comparação entre as tecnologias MOS e $G a A S$, esta última com grande aplicações na faixa de microondas. Também serão levantadas as principais vantagens e desvantagens de cada tecnologia.

\subsection{TECNOLOGIA CMOS}

A tecnologia MOS (Metal-óxido semicondutor) tem apresentado uma evolução extraordinária desde sua implementação nos anos 60. A miniaturização foi a maior responsável pela proliferação dos circuitos integrados em MOS, que em conjunto com a alta integração apresentada pela tecnologia (possibilidade de projetar um circuito complexo em um único pastilha) e o seu baixo custo de produção, levaram a predominância desta tecnologia em uma ampla gama de aplicações. Dentre as tecnologias MOS, a tecnologia CMOS (Complemetary MOS) destaca-se por permitir a implantação de transistores tipo $\mathrm{N}$ ou tipo P em um mesmo circuito integrado, o que lhe confere uma maior flexibilidade de projeto [1].

Com essas vantagens, os circuitos integrados MOS dominaram a eletrônica digital e analógica de baixa frequência. Entretanto, com o contínuo avanço da tecnologia MOS, chega-se a um ponto onde esta passa a rivalizar com tecnologias ( $\mathrm{GaAs}$, SiGe, entre outras) já estabelecidas na área de rádio-frequência (RF). A seguir, serão detalhadas as características dos elementos passivos (resistor, capacitor e indutor) e do transistor em circuitos integrados CMOS. 


\subsubsection{Transistor MOS}

\subsubsection{Estrutura de um MOSFET}

Na Fig.2.1, pode-se visualizar uma estrutura NMOS. Esta estrutura consiste de um corpo composto por substrato $\mathrm{P}$, onde são inseridas duas regiões de substrato $\mathrm{n}+$ fortemente dopadas, nomeadas fonte e dreno. Sobre essa estrutura, ocorre a adição de dióxido de silício $\left(\mathrm{SiO}_{2}\right)$, cuja função é isolação, seguido de um condutor (podendo este ser de polisilício ou de metal). Esse arranjo configura o terminal denominado porta.

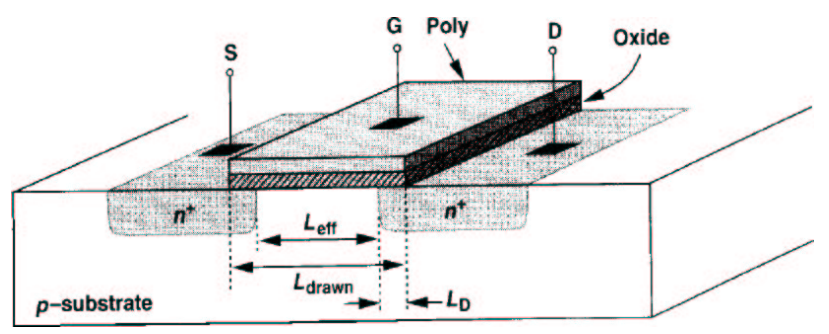

Figura 2.1: Estrutura de um transistor NMOS [1]

A distância de separação entre dreno e fonte é chamada de L, comprimento, e o tamanho dessas estruturas é chamado de W, largura. O desempenho de um transistor MOS depende basicamente de L e da espessura do dióxido de silício na porta (TOX). Os esforços, a cada avanço da tecnologia, são para minimizar esses valores sem degradar os outros parâmetros do dispositivo.

A qualidade do substrato também influencia muito o desempenho do dispositivo. O substrato também constitui, em conjunto com porta, dreno e fonte, um terminal nesta tecnologia. Este quarto terminal deve ser ligado ao nível de tensão de polarização mais baixo possível (no caso do transistor NMOS), visto que os diodos formados por dreno/substrato e fonte/substrato devem estar polarizados reversamente. Assim, a corrente que percorre a estrutura MOS será apenas vertical.

Na tecnologia CMOS (Complementary MOS), tanto transistores NMOS como PMOS podem ser produzidos. Essa técnica, torna-se portanto bastante versátil, pois permite a implementação de uma diversidade maior de circuitos.

\subsubsection{Modelo de Schichman-Hodges}

Neste trabalho, foi utilizado o modelo de Schichman-Hodges para representação dos transistores. Esse modelo, também conhecido como modelo spice - level 1, tem equações bastante simples e bastante próximas da teoria eletrônica. Ou seja, esse modelo não inclui correções para efeitos de segunda ordem ou 
maiores, como condução sub-limiar ou mobilidade dependente do campo lateral. A Tab. I.1 informa os parâmetros utilizados pelo QUCS para simulação do transistor.

Na Fig.2.2, pode ser melhor entendida a dinâmica de algum dos parâmetros ilustrados na Tab.I.1, pois a mesma mostra um transistor do ponto de vista de circuito, levando em consideração as interações entre os componentes do transistor (junções p-n, poli, $\mathrm{SiO}_{2}$, entre outros).

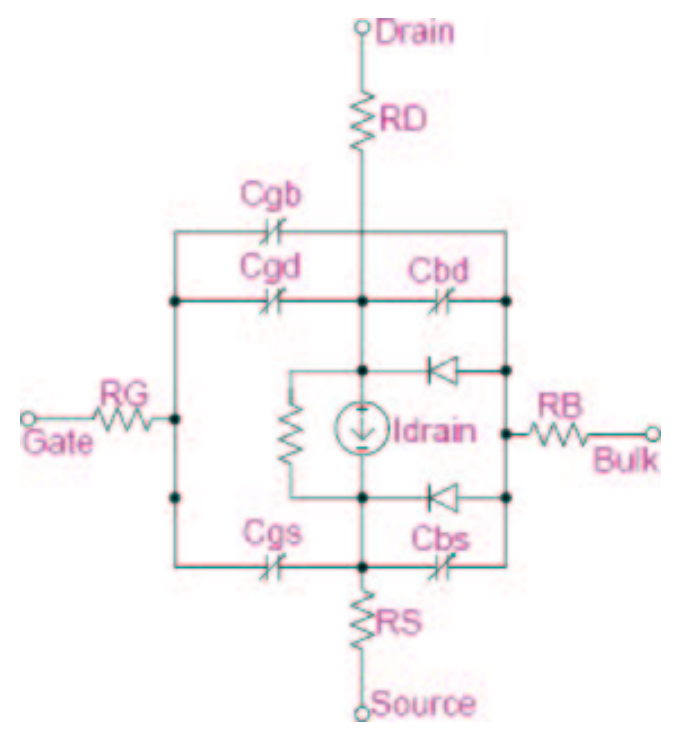

Figura 2.2: Modelo para representação de um transistor

A partir de valores atribuídos aos parâmetros presentes nesta tabela, é feito o cálculo da corrente no dreno, das capacitâncias parasitas e da transcondutância dos transistores empregados. As equações utilizadas no modelo são explicitadas abaixo :

Para o cálculo da corrente no dreno $\left(I_{d}\right)$ :

Quando o transistor encontra-se na região de triodo, ou seja, quando $V_{d s} \leq V_{g s}-V_{t h}$ :

$$
I_{d}=\mu_{n} C_{o x} \frac{W}{L}\left[\left(V_{g s}-V_{t}\right) V_{d s}-\frac{V_{d s}^{2}}{2}\right]\left(1+\lambda V_{d s}\right)
$$

Quando ele encontra-se na região de saturação, $V_{d s} \geq V_{g s}-V_{t h}$ :

$$
I_{d}=\mu_{n} C_{o x} \frac{W}{2 L}\left(V_{g s}-V_{t}\right)^{2}\left(1+\lambda V_{d s}\right)
$$

Onde,

$$
C_{o x}=\frac{\epsilon_{0} \epsilon_{r o x}}{T O X}
$$


Tabela 2.1: Parâmetros de caracterização de transistores - Level 1

\begin{tabular}{|c|c|}
\hline Parâmetro & Descrição \\
\hline $\mathrm{Vt} 0$ & Tensão de limiar com polarização nula \\
\hline $\mathrm{Kp}$ & Coeficiente de transcondutância \\
\hline Gamma & Limiar do substrato \\
\hline Phi & Potencial de superfície \\
\hline Lambda & Parâmetro de modulação de comprimento do canal \\
\hline Is & Corrente de saturação na junção \\
\hline $\mathrm{Rd}$ & Resistência no dreno \\
\hline Rs & Resistência na fonte \\
\hline $\operatorname{Rg}$ & Resistência na porta \\
\hline $\mathrm{N}$ & Coeficiente de emissão da junção \\
\hline $\mathrm{W}$ & Largura do canal \\
\hline $\mathrm{L}$ & Comprimento do canal \\
\hline $\mathrm{Ld}$ & Comprimento de difusão lateral \\
\hline Tox & Espessura de óxido de silício \\
\hline Cgso & Capacitância porta-fonte \\
\hline Cgdo & Capacitância porta-dreno \\
\hline Cgbo & Capacitância porta-substrato \\
\hline $\mathrm{Pb}$ & Potencial na junção \\
\hline $\mathrm{Mj}$ & Coeficiente de graduação no fundo da junção \\
\hline $\mathrm{Fc}$ & Coeficiente de capacitância de depleção na junção polarização direta \\
\hline Cjsw & Capacitância periférica na junção com polarização nula \\
\hline Mjsw & Coeficiente de graduação periférica na junção \\
\hline Nsub & Densidade da dopagem no substrato substrato \\
\hline Uo & Mobilidade na superfície \\
\hline Rsh & Resistência de difusão entre dreno e fonte \\
\hline $\mathrm{Cj}$ & Capacitância no fundo da junção com polarização nula \\
\hline Tpg & Tipo de material do gate \\
\hline
\end{tabular}


Onde,

$$
\epsilon_{0}=8,85 \cdot 10^{-12} \mathrm{~F} / \mathrm{m}
$$

$\mathrm{e}$

$$
\epsilon_{\text {rox }}=3,9
$$

$$
V_{t}=V T O+G A M M A\left(\left(P H I-V_{b s}^{1 / 2}\right)-P H I^{1 / 2}\right)
$$

O cálculo das capacitâncias parasitas é feito a partir das seguintes fórmulas:

$$
\begin{aligned}
& C_{g d}=C G D O . W \\
& C_{g s}=C G S O . W \\
& C_{g b}=C G B O . W
\end{aligned}
$$

O cálculo da transcondutância $(\mathrm{gm})$ é feito a partir de:

$$
g m=\mu_{n} C_{o x}\left(\frac{W}{L}\right)\left(V_{g s}-V_{t}\right)
$$

\subsubsection{Figuras de Mérito em altas freqüências}

Exitem basicamente duas figuras de mérito que são bastante utilizadas para mensuração do desempenho de transistores em altas freqüências, são elas $\omega_{\tau}$ e $\omega_{\max }$.É importante frisar, no entanto, que figuras de mérito devem ser encaradas com certa visão crítica, pois as mesmas não passam de um 'resumo', muitas vezes incompleto, do que se passa no circuito. O uso destas figuras de mérito é, portanto, uma tentativa de caracterizar quantidades multidimensionais com um único número, ou seja, buscar a simplificação [2].

$\omega_{\tau}$ e $\omega_{\max }$, representam respectivamente, as freqüências em que o ganho de corrente e o de potência são unitários. A fórmula mais comum de $\omega_{\tau}$ (Eq.2.11) assume que o dreno é terminado em um curto 
circuito, enquanto que na porta tem-se fonte ideal de corrente. Devido à presença do curto no dreno, $\omega$ de corrente na porta desconsidera os efeitos da resistência série presente na porta $\left(R_{g}\right)$ sobre $\omega_{\tau}$. Estes dois elementos, $C_{j d b}$ e $R_{g}$ têm grande influência sobre o comportamento do transistor em altas freqüências, e mesmo assim não são levados em consideração por $\omega_{\tau}$.

$$
\omega_{\tau}=\frac{g m}{C_{g s}+C_{g d}}
$$

Como pode ser visto na Eq.2.11, o cálculo de $\omega_{\tau}$ é bastante simples, mas muito vezes não é o resultado mais interessante. O conhecimento da freqüência de ganho unitário $\left(\omega_{\max }\right)$ apresenta, geralmente, resultados mais relavantes. A obtenção desta figura de mérito não é simples, porém a partir de algumas simplificação pôde-se chegar à Eq.2.12. Para obter a Eq.2.12, considerou-se a impedância de entrada com o dreno em curto e ignorou-se o efeito da capacitância entre porta e dreno $\left(C_{g d}\right)$, como feito para obtenção de $\omega_{\tau}$. Mas levou-se $C_{g d}$ em consideração durante o cálculo da resistência de saída, pois o cômputo da máxima potência requer o casamento conjugado. Tanto $\omega_{\max }$, quanto $\omega_{\tau}$ devem ser encarados como indicações brutas de desempenho em alta frequência.

$$
\omega_{\max } \approx \frac{1}{2} \sqrt{\frac{\omega_{\tau}}{R_{g} C_{g d}}}
$$

\subsubsection{Resistor}

A implementação de uma resistência em uma pastilha MOS pode ser feita, basicamente, de duas maneiras: via utilização de polisilício ou via difusão fonte-dreno. O utilização do polisilício (poli) implica em baixos níveis de tolerância, atingindo até 35\% para a estrutura de poli silicado e chegando a $50 \%$ para estruturas não silicado.

O poli é silicado por algumas foundries para redução de sua resistência. Portanto, essa estrutura é apropriada para, basicamente, pequenos valores de resistência. O coeficiente de temperatura, alteração de resistência devido a mudança na temperatura de operação deste tipo de resistência, está explicitado na Eq.2.13. Essa fórmula depende do nível de dopagem e da composição do poli [2].

$$
T C \approx \frac{1}{R} \frac{\delta R}{\delta T}
$$

O poli não silicado tem uma maior resistência e seu coeficiente de temperatura pode variar amplamente em função dos processos de produção. Em geral, pode-se dizer que esse tipo de resistência tem um valor 
moderado de coeficiente de temperatura e apresentam baixos valores de capacitâncias parasitas por área ocupada.

Outra opção são os resistores de difusão fonte-dreno que têm coeficientes de temperatura e valores de resistência similares ao poli silicado. Nesse caso, há a ocorrência de capacitâncias parasitas em alto grau e limitação em relação à variação do nível de tensão aplicado. Pois uma variação muito grande de tensão pode fazer com que a resistência se altere.

Para criação de resistências de alto valor, utilizam-se poços, cuja resistências variam de 1-10k $\Omega$ por unidade de área. Essa configuração apresenta um alto nível de capacitâncias parasitas, devido à grande área de junção formada entre a fonte e o substrato. O resistor resultante tem uma péssima tolerância, em torno de 50 a $80 \%$, alto coeficiente de temperatura e baixa robustez em relação à variação de tensão.

O transistor também pode ser utilizado como resistor, quando na região de triodo. No entanto, um resistor obtido com esta configuração apresenta baixa tolerância (pois o mesmo depende da mobilidade dos portadores e da tensão de limiar), alto coeficiente de temperatura (devido também à dependência da mobilidade e a variação de tensão de limiar com a temperatura) e alta não-linearidade (devido à dependência de tensão entre fonte e dreno). A Eq. 2.14 descreve um resistor feito a partir de um transistor MOS, na qual podem ser visualizados os problemas citados anteriormente. Essas características frequentemente limitam o uso deste tipo de transistor a circuitos não-críticos, fora do caminho percorrido pelo sinal de informação.

$$
r_{d s} \approx\left[\mu_{n} C_{o x} \frac{W}{L}\left[\left(V_{g} s-V_{t}\right)-V d s\right]^{-1}\right.
$$

\subsubsection{Capacitor}

Basicamente todas as camadas de interconexão (poli e metais como $\mathrm{Al}$ e $\mathrm{Cu}$, geralmente) podem ser utilizados para se projetar o capacitor, cujo dielétrico é constituído de $\mathrm{SiO}_{2}$. Esse dielétrico deve ter pouca espessura (da ordem de 0,5 - $1 \mu \mathrm{m}$ ), para assim se reduzir a capacitância entre as camadas, reduzindo assim a capactância por unidade de área.

Deve-se estar atento ao fato de que nesta tecnologia o capacitor de placas paralelas não é a melhor escolha de projeto. Devido, basicamente, à existência de capacitâncias parasitas entre a placa inferior do capacitor e outro condutor (especialmente o substrato) localizado sob a mesma. Esse elemento parasita pode variar de 10 a $30 \%$ do valor da capacitância principal e geralmente limita severamente o funcionamento do circuito [2]. 
A alternativa geralmente adotada para projetos de capacitores MOS é mostrada na Fig.2.3. Nessa estrutura, a capacitância total por unidade de área é aumentada via exploração do 'fluxo lateral', obtido pelo aumento do perímetro de contato entre placas. Outra forma de aumentar a capacitância se dá pela utilização de mais de um par de camadas de interconexão, numa estrutura sanduíche.

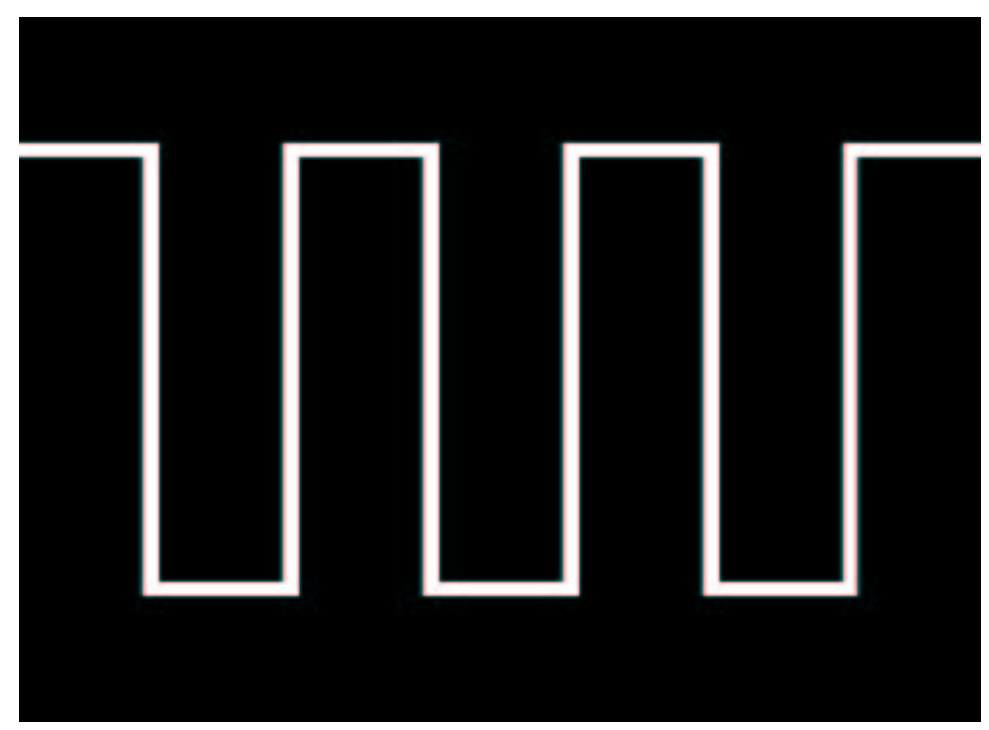

Figura 2.3: Exemplo de capacitor que explora o fluxo lateral

A utilização do fluxo lateral está associada à diminuição da capacitância parasita entre placa inferior e condutor, pois sua exploração faz uso de uma menor de área para obtenção um dado valor de capacitância, em comparação a outros métodos. O perímetro é portanto importante na definição da máxima capacitância a ser obtida. O estudo de fractais, estruturas que, em uma área finita, têm perímetro infinito, tendem a ser muito úteis para a criação de estruturas que maximizem a relação capacitância/área[2].

Outra alternativa é a utilização de um capacitor MOS, aproveitando o processo de fabricação CMOS para gerar uma capacitância, presente na porta de todo transistor desta tecnologia. O valor de capacitância/área, deste processo, depende da espessura do $\mathrm{SiO}_{2}$, mas é tipicamente de 20 a 100 vezes maior do que a de um capacitor que utiliza placas de interconexão. O capacitor MOS deve ser mantido em inversão forte (Vgs»Vth), pois caso contrário o valor da capacitância será pequena, com perdas e altamente não linear.

Para esse tipo de capacitor, o fator de qualidade (Q) depende da resistência do canal, definido pela Eq.2.14. A Fig. 2.4 apresenta como deve ser o modelo de primeira ordem deste capacitor. Fica evidente, a partir da análise da Fig.2.4, que para maximizar o valor de Q, deve-se adotar o menor valor possível de L. Pois a resistência $R_{d s}$ é diretamente proporcional à comprimento do canal (L).

O uso de junções P-N também se apresenta como opção, uma vez que a capacitância entre junções depende da polarização aplicada e o mesmo é amplamente utilizado na síntese de circuitos sintonizados 


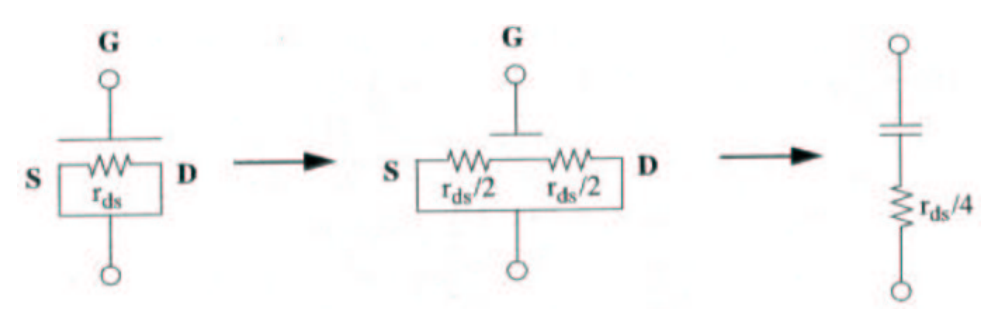

Figura 2.4: Evolução do modelo de capacitância da porta [2]

eletronicamente. Diodos utilizados para esse propósito são chamados varactors. Sabendo portanto que a capacitância da junção, apresenta-se a Eq.2.15, que a define.

$$
C_{j} \approx \frac{C_{j 0}}{\left(1-V_{f} /(\Phi)^{n}\right)}
$$

Onde $C_{j o}$ é a capacitância incremental em $0 \mathrm{~V}, V_{f}$ é a tensão de polarização direta através da junção, $\Phi$ é a tensão de superfície do substrato e n é um parâmetro que depende da dopagem. O Q deste tipo de capacitor varia de maneira inversa com relação à banda de sintonia. A dopagem assimétrica, necessária para gerar grande variação da capacitância por unidade de tensão (V), adiciona um valor de resistência relativamente grande em série. Portanto o Q é mínimo quando a capacitância é máxima.

\subsubsection{Indutores}

Em circuitos RF, os indutores são a maior causa de falhas em processos envolvendo circuitos integrados. A obtenção de indutores aceitáveis em termos de fator de qualidade e de elementos parasitários é crucial para o desenvolvimento desse tipo de circuito. Em processos de fabricação, os indutores de projeto muitas vezes podem ser implementados na tecnologia, mas sempre apresentam alto ruído, distorção e consumo, quando comparados com indutores feitos a partir de enrolamento[2].

Os indutores planares em espiral são os mais utilizados para soluções on-chip. Na Fig.2.5, podem ser visualizados os formatos-padrão deste tipo de indutor. Os efeitos do formato sobre o funcionamento do indutor, em relação à Q e à própria indutância, são funções de segunda ordem. Mas o desempenho das estruturas octogonais e circulares apresentam-se melhores do que o da estrutura quadrada e, portanto, devem ser favorecidos durante o layout.

Os projetos desse elemento de circuito, em geral, utilizam a camada mais alta de metal para síntese da parte principal do indutor (espiral). A conexão com o centro da espiral é feita por uma 'fita' sob a parte principal, composta de metal de nível mais baixo. O uso do metal da última camada para realiza- 


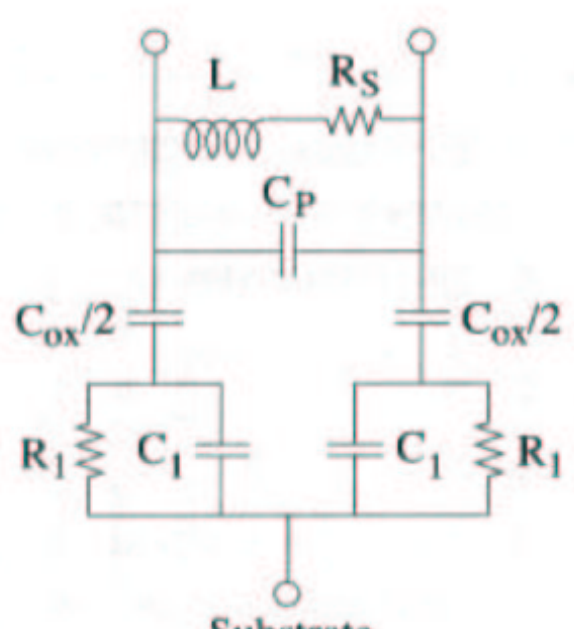

Substrate

Figura 2.6: Modelo equivalente de um indutor planar na tecnologia CMOS (elementos parasitas)[2]

são problemas adicionais apresentados por esses elementos. Na tecnologia MOS, o substrato apresenta-se próximo do indutor e tem uma condutividade relativamente boa, criando-se assim um capacitor de placas paralelas que ressoa em conjunto com o indutor. A frequiência em que ocorre esta ressonância é considerada o maior limite de freqüência no qual o indutor é funcional. Além disso, o substrato contribui com perdas devido à resistência presente no substrato. A proximidade com o substrato também degrada $\mathrm{Q}$ devido à energia acoplada ao substrato ruidoso.

$$
\begin{gathered}
R_{s} \approx \frac{l}{\omega \sigma \delta\left(1-e^{-t / \delta}\right)} \text { onde, } \delta=\sqrt{\frac{2}{\varpi \mu_{o} \sigma}} \\
C_{l} \approx \frac{\varpi l C_{s u b}}{2} \\
C_{p}=n \varpi^{2} \frac{\epsilon_{o x}}{t_{o} x}
\end{gathered}
$$

Outro elemento parasita é a capacitância paralela ao indutor $\left(C_{p}\right)$ (Eq.2.18), que ocorre devido ao posicionamento da 'fita' sob o indutor e seu corpo principal (espiras). A capacitância lateral entre as voltas do indutor pode ser desconsiderada, pois a conexão série dessas capacitâncias, presente entre os extremos do indutor, prevalece. A Fig. 2.7 ilustra a estrutura do indutor com a inclusão dos parasitas citados posteriormente. 
tação de pastilhas maiores (em torno de $300 \mathrm{~mm}$ de diâmetro, enquanto que as de GaAs têm em torno de $150 \mathrm{~mm})$. O Si é o elemento mais abundante na crosta terrestre, onde pode ser encontrado na forma de minerais silicados. A economia de escala disponível para o $S i$ acabou por inviabilizar um avanço maior da tecnologia baseada no GaAs.

A segunda vantagem do silício é a existência do dióxido de silício $\left(\mathrm{SiO}_{2}\right)$, um dos melhores isolantes conhecidos. $\mathrm{O} \mathrm{SiO}$ pode ser facilmente incorporado aos circuitos de $\mathrm{Si}$, e tais camadas são aderentes ao silício sobre o qual se situam. GaAs não tem uma aderência estável com a camada isolante.

A terceira, é a maior mobilidade das lacunas no silício quando comparado com o $G a A s$, o que torna a síntese de circuitos mais versáteis e melhor desempenho de estruturas complementares (que utilizam tanto elétrons quanto lacunas) por parte do $S i$.

\subsection{CONSIDERAÇÕES FINAIS}

Neste Capítulo, a tecnologia MOS foi abordada. Os transistores MOS foram analisados a partir de seus aspectos construtivos, modelos de simulação e figuras de mérito em altas frequências. Elementos de circuito na tecnologia MOS também foram apresentados, atendo-se às opções e limitações que a tecnologia oferece. O capítulo foi então finalizado com a comparação entre as tecnologias MOS e GaAs, o que permitiu avaliar diferentes as nuances dessas duas tecnologias. No próximo capítulo, é apresentada a teoria eletromagnética, assim as teorias básicas para projetos de amplificadores são abordadas. 



\subsection{CONSIDERAÇÕES INICIAIS}

Neste capítulo, será abordada a teoria de microondas com foco na síntese de amplificadores de microondas classe A. Serão apresentadas as diferentes classes de amplificadores, a teoria de microondas necessária para a síntese de amplificadores lineares, e ainda o software utilizado para simulações computacionais. Utilizando a teoria de microondas em conjunto com técnicas de otimização mostradas no próximo capítulo será feita a síntese de amplificadores de microondas classe A em tecnologia CMOS.

\subsection{AMPLIFICADORES DE MICROONDAS}

Circuitos amplificadores são circuitos que produzem a partir de um sinal de entrada, um sinal de saída com maior amplitude, ou seja, adicionam ganho ao sinal. Diferentes tipos de amplificadores produzem diferentes tipos de ganho (ganho de tensão, ganho de corrente ou ganho de potência).

Os amplificadores de microondas são elementos muito importantes dos sistemas de comunicação. Eles são utilizados tanto nos circuitos de transmissão como nos circuitos de recepção. Nos circuitos de transmissão, por exemplo, amplificam a potência do sinal a ser transmitido pelas antenas, aumentando assim o alcance dos sistemas. Já nos circuitos de recepção são utilizados, por exemplo, para aumentar a amplitude dos sinais recebidos. Dessa forma, fazem com que os sinais recebidos, geralmente com amplitudes muito baixas, possam acionar mais eficientemente os outros circuitos de recepção (misturadores, demoduladores e detectores). 


\subsubsection{Classes de operação}

Os amplificadores de potência podem ser divididos quanto a suas classes de operação. As classes de operação são: A, B, AB, C, D, E e F [12]. Diferentes classes de operação significam diferentes condições de polarização, diferentes funcionamentos, diferentes eficiências e diferentes condições de linearidade.

\subsubsection{Classe A}

Os amplificadores classe A são amplificadores nos quais os transistores estão polarizados na região ativa. Isso faz com que a amplitude do sinal de entrada tenha de ser pequena (amplificadores de pequenos sinais), evitando assim distorções por saturação ou corte dos transistores. O sinal de saída dos amplificadores classe A acompanha a excursão, do sinal de entrada do mesmo, sendo, portanto, uma cópia exata, mas amplificada do sinal entrada. Podem ser considerados praticamente lineares.

Mesmo que não seja aplicado um sinal na entrada, os amplificadores classe A estão sempre consumindo potência da fonte de alimentação. Isso faz com que seu rendimento seja de no máximo $50 \%$.

\subsubsection{Classe B}

Os amplificadores classe B são amplificadores nos quais os transistores estão polarizados na região de corte. Dessa forma, os transistores só conduzem em metade da excursão do sinal de entrada. São necessários, portanto, pelo menos dois transistores para amplificar o sinal de entrada, um para o semi-ciclo positivo e outro para o semi-ciclo negativo. Como não há simultaneidade entre o fim da condução de um transistor e o início da condução do outro, provocam distorção no sinal. Essa distorção é conhecida como distorção de transição. Apresentam um rendimento máximo de 78,5\%. No entanto, provocam distorção no sinal e um nível de intermodulação maior.

\subsubsection{Classe AB}

Os amplificadores classe $\mathrm{AB}$ são amplificadores nos quais os transistores estão polarizados um pouco acima da região de corte. Têm o funcionamento similar ao dos amplificadores classe B, no entanto, por estarem na eminência de conduzir, o efeito da distorção de transição é minimizado.

Dessa forma, possuem uma distorção bem menor do que os amplificadores classe B. Para isso têm circuitos um pouco mais complexos e rendimento um pouco pior. 
Os amplificadores classe C são amplificadores nos quais os transistores estão polarizados abaixo da região de corte. Provocam muita distorção no sinal, no entanto, tem um rendimento maior do que o da classe B. A distorção no sinal pode ser diminuída com a utilização de filtro que elimine as harmônicas de distorção geradas.

\subsubsection{Classe D}

Os amplificadores classe D são amplificadores que funcionam com o chaveamento dos transistores. Dessa forma, a única dissipação de energia ocorre no curto espaço de tempo que os transistores demoram para chavear. O rendimento desses amplificadores normalmente é entre $85 \%$ e $95 \%$.

Durante a amplificação o sinal de entrada é convertido em uma seqüência de pulsos. A duração de cada pulso é proporcional à amplitude do sinal naquele dado momento. $\mathrm{O}$ sinal de saída possui componentes espectrais indesejadas e, por isso, precisa passar por um filtro passivo a fim de ter comportamento semelhante ao sinal de entrada.

\subsubsection{Classe $\mathrm{E}$}

Os amplificadores classe E são amplificadores que também funcionam com o chaveamento dos transistores. Eles possuem grande eficiência e distorção similar aos amplificadores classe B. A eficiência é maximizada projetando-se o amplificador de forma a não existirem, ao mesmo tempo, no transistor, tensão e corrente com valores elevados. Dessa forma, a potência dissipada no transistor é praticamente nula e a eficiência elevada.

\subsubsection{Classe F}

Os amplificadores classe F são amplificadores que também funcionam com o chaveamento dos transistores. A classe F baseia-se na manipulação das harmônicas das formas de onda da corrente e tensão no dispositivo transistor, de modo a maximizar o rendimento do amplificador.

Eles também são conhecidos como ressoadores múltiplos. Esse nome deve-se à manipulação de várias harmônicas das formas de onda de tensão e de corrente do amplificador. Possuem uma eficiência teórica máxima de $100 \%$. 


\subsection{TEORIA DE MICROONDAS}

Os amplificadores de microondas são os amplificadores que trabalham na faixa de frequiência de 300 MHz a $300 \mathrm{GHz}$. Por causa da alta freqüência e conseqüente pequeno comprimento de onda, a teoria de circuitos convencional geralmente não pode ser aplicada, tornando a engenharia de microondas diferente de outras áreas da engenharia elétrica. O pequeno comprimento de onda faz com que a fase da corrente, ou da tensão, varie significantemente dentro dos componentes dos circuitos.

Em freqüências mais baixas, essa variação de fase é insignificante e dessa forma a teoria clássica de circuitos, que é uma simplificação das equações de Maxwell para este caso especial, pode ser aplicada. Já para freqüências ainda mais altas do que $300 \mathrm{GHz}$, temos os sistemas óticos, nos quais o comprimento de onda é muito menor do que as dimensões dos componentes [13]. Nesse caso, as equações de Maxwell podem ser simplificadas na teoria de óptica geométrica.

Dessa forma, os elementos de circuitos de microondas normalmente são elementos distribuídos, ou seja, possuem características eletromagnéticas que dependem de suas dimensões e formato.

\subsubsection{Linhas de transmissão}

A teoria de linhas de transmissão liga a teoria clássica de circuitos com a teoria de campos eletromagnéticos. Dessa forma, ela desempenha um papel muito importante na engenharia de microondas.

A grande diferença entre a teoria de circuitos e a teoria de linhas de transmissão é o comprimento elétrico dos componentes. A análise com teoria de circuitos exige que a dimensão dos componentes analisados seja muito menor do que o comprimento de onda dos sinais, enquanto as linhas de transmissão têm dimensão próxima ou algumas vezes maior do que o comprimento de onda dos sinais. As linhas de transmissão são dessa forma elementos de parâmetros distribuídos.

As linhas de transmissão são frequentemente representadas por uma linha de dois fios condutores (Fig. 3.1(a)). Elas podem ser modeladas como elementos de parâmetros distribuídos ao longo da linha (Fig. 3.1(b)), para isso os valores de R, L, G e C são especificados por unidade de comprimento.

A indutância em série L representa a auto-indutância total dos dois condutores em H/m. A capacitância em paralelo $\mathrm{C}$ existe devido à proximidade dos dois condutores e é dada em $\mathrm{F} / \mathrm{m}$. A resistência série $\mathrm{R}$ representa a resistência devida à condutividade finita dos dois condutores em Ohms $/ \mathrm{m}$. Finalmente, a condutância em paralelo G representa a perda no material dielétrico entre os condutores. Dessa forma, $\mathrm{R} \mathrm{e}$ 


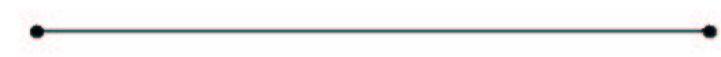

(a) Representação por par de fios condutores

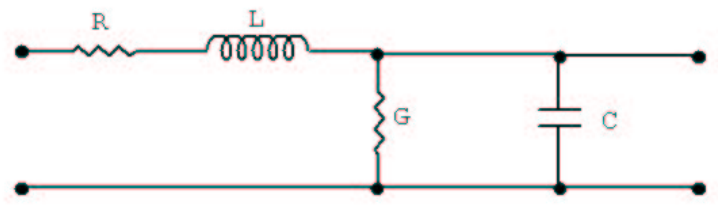

(b) Representação incluindo parâmetros distribuídos

Figura 3.1: Representação de linhas de transmissão

$\mathrm{G}$ representam perdas na linha de transmissão.

Considerando o circuito da Fig. 3.1(b), utilizando as leis de Kirchhhoff de tensão e de corrente, e considerando o comprimento da linha infinitesimal, chega-se às equações que definem a linha de transmissão. Para o caso de regime permanente senoidal, temos a Eq. 3.1 e a Eq. 3.2.

$$
\begin{aligned}
& \frac{d V(z)}{d z}=-(R+j \omega L) I(z) \\
& \frac{d I(z)}{d z}=-(G+j \omega C) V(z)
\end{aligned}
$$

Resolvendo a Eq. 3.1 e a Eq. 3.2 simultaneamente, a tensão e a corrente na linha são encontradas em função da constante de propagação $\gamma($ Eq. 3.3 e Eq. 3.4).

$$
\begin{aligned}
& V(z)=V_{0}^{+} e^{-\gamma z}+V_{0}^{-} e^{\gamma z} \\
& I(z)=I_{0}^{+} e^{-\gamma z}+I_{0}^{-} e^{\gamma z} \\
& \text { onde }: \gamma=\alpha+j \beta=\sqrt{(R+j \omega L)(G+j \omega C)}
\end{aligned}
$$

Os termos com índice ${ }^{+}$se propagam na direção $+z$ e os termos com índice ${ }^{-}$se propagam na direção -z. Substituindo a Eq. 3.3 na Eq. 3.1, encontra-se a corrente em cada ponto da linha (Eq. 3.5).

$$
I(z)=\frac{\gamma}{(R+j \omega L)}\left[V_{0}^{+} e^{-\gamma z}+V_{0}^{-} e^{\gamma z}\right]
$$


Comparando a Eq. 3.5 com a Eq. 3.4, observa-se que uma impedância característica, $\mathrm{Z}_{0}$, pode ser definida relacionando a onda de tensão e a onda de corrente em qualquer ponto da linha de transmissão (Eq. 3.6 e Eq. 3.7).

$$
\begin{aligned}
& Z 0=\frac{(R+j \omega L)}{\gamma}=\sqrt{\frac{R+j \omega L}{G+j \omega C}} \\
& \frac{V_{0}^{+}}{I_{0}^{+}}=Z 0=-\frac{V_{0}^{-}}{I_{0}^{-}}
\end{aligned}
$$

Considerando uma carga arbitrária $\mathrm{Z}_{L}$ na terminação de uma linha de transmissão, uma onda tensão incidente gerada em z $<0$ (Fig. 3.2), e sabendo que a relação entre tensão incidente e corrente incidente na linha é igual a $Z_{0}$, pode-se analisar o comportamento da tensão e da corrente na carga. A relação entre tensão e corrente na carga é definida por $\mathrm{Z}_{L}$ (Eq. 3.8). Dessa forma, uma onda de tensão refletida com uma amplitude correta deve ser gerada para satisfazer essa condição (Eq. 3.9). A relação entre tensão incidente e tensão refletida é conhecida como coeficiente de reflexão,Г (Eq. 3.10).

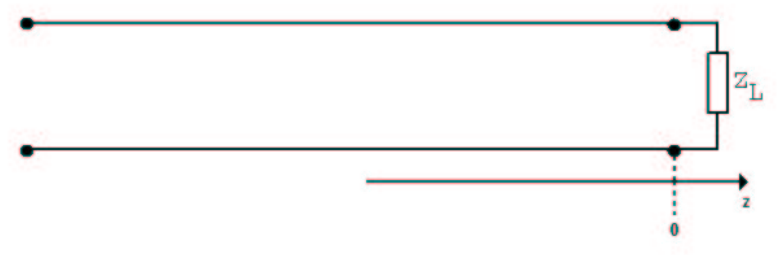

Figura 3.2: Linha de transmissão ligada à carga $\mathrm{Z}_{L}$

$$
\begin{aligned}
& Z_{L}=\frac{V(0)}{I(0)}=\frac{V_{0}^{+}+V_{0}^{-}}{V_{0}^{+}-V_{0}^{-}} Z_{0} \\
& V_{0}^{-}=\frac{Z_{L}-Z_{0}}{Z_{L}+Z_{0}} V_{0}^{+} \\
& \Gamma=\frac{V_{0}^{-}}{V_{0}^{+}}=\frac{Z_{L}-Z_{0}}{Z_{L}+Z_{0}}
\end{aligned}
$$

Pode-se, ainda, definir a relação entre a potência incidente na carga e a potência refletida pela carga. Essa relação é chamada de perda de retorno, RL - Return Loss (Eq. 3.11)

$$
R L=-20 \log |\Gamma| d B
$$

Quando o coeficiente de reflexão é igual a 0, dize-se que existe casamento entre a linha de transmissão e a carga e não há perda de retorno. Quando o coeficiente de reflexão tem módulo igual a 1, toda a onda 
incidente é refletida na carga. Dessa forma, nenhuma potência é transmitida para a carga e tem-se uma perda de retorno de $0 \mathrm{~dB}$.

Quando o coeficiente de reflexão é diferente de zero, a presença de uma onda refletida leva à existência de ondas estacionárias sobre a linha. Assim, a magnitude da tensão não é a mesma em toda a linha de transmissão. A relação entre as magnitudes máxima e mínima da tensão na linha de transmissão define o coeficiente de onda estacionária (VSWR). Esse coeficiente é maior quanto maior for o coeficiente de reflexão (Eq. 3.12).

$$
V S W R=\frac{V_{\max }}{V_{\min }}=\frac{1+|\Gamma|}{1-|\Gamma|}
$$

Um coeficiente de onda estacionária igual a 1 implica em casamento entre linha de transmissão e carga. Quando o descasamento é total, esse coeficiente tende a infinito.

O fluxo de potência em uma linha de transmissão é constante em toda a sua extensão. A tensão, para o caso em que o coeficiente de reflexão não é nulo, varia em função da posição na linha. Portanto, a impedância vista olhando para a linha varia com a posição. A impedância de entrada olhando para a carga é, também, função da posição na linha. A uma distância $1=-z$ da carga, essa impedância é definida pela Eq. 3.13.

$$
Z_{i n}=\frac{1+\Gamma e^{-2 j \beta l}}{1-\Gamma e^{-2 j \beta l}}
$$

Quando a análise do descasamento entre gerador e linha de transmissão é feita, em conjunto com a análise do descasamento entre linha de transmissão e carga, observa-se que a máxima transferência de potência do gerador para a carga não é obtida quando os coeficientes de reflexão são nulos. Ou seja, a máxima transferência de potência requer uma onda estacionária sobre a linha.

Isso acontece porque múltiplas reflexões ocorrem nas extremidades da linha, fazendo com que a potência final transmitida seja maior do que no caso de reflexão nula. Se for fixada a impedância do gerador, é possível mostrar que a máxima transferência de potência ocorre quando a impedância de entrada vista na linha, em direção à carga, é igual ao complexo conjugado da impedância do gerador. 


\subsection{CARTA DE SMITH}

A Carta de Smith, mostrada na Fig. 3.3, é uma ferramenta gráfica que auxilia a resolução de problemas de linhas de transmissão. Além de ser uma ferramenta gráfica, ela faz parte da maioria das ferramentas de simulação e de equipamentos para teste de dispositivos de microondas [13].

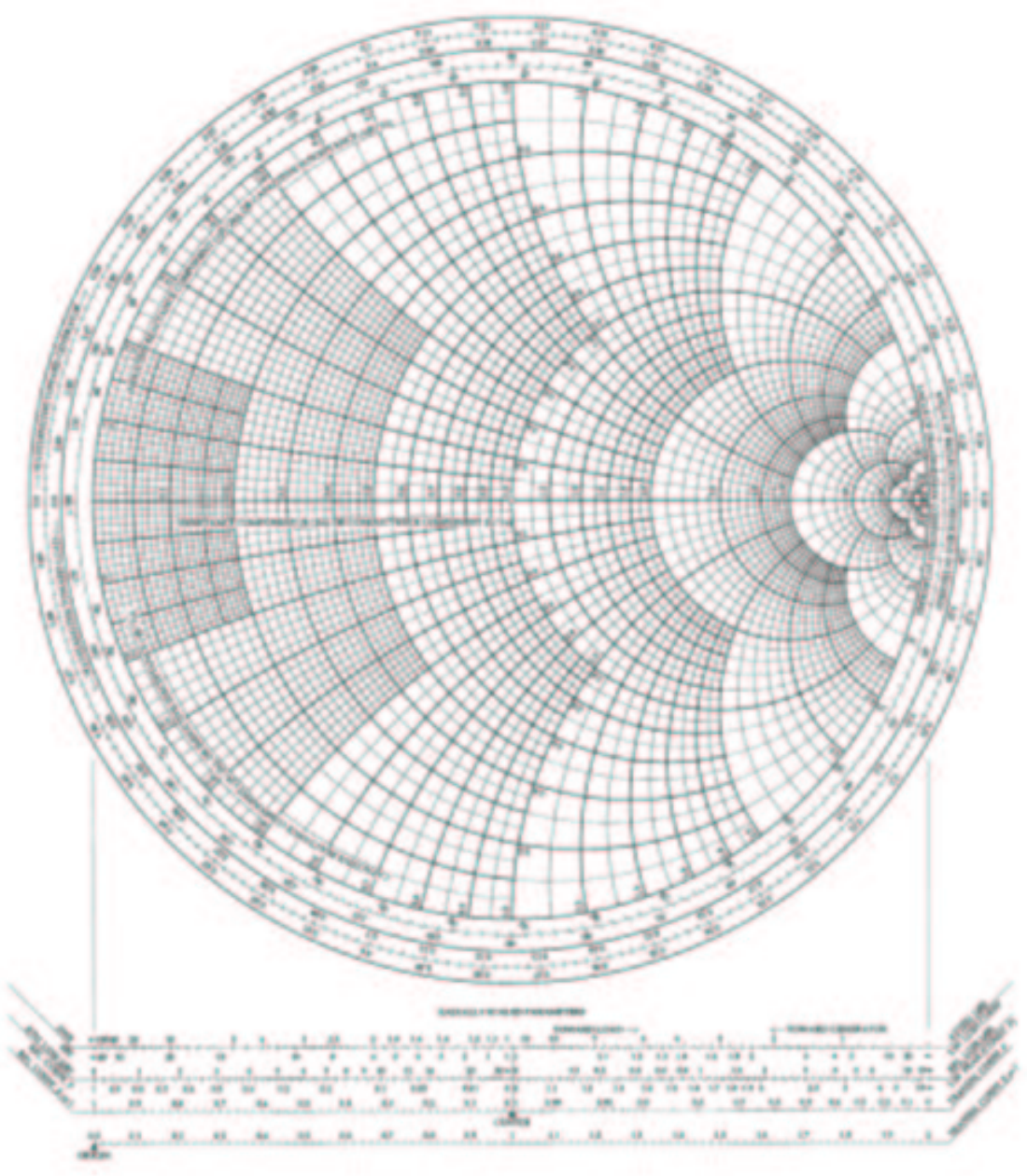

Figura 3.3: Carta de Smith

Sua real utilidade, no entanto, é a possibilidade de conversão de coeficientes de reflexão em impedâncias, ou admitâncias, e vice-versa. Para isso, utilizam-se os círculos de impedância, ou admitância, impressos na carta. As impedâncias tratadas em uma carta de Smith são geralmente normalizadas pela impedância característica da linha de transmissão.

Além da conversão de coeficientes de reflexão em impedâncias, a carta de Smith pode ser usada para resolver a Eq. 3.13. A impedância de entrada normalizada, a uma distância 1 da carga, e com um dado coeficiente de reflexão na carga, pode ser lida graficamente na carta. Uma outra aplicação da carta de Smith é a conversão de valores de impedância em admitância, e vice-versa. 


\subsection{CASAMENTO DE IMPEDÂNCIAS}

O casamento de impedâncias consiste em fazer com que a máxima transferência de potência seja atingida no circuito em questão. Uma rede para casamento de impedância sempre pode ser encontrada se a impedância de carga tiver parte real não-nula. Existem muitas formas de realizar um casamento de impedância onde cada uma elas têm suas vantagens e desvantagens.

Alguns fatores são levados em conta na escolha da rede de casamento: complexidade, banda de casamento, implementação na tecnologia utilizada e adaptabilidade para cargas variáveis. Algumas das abordagens mais simples de casamento de impedâncias são ilustrados em seguida.

\subsubsection{Elementos concentrados}

É a forma mais simples de se realizar o casamento. A sua implementação é feita adicionando-se capacitores em série e indutores em paralelo, ou o contrário, entre as impedâncias que se deseja casar.

\subsubsection{Estube simples}

Consiste em adicionar um pedaço de linha de transmissão (ou estube), entre as impedâncias a serem casadas, a uma certa distância da carga. Essa linha pode estar aberta ou em curto-circuito, em série ou em paralelo. O comprimento desse pedaço de linha, e a distância entre ele e a carga são calculados de forma a obter o casamento desejado. Esse circuito é conveniente, em microondas, porque não requer elementos concentrados de circuito.

\subsubsection{Estube duplo}

O casamento, agora, consiste em adicionar um par de estubes. Dessa forma, a distância entre os estubes e a carga não influencia mais o casamento. Para se obter o casamento desejado, deve-se definir a distância entre os dois estubes e a reatância a ser fornecida por cada um deles.

\subsubsection{Transformador de quarto de onda}

Consiste em adicionar uma linha de transmissão com um quarto do comprimento de onda entre as impedâncias que se deseja casar. A impedância característica dessa linha de transmissão é projetada para que o casamento seja realizado, mas efetua casamento entre impedâncias reais. Múltiplas seções de linhas 
de transmissão podem ser usadas. Dessa forma, é possível efetuar um casamento para uma banda mais larga.

\subsection{PARÂMETROS DE ESPALHAMENTO}

Circuitos de microondas lineares podem ser completamente caracterizados por parâmetros medidos nos terminais (portas) dos circuitos [14]. Para se realizar uma análise, não é necessário conhecer a constituição dos mesmos.

Uma das formas de se caracterizar um circuito de microondas linear é utilizar a relação entre as ondas de tensão incidentes e refletidas nas portas do circuito. Essas relações podem ser agrupadas em uma matriz. Essas relações são chamadas de parâmetros espalhamento, e a matriz que os agrupa é chamada de matriz espalhamento. Os parâmetros espalhamento de alguns componentes e circuitos podem ser calculados com técnicas de análise, já outros dispositivos têm seus parâmetros obtidos através de medições com aparelhos adequados.

Dada uma rede de $\mathrm{N}$ portas, a amplitude da onda incidente de tensão na porta $\mathrm{N}$ é $V_{n}^{+}$e a amplitude da onda refletida na porta $\mathrm{n}$ é $V_{n}^{-}$, a matriz espalhamento é definida pela Eq. 3.14.

$$
\begin{aligned}
& {\left[\begin{array}{c}
V_{1}^{-} \\
V_{2}^{-} \\
\vdots \\
V_{n}^{-}
\end{array}\right]=\left[\begin{array}{cccc}
S_{11} & S_{12} & \cdots & S_{1 N} \\
S_{21} & \ddots & & \vdots \\
\vdots & & \ddots & \vdots \\
S_{N 1} & \cdots & \cdots & S_{N N}
\end{array}\right]\left[\begin{array}{c}
V_{1}^{+} \\
V_{2}^{+} \\
\vdots \\
V_{n}^{+}
\end{array}\right]} \\
& \text {onde }: S_{i j}=\left.\frac{V_{i}^{-}}{V_{j}^{+}}\right|_{V_{k}^{+}=0 \text { para } k \neq j}
\end{aligned}
$$

Portanto, para determinar um parâmetro espalhamento, injetamos uma onda incidente na porta $\mathrm{J}$ e medimos a onda que sai na porta I. A onda incidente em todas as portas, exceto na porta $\mathrm{J}$, deve ser nula. Temos, então:

- $\mathrm{S}_{i i}$ - Coeficiente de reflexão na porta I com as demais casadas.

- $\mathrm{S}_{i j}$ - Coeficiente de transmissão entre a porta I e a $\mathbf{J}$ com as demais casadas.

É importante ressaltar que as ondas incidentes utilizadas na definição dos parâmetros espalhamento são 
normalizadas pela raiz da impedância vista na entrada de cada uma das portas. Dessa forma, o quadrado do módulo destas ondas tem significado de potência:

- $\left|V n^{+}\right|^{2}$ - Potência incidente na porta $\mathrm{N}$ da estrutura.

- $\left|V n^{-}\right|^{2}$ - Potência refletida na porta $\mathrm{N}$ da estrutura.

O quadrado do módulo dos parâmetros de espalhamento tem também significado de potência:

- $\left|S_{i i}\right|^{2}$ - Perda de potência devida à reflexão na porta I da estrutura.

- $\left|S_{i j}\right|^{2}$ - Ganho de potência entre as portas I e J da estrutura.

\subsection{QUADRIPOLOS ATIVOS}

Circuitos de microondas que possuem apenas duas portas, uma de entrada e uma de saída, podem ser estudados como quadripolos. Os amplificadores de microondas, de uma forma geral, são circuitos que apresentam apenas duas portas. Além disso, possuem elementos ativos, sendo classificados como quadripolos ativos.

As características básicas de um quadripolo ativo são: ganho, estabilidade e ruído. Todas essas características são analisadas a partir dos parâmetros espalhamento dos quadripolos.

\subsubsection{Estabilidade}

A estabilidade de um sistema linear pode ser definida como a existência de uma saída limitada para qualquer entrada limitada. Para um quadripolo ativo, essa condição pode ser avaliada a partir dos seus parâmetros espalhamento. Um quadripolo pode ser classificado quanto a sua estabilidade de duas formas: incondicionalmente estável (o componente é estável para quaisquer impedâncias apresentadas em suas portas) e condicionalmente estável (a estabilidade depende das impedâncias apresentadas em suas portas).

Para que um quadripolo seja estável, é necessário que tenhamos $\left|\Gamma_{L}\right|<1$ e $\left|\Gamma_{i n}\right|<1$ simultaneamente. Para um quadripolo com impedâncias de fonte e carga já definidas, por exemplo um amplificador projetado com uma fonte de impedância de $50 \Omega$ e uma carga de $50 \Omega$, a análise da estabilidade torna-se bem simples. O quadripolo é estável se $\left|S_{11}\right|$ e $\left|S_{22}\right|$ do conjunto todo forem menores do que 1, para todas as frequiências menores ou iguais à sua freqüência de operação. 
No caso de um quadripolo sem impedâncias de entrada e saída definidas, a análise da estabilidade se torna mais complexa. Apesar da condição para estabilidade ser a mesma, para garantir a estabilidade devemos analisar o comportamento de $\left|\Gamma_{L}\right|$ e $\left|\Gamma_{i n}\right|$. Esse comportamento depende das impedâncias apresentadas na entrada e na saída do quadripolo.

Para que um quadripolo ativo seja incondicionalmente estável, faz-se necessário que o fator de estabilidade, $\mathrm{K}\left(\right.$ Eq. 3.15), seja maior do que 1 e que $B_{1}$ (Eq. 3.16) e $B_{2}$ (Eq. 3.17) sejam positivos. Dessa forma, garantimos que $\left|\Gamma_{L}\right|<1$ e $\left|\Gamma_{i n}\right|<1$ e que o quadripolo é estável independentemente das impedâncias apresentadas.

$$
\begin{aligned}
& K \triangleq \frac{1-\left|S_{11}\right|^{2}-\left|S_{22}\right|^{2}+|\Delta|^{2}}{2\left|S_{12} S_{21}\right|} \\
& B_{1} \triangleq 1+\left|S_{11}\right|^{2}-\left|S_{22}\right|^{2}-|\Delta|^{2} \\
& B_{2} \triangleq 1+\left|S_{22}\right|^{2}-\left|S_{11}\right|^{2}-|\Delta|^{2} \\
& \text { onde }: \Delta \triangleq S_{11} S_{22}-S_{12} S_{21}
\end{aligned}
$$

Se a condição de estabilidade incondicional não for atingida, a análise da estabilidade passa a ser a análise de quais impedâncias, que apresentadas nas extremidades do quadripolo, permitem operação estável. Essa análise pode ser realizada algebricamente ou graficamente, utilizando a carta de Smith. Para essa análise definimos o conceito de círculos de estabilidade.

\subsubsection{Círculos de estabilidade}

Atendendo à condição de estabilidade que diz que $\left|\Gamma_{i n}\right|<1$ no plano de impedâncias de entrada, temos o círculo unitário de impedâncias dentro do qual $\left|\Gamma_{i n}\right|<1$. Para saber no plano de carga, as impedâncias que provocam instabilidade, transformamos o círculo $\left|\Gamma_{i n}\right|=1$ para o plano de carga. O resultado é o círculo com centro, $C_{e s}$ (Eq.3.18), e raio, $\rho_{e s}$ (Eq.3.19). 


$$
\begin{aligned}
& C_{e s}=\frac{C_{2}^{*}}{D_{2}} \\
& \rho_{e s}=\left|\frac{S_{12} S_{21}}{D_{2}}\right| \\
& D_{2} \triangleq\left|S_{22}\right|^{2}-|\Delta|^{2} \\
& C_{2} \triangleq S_{22}-\Delta S_{11}^{*} \\
& \text { onde }: \Delta \triangleq S_{11} S_{22}-S_{12} S_{21}
\end{aligned}
$$

O círculo resultante no plano de carga é chamado de círculo de estabilidade para o plano de impedâncias de carga. De maneira análoga, pode-se definir o círculo de estabilidade no plano de impedâncias de entrada.

A verificação algébrica dos valores de $\mathrm{K}$ e $B_{1}$ leva a três possibilidades:

1. $K>1$ e $B_{1}>0$ - Estabilidade incondicional.

2. $K>1$ e $B_{1}<0$ - Estabilidade condicional.

3. $K<1$ e $B_{1}<0$ - Estabilidade condicional.

A análise completa consiste em verificar a posição relativa do círculo de estabilidade, com o círculo unitário de impedâncias. Seis diferentes situações ocorrem para $\left|S_{11}\right|<1$. Caso $\left|S_{11}\right|>1$, a análise se inverte:

1. $K>1 B_{1}>0$ e $D_{2}>0$. Os círculos não se interseccionam, sistema incondicionalmente estável.

2. $K>1 B_{1}>0$ e $D_{2}<0$. O círculo de estabilidade contém o círculo unitário, sistema incondicionalmente estável.

3. $K<1 \quad B_{1}<0$ e $D_{2}>0$. O círculo unitário contém o círculo de estabilidade, sistema condicionalmente estável. As impedâncias que garantem operação estável são aquelas que estão co círculo unitário, mas não estão no círculo de estabilidade.

4. $K>1 B_{1}<0$ e $D_{2}<0$. O círculo unitário contém o círculo de estabilidade, sistema condicionalmente estável. As impedâncias que garantem operação estável são aquelas que estão no círculo unitário, e também no círculo de estabilidade.

5. $K<1 \quad B_{1}<0$ e $D_{2}>0$. O círculo de estabilidade intersecciona o círculo unitário, sistema condicionalmente estável. As impedâncias que garantem operação estável são aquelas que estão no círculo unitário, mas não estão no círculo de estabilidade. 
6. $K<1 B_{1}<0$ e $D_{2}<0$. O círculo de estabilidade intersecciona o círculo unitário, sistema condicionalmente estável. As impedâncias que garantem operação estável são aquelas que estão no círculo unitário, e também no círculo de estabilidade.

\subsubsection{Ganho}

Pode-se definir quatro diferentes potências envolvidas no funcionamento de um quadripolo ativo. A Fig. 3.4 mostra essas definiçõos.

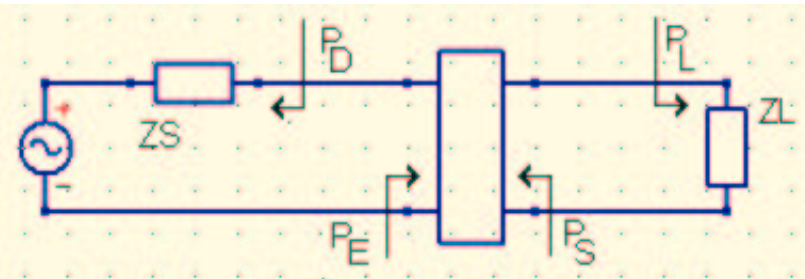

Figura 3.4: Potências em quadripolos ativos

- $P_{D}$ - Potência disponível do gerador - potência que o gerador entregaria, se esse estivesse casado com o conjugado da impedância de entrada do quadripolo.

- $P_{E}$ - Potência que efetivamente entra no quadripolo - diferença entre a potência incidente e a potência refletida na entrada do quadripolo.

- $P_{S}$ - Potência disponível na saída do quadripolo - potência que o quadripolo entregaria à carga, se esse estivesse casado com o complexo conjugado da impedância de carga.

- $P_{L}$ - Potência efetivamente entregue à carga - diferença entre potência incidente e potência refletida na carga.

\subsubsection{Ganho de Transdução - $G_{T}$}

É a razão entre a potência efetivamente entregue à carga e a potência disponível do gerador. Considera as impedâncias de carga e de fonte ligadas ao quadripolo. Mede a eficiência global do quadripolo. 


$$
\begin{aligned}
& G_{T}=\frac{P_{L}}{P_{D}} \\
& G_{T}=\frac{\left|S_{21}\right|^{2}\left(1-\left|\Gamma_{S}\right|^{2}\right)\left(1-\left|\Gamma_{L}\right|^{2}\right)}{\left|\left(1-S_{11} \Gamma_{S}\right)\left(1-S_{22} \Gamma_{L}\right)-S_{12} S_{21} \Gamma_{L} \Gamma_{S}\right|^{2}} \\
& \text { onde }: \Gamma_{S}=\frac{Z_{S}-Z_{O}}{Z_{S}+Z_{O}} e \Gamma_{L}=\frac{Z_{L}-Z_{O}}{Z_{L}+Z_{O}}
\end{aligned}
$$

\subsubsection{Ganho de Potência - G}

É a razão entre a potência entregue à carga e a potência que efetivamente entra no quadripolo. Considera apenas a impedância de carga ligada ao quadripolo.

$$
\begin{aligned}
& G=\frac{P_{L}}{P_{E}} \\
& G=\frac{\left|S_{21}\right|^{2}\left(1-\left|\Gamma_{L}\right|^{2}\right)}{\left(1-\left|S_{11}\right|^{2}\right)+\left|\Gamma_{L}\right|^{2}\left(\left|S_{22}\right|^{2}-|\Delta|^{2}\right)-2 \operatorname{Re}\left(\Gamma_{L} C_{2}\right)} \\
& \text { onde }: C_{2}=S_{22}-S_{11}^{*} \Delta e \Delta=S_{11} S_{22}-S_{12} S_{21}
\end{aligned}
$$

\subsubsection{Ganho de Disponível - $G_{D}$}

É a razão entre a potência disponível na saída do quadripolo e a potência disponível no gerador. Considera apenas a impedância de fonte ligada ao quadripolo.

$$
\begin{aligned}
& G_{D}=\frac{P_{S}}{P_{D}} \\
& G_{D}=\frac{\left|S_{21}\right|^{2}\left(1-\left|\Gamma_{S}\right|^{2}\right)}{\left(1-\left|S_{22}\right|^{2}\right)+\left|\Gamma_{S}\right|^{2}\left(\left|S_{11}\right|^{2}-|\Delta|^{2}\right)-2 \operatorname{Re}\left(\Gamma_{S} C_{1}\right)} \\
& \text { onde }: C_{1}=S_{11}-\Delta S_{22}^{*} \text { e } \Delta=S_{11} S_{22}-S_{12} S_{21}
\end{aligned}
$$

\subsubsection{Ganho de Tensão - $G_{V}$}

O ganho de tensão é definido como a razão entre a tensão na carga e a tensão nos terminais do gerador. Não depende da impedância do gerador. 


$$
\begin{aligned}
G_{V} & =\frac{V_{2}}{V_{1}} \\
G_{V} & =\frac{S_{21}\left(1+\Gamma_{L}\right)}{\left(1-\Gamma_{L} S_{22}\right)\left(1+S_{11}\right)+S_{12} S_{21} \Gamma_{L}}
\end{aligned}
$$

\subsubsection{Círculos de ganho constante}

Observa-se que no plano da carta de Smith existe apenas um par de impedâncias (uma de entrada e uma de saída) que fornece ganho máximo de potência. No entanto, para qualquer ganho diferente do ganho máximo, existe um círculo de impedâncias definido sobre o plano da carta de Smith.

Os círculos de ganho constante podem ser definidos tanto no plano de impedâncias de saída como no plano de impedâncias de entrada. No plano de impedâncias de saída, escolhendo um ganho de potência normalizado (Eq. 3.30), temos o círculo de centro, $C_{g s}$ (Eq. 3.31), e o raio, $\rho_{g s}$ (Eq. Eq. 3.32), definidos em [13].

$$
\begin{aligned}
& g=\frac{G}{\left|S_{21}\right|^{2}} \\
& C_{g s}=\frac{g C_{2}^{*}}{1+g D_{2}} \\
& \rho_{g s}=\frac{\sqrt{1-2 K\left|S_{12} S_{21}\right| g+\left|S_{12} S_{21}\right|^{2} g^{2}}}{1+g D_{2}} \\
& \text { onde }: C_{2}=S_{22}-\Delta S_{11}^{*} \text { e } D_{2}=\left|S_{22}\right|^{2}-|\Delta|^{2}
\end{aligned}
$$

Utilizando-se essas equações, pode-se escolher $\Gamma_{L}$ para o ganho desejado. A partir de $\Gamma_{L}$, obtém-se $\Gamma_{S}$ utilizando-se as Eqs. 3.33 e 3.34. Com $\Gamma_{L}$ e $\Gamma_{S}$ definidos, sintetiza-se o circuito de casamento de impedâncias que fornece o ganho especificado. Esse procedimento poderia ser realizado de forma análoga, considerando-se o plano de impedâncias de entrada, obtendo-se $\Gamma_{S}$, e a partir de $\Gamma_{S}$ obtendo-se $\Gamma_{L}$.

$$
\begin{aligned}
& \Gamma_{i n}=S_{11} \frac{\Gamma_{L} S_{12} S_{21}}{1-S_{22} \Gamma_{L}} \\
& \Gamma_{S}=\Gamma_{i n}^{*}
\end{aligned}
$$


Quando se consideram quadripolos incondicionalmente estáveis, pode-se mostrar que existe um ganho máximo disponível. As impedâncias que sintetizam esse ganho máximo podem ser obtidas a partir da carta de Smith, observando-se o ganho para o qual o círculo de ganho constante se reduz a apenas um ponto (Eq. 3.35). Dessa forma, só existe uma impedância de entrada e uma impedância de saída que leva ao ganho máximo. Essas impedâncias são definidas pelos coeficientes de reflexão $\Gamma_{S \max }$ (Eq. 3.36) e $\Gamma_{\operatorname{Lmax}}$ (Eq. 3.37).

$$
\begin{aligned}
G_{\text {max }} & =M G D=g\left|S_{21}\right|^{2}=\frac{\left|S_{21}\right|}{\left|S_{12}\right|}\left(K \pm \sqrt{K^{2}-1}\right) \\
\Gamma_{L \max } & =\frac{B_{2} \pm \sqrt{B_{2}^{2}-4\left|C_{2}\right|^{2}}}{2 C_{2}} \\
\Gamma_{S \max } & =\frac{B_{1} \pm \sqrt{B_{1}^{2}-4\left|C_{1}\right|^{2}}}{2 C_{1}}
\end{aligned}
$$

\subsubsection{Ruído}

O ruído é um dos maiores limitadores dos sistemas de comunicação. Ele pode ser definido como uma forma de energia que interfere de maneira indesejada sobre os sinais de informação. Existem diferentes tipos de ruídos: ruídos cósmicos, ruído térmico, ruído de disparo (transistores e válvulas), entre outros.

O ruído tem, de forma geral, caráter aleatório. Apesar de não poder ser modelado deterministicamente, ele pode ser modelado estatisticamente. Para a maioria dos tipos de ruído, a intensidade média é constante para todas as frequiências do espectro eletromagnético. O modelamento, por isso, assume que a potência de ruído é proporcional à largura de banda sobre a qual ele é medido.

\subsubsection{Ruído térmico}

O ruído térmico é resultado da agitação térmica dos elétrons presentes em qualquer material. Essa agitação térmica promove um movimento desordenado dos elétrons, provocando a liberação de energia. O ruído térmico tem sua intensidade média constante sobre todo o espectro de frequiências e não depende da existência de corrente elétrica para existir. A potência máxima disponível de ruído térmico é definida pela Eq. 3.38 [14]. 


$$
\begin{aligned}
& P=k T B \\
& \text { onde }: k=\text { constante de Boltzmann }=1.38 \times 10^{-23}(\mathrm{~J} / \mathrm{K}) \\
& T=\text { temperatura absoluta }(\mathrm{K}) \\
& \text { e } B=\text { largura de banda do ruido }(\mathrm{Hz})
\end{aligned}
$$

\subsubsection{Ruído de disparo}

O ruído de disparo (ou ruído Schottky) existe nas válvulas e nos semicondutores. Esse ruído existe porque o fluxo de elétrons que passa por esses dispositivos não é constante. O ruído de disparo tem sua intensidade média constante sobre todo o espectro de frequiências, e depende diretamente da corrente elétrica média que o gera. Geralmente, é expresso através da corrente média quadrática de ruído, fórmula de Schottky (Eq. 3.39) [14].

$$
\begin{aligned}
& \overline{i^{2}}=2 e I B \\
& \text { onde }: e=1.6 \times 10^{-19} \text { Coulomb } \\
& I=\text { corrente média }(A) \\
& \text { e } B=\text { largura de banda do ruido }(H z)
\end{aligned}
$$

\subsubsection{Temperatura equivalente de ruído}

A temperatura equivalente de ruído, $T_{e}$, é a temperatura na qual, uma resistência colocada na entrada produziria a potência de ruído disponível na saída. É importante ressaltar que ela é uma equivalência matemática, e não uma temperatura no sentido físico. Conhecendo-se a potência de ruído disponível na saída, $P_{o}$, é possível determinar a temperatura equivalente de ruído (Eq. 3.40) [14]. 


$$
\begin{aligned}
& P_{o}=G k\left(T_{o}+T_{e}\right) B \\
& \text { onde }: k=\text { constante de Boltzmann }=1.38 \times 10^{-23}(\mathrm{~J} / \mathrm{K}) \\
& T_{o}=\text { temperatura ambiente } 290 \mathrm{~K} \\
& G=\text { ganho da estrutura } \\
& \text { e } B=\text { largura de banda do ruído }(\mathrm{Hz})
\end{aligned}
$$

\subsubsection{Figura de ruído}

A figura de ruído (F) é definida como a relação entre a potência de ruído disponível na saída de um quadripolo, e a potência de ruído produzida por uma resistência, à temperatura $T_{o}$, na entrada do mesmo (Eq. 3.41) [14]. Sua maior funcionalidade é medir a quantidade de ruído que um dado circuito, ou componente, adiciona a um sistema.

$$
F=1+\frac{T_{e}}{T_{o}}
$$

Existe uma impedância de fonte, que se apresentada ao quadripolo fornece uma figura de ruído mínima. Essa impedância corresponde ao coeficiente de reflexão $\Gamma_{O}$. Para essa impedância, a figura de ruído assume um valor mínimo (Fmin).

\subsubsection{Círculos de figura de ruído constante}

Para impedâncias de fonte diferentes da impedância para figura de ruído mínima, é possível determinar sobre o plano da carta de Smith, círculos sobre os quais a figura de ruído é constante. Na definição desses círculos, temos o parâmetro $\mathrm{N}$ (Eq. 3.42), no qual $\mathrm{F}$ é a figura de ruído desejada. $\mathrm{O}$ raio, $\rho_{F}$, e o centro, $c_{F}$ , do círculo para a figura de ruído F são então definidos (Eq. 3.43 e Eq. 3.44), como em [13].

$$
\begin{aligned}
& N=\frac{F-F_{\min }}{4 r_{n}}\left|1+\Gamma_{O}\right|^{2} \\
& \rho_{F}=\frac{\sqrt{N^{2}+N\left(1-\left|\Gamma_{O}\right|^{2}\right)}}{1+N} \\
& c_{F}=\frac{\Gamma_{O}}{1+N}
\end{aligned}
$$


Se uma figura de ruído desejada é escolhida, é possível obter os coeficientes de reflexão $\Gamma_{S}$ e $\Gamma_{L}$ necessários para obtê-la. De posse dos coeficientes de reflexão, é possível sintetizar os circuitos de casamento necessários para o projeto completo do circuito.

\subsection{SOFTWARE UTILIZADO PARA SIMULAÇÕES}

O QUCS(Quiet Universal Circuit Simulator) é um simulador de circuitos que permite a simulação em pequenos e grandes sinais, e de ruído de circuitos. Ele possui uma interface gráfica (Fig. 3.5) para a inserção dos esquemáticos dos circuitos e para a visualização dos resultados. Essa interface foi desenvolvida utilizando-se a plataforma Qt (Qt by Trolltech), o que permite sua utilização em ambientes Solaris, NetBSD, FreeBSD, MacOS, Windows and Cygwin.

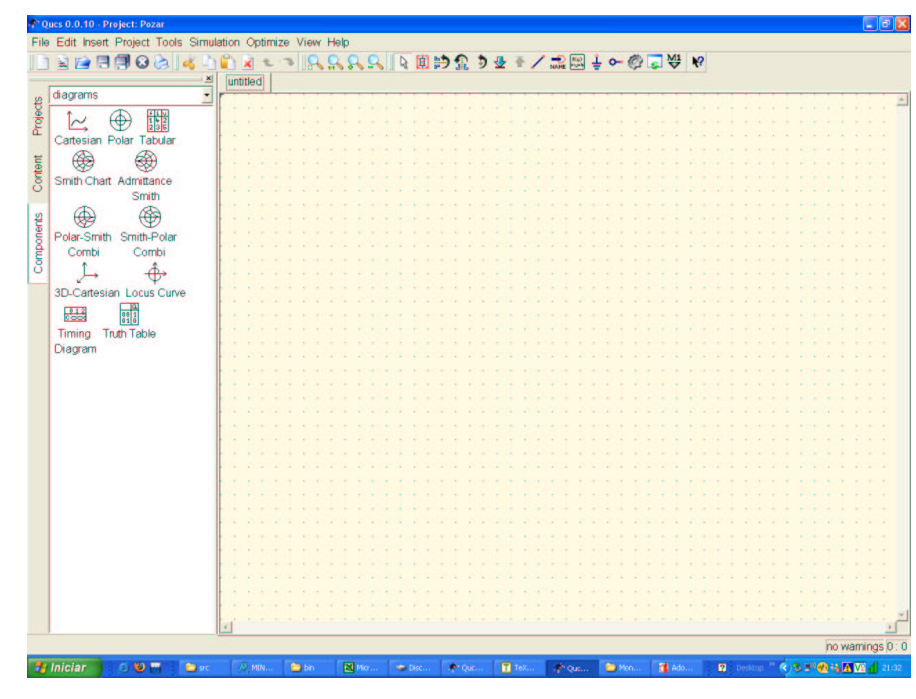

Figura 3.5: Interface gráfica do QUCS

O núcleo do simulador é um módulo independente acionado por linha de comando. Ele recebe como parâmetro de entrada a lista dos elementos do circuito e suas interconexões(Netlist) e retorna como saída um conjunto de dados(Dataset) com os resultados da simulação. O simulador realiza diferentes tipos de simulação: DC, AC, ruído, transiente, Harmonic Balance e Parâmetros S. No entanto, ele ainda se encontra em fase de desenvolvimento e por isso algumas de suas funcionalidades ainda não estão implementadas, ou têm operação instável. A simulação de parâmetros $\mathrm{S}$ e simulação de ruído são amplamente utilizadas no presente trabalho. 


\subsubsection{Exemplos de simulações}

As Figs. 3.6 e 3.7, mostram exemplos de circuitos e o resultados de algumas simulações. A Fig. 3.6-a tem o esquemático de um amplificador com rede de casamento implementada com estubes série e estubes paralelo[13]. A Fig. 3.6-b mostra o resultado da simulação dos parâmetros $\mathrm{S}$ do mesmo amplificador. A Fig. 3.7-a tem o esquemático de um circuito RLC paralelo. A Fig. 3.7-b mostra o resultado da simulação de parâmetros S do circuito RLC paralelo. A Fig. 3.7-c mostra o resultado da simulação de ruído do circuito RLC paralelo.

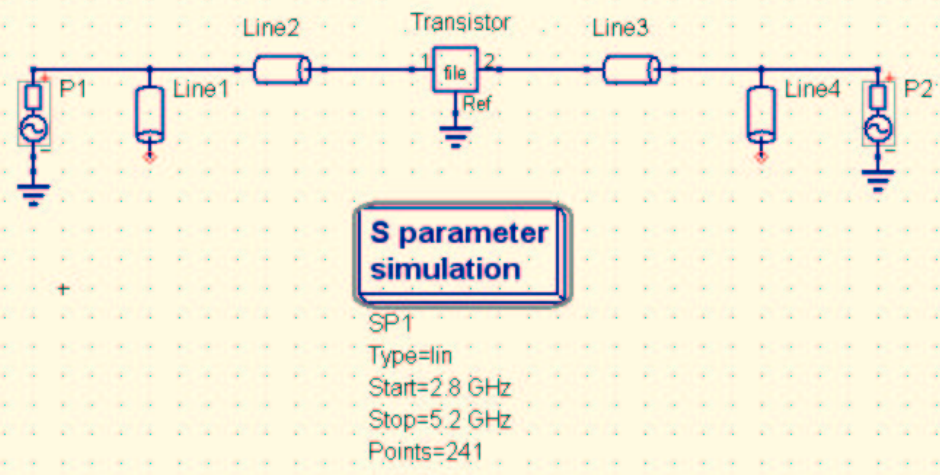

(a) Esquemático
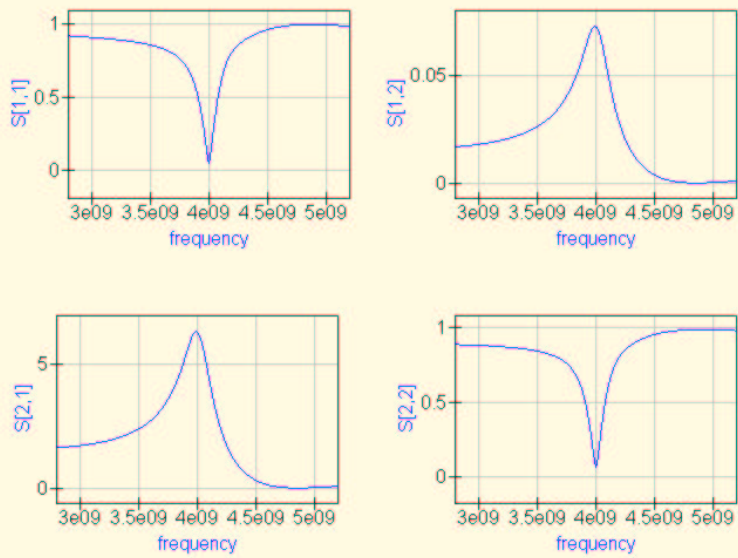

(b) Resultado da simulação de parâmetros $\mathrm{S}$

Figura 3.6: Circuito Exemplo 1

\subsection{CONSIDERAÇÕES FINAIS}

Neste capítulo, foi apresentada a teoria de microondas necessária à síntese de amplificadores classe A. Foram definidas as classes de operação dos amplificadores de potência, a teoria de linhas de transmissão 

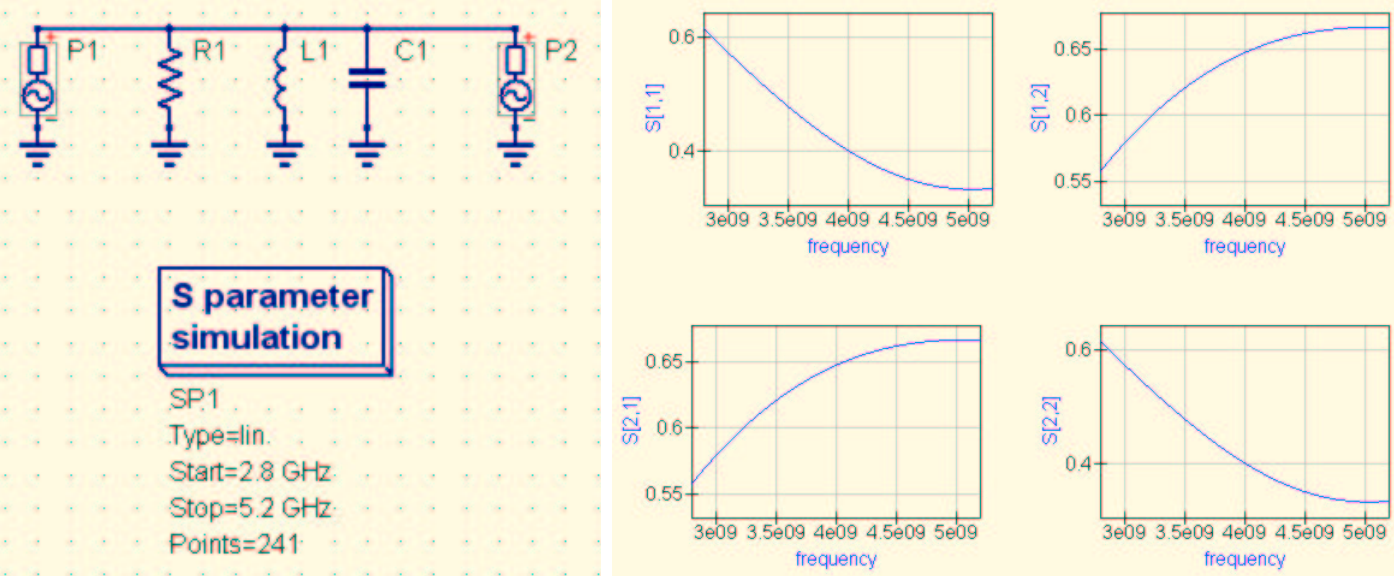

(a) Esquemático

(b) Resultado da simulação de parâmetros $\mathrm{S}$
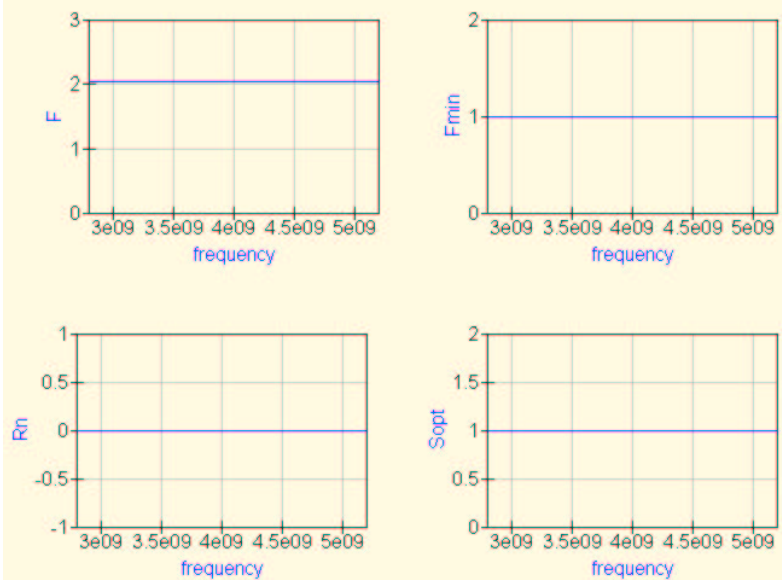

(c) Resultado da simulação de ruído

Figura 3.7: Circuito Exemplo 2

e de parâmetros S. O simulador de circuitos utilizado e algumas simulações foram mostradas. O próximo capítulo apresentaos algoritmos evolucionários implementados e integrados a esse simulador. 


\section{ALGORITMOS EVOLUCIONÁRIOS}

\subsection{CONSIDERAÇÕES INICIAIS}

Neste capítulo, será abordada a teoria de algoritmos evolucionários. Os algoritmos evolucionários são classificados como uma nova forma de algoritmos computacionais. Eles se baseiam em processos biológicos, como a evolução e os sistemas imunológicos, na busca por uma nova forma de resolver problemas de otimização. Os algoritmos genéticos (algoritmos evolucionários baseados no fenômeno biológico da evolução) e os algoritmos imunológicos (algoritmos evolucionários baseados em sistemas imunológicos naturais) são então tratados e suas implementações mostradas, sendo essa teoria aplicada na otimização de amplificadores de microondas.

\subsection{SISTEMAS INTELIGENTES}

Os algoritmos evolucionários podem ser classificados na categoria de sistemas inteligentes. Sistemas inteligentes são aqueles, nos quais a abordagem para a solução de problemas não se baseia na arquitetura padrão dos computadores digitais convencionais. Em vez de seguir uma estrutura rígida e uma seqüência bem definida, os sistemas inteligentes tentam agregar características típicas do comportamento da inteligência. Dentro da categoria de sistemas inteligentes se encontram as chamadas Redes Neurais, os Sistemas Especialistas, a Lógica fuzzy, e ainda, os algoritmos evolucionários.

A aplicação dos sistemas inteligentes na engenharia é observada em diversos campos. As áreas de controle, de processamento de sinais e de otimização têm problemas que justificam a aplicação de tais sistemas. A área de otimização, mais especificamente, tem nos sistemas evolucionários uma poderosa arma na solução de seus problemas. 


\subsection{CONCEITOS GERAIS}

Os algoritmos evolucionários baseiam-se em alguns fenômenos biológicos para tentar realizar a otimização de funções matemáticas complexas. A aplicação de tais técnicas justifica-se, principalmente, quando as funções a serem otimizadas são extremamente complexas e o espaço de busca por soluções é extremamente grande, sendo difícil uma modelagem adequada do problema de otimização.

Esse é o caso da otimização de circuitos amplificadores de microondas. Nesse caso, a modelagem de parâmetros de avaliação do circuito, como ganho, banda e estabilidade, em função de parâmetros dos componentes do mesmo é extremamente complexa. Além disso, quando o projeto de amplificadores de microondas é feito utilizando-se a tecnologia CMOS, a inserção de elementos parasitas faz com que os projetos e as otimizações tornem-se ainda mais complexos.

Os algoritmos evolucionários baseiam-se em um processo artificial de seleção de possíveis soluções que se alteram de uma iteração para outra. Esse processo de seleção norteia-se apenas pelo resultado final das funções a serem otimizadas, para cada uma das soluções testadas. O processo de seleção de soluções que se perpetuam em outras iterações, e ainda, o processo de criação de novas soluções a partir das soluções anteriores é o que difere um algoritmo evolucionário de outro. O fluxo geral de solução de um problema utilizando-se algoritmos evolucionários está mostrado na Fig. 4.1.

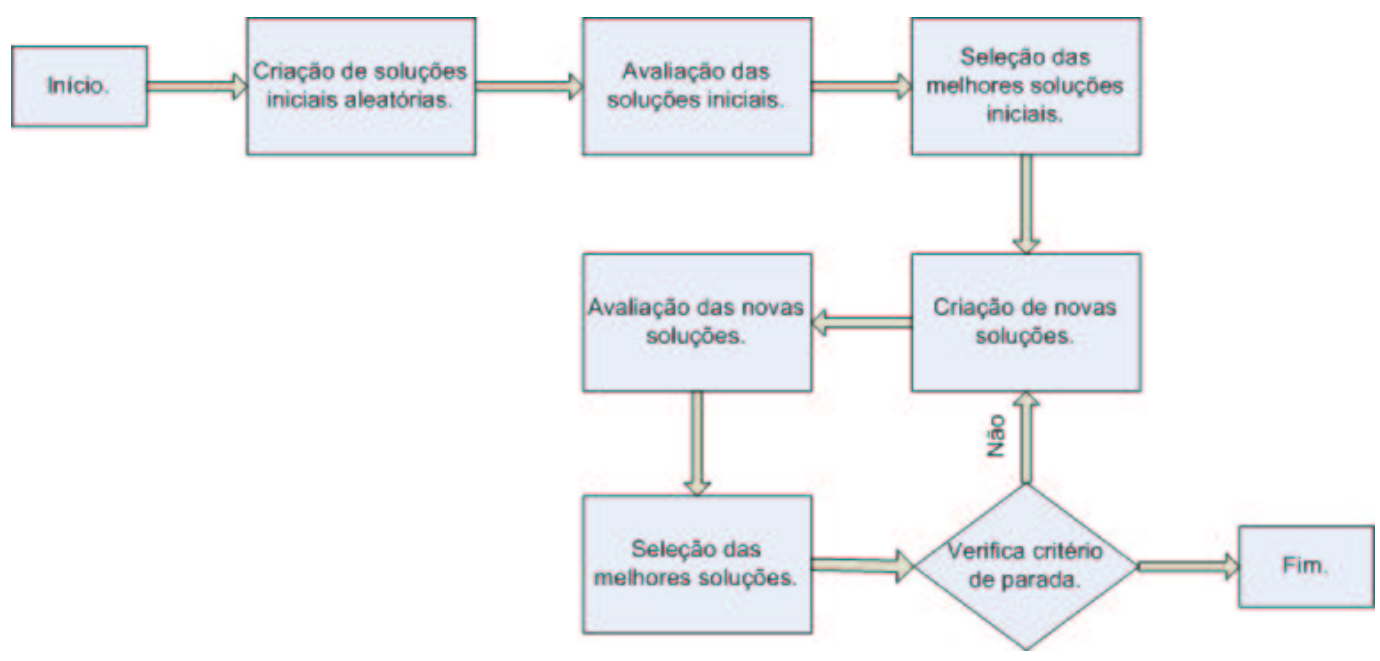

Figura 4.1: Fluxo de execução de um algoritmo evolucionário

Primeiramente, é gerada uma população de soluções iniciais aleatórias. Essas soluções são então avaliadas quanto aos objetivos desejados. Feita a avaliação, as melhores soluções são selecionadas para gerarem novas soluções. As novas soluções são então avaliadas e é feita, novamente, a seleção das melhores soluções para a próxima iteração. 
Assim, o processo repete-se até que algum critério de parada seja atingido. Temos ao fim, um conjunto de soluções melhores do que o conjunto de soluções iniciais. A definição dos critérios de seleção, das funções de avaliação dos objetivos e do método de criação dos novos indivíduos especifica o algoritmo evolucionário utilizado.

\subsubsection{Criação de soluções iniciais}

As soluções iniciais são, em geral, geradas de forma aleatória. Para isso, deve ser definido o espaço de busca de cada uma das variáveis a ser otimizada. Uma distribuição uniforme dentro desse espaço de busca é, em geral, empregada. Dessa forma, tende-se a obter soluções espaçadas por todo o universo de busca.

\subsubsection{Avaliação das soluções}

A avaliação das soluções, tanto iniciais, como geradas no processo de otimização, desse ser efetuada através da definição de uma ou mais funções que avaliem o atendimento de cada um dos objetivos da otimização. O objetivo da otimização passa a ser, portanto, minimizar ou maximizar cada uma dessas funções. Para simplificar a implementação dos algoritmos evolucionários todas as funções de avaliação foram implementadas de forma que a otimização seja uma minimização dos valores das mesmas.

As funções de avaliação do objetivo desejado são também chamadas de funções-objetivo. A quantidade de funções-objetivo existentes em um problema de otimização influencia na seleção das soluções que se perpetuam no decorrer da execução do algoritmo. Os problemas com apenas uma função-objetivo são chamados de mono-objetivo, já os problemas com duas ou mais funções objetivo são chamados de multiobjetivos. As funções-objetivo podem ser, por exemplo, o ganho e a largura de banda de uma topologia de amplificador qualquer.

\subsubsection{Seleção das melhores soluções}

A seleção das soluções no caso mono-objetivo é simples: as soluções selecionadas são aquelas que têm uma melhor avaliação para a função-objetivo definida.

No caso multiobjetivo, a seleção das soluções torna-se um problema mais complexo. A solução para esse tipo de problema utiliza o conceito de frentes de pareto. 
Tabela 4.1: Soluções do problema exemplo

\begin{tabular}{|c|c|c|c|c|c|}
\hline$N^{o}$ & Parâmetro 1 & Parâmetro 2 & Parâmetro 3 & Objetivo 1 & Objetivo 2 \\
\hline 1 & 1 & 4 & 6 & 1 & 4 \\
\hline 2 & 5 & 8 & 2 & 5 & 8 \\
\hline 3 & 3 & 1 & 9 & 9 & 10 \\
\hline 4 & 9 & 7 & 3 & 2,2 & 3,3 \\
\hline 5 & 4 & 8 & 4 & 6,7 & 7 \\
\hline 6 & 10 & 10 & 8 & 7,6 & 6 \\
\hline 7 & 6 & 3 & 1 & 3,9 & 1,7 \\
\hline 8 & 7 & 5 & 10 & 10 & 9 \\
\hline 9 & 2 & 2 & 5 & 4 & 1 \\
\hline 10 & 8 & 6 & 7 & 8 & 5 \\
\hline
\end{tabular}

\subsubsection{Frentes de Pareto}

As frentes de pareto são agrupamentos de soluções sobre as quais não podemos afirmar que uma é melhor do que a outra, se considerarmos apenas o valor das funções objetivo.

Como exemplo, dez soluções para um dado problema são mostradas na Tab. 4.1. Essas soluções são exemplos possíveis de serem obtidos quando o algoritmo evolucionário é executado. Percebe-se que são obtidas soluções com função-objetivo 1 muito boa, mas com função-objetivo 2 muito ruim; soluções com função-objetivo 1 muito ruim, mas com função-objetivo 2 muito boa; e ainda soluções intermediárias.

Na Fig. 4.2, as dez soluções são mostradas no espaço das funções-objetivo definidas e as frentes de pareto estão destacadas. Observando o valor de suas funções objetivo, as soluções são agrupadas em diferentes frentes de pareto. Dessa forma, as soluções 1, 4, 7 e 9 ficam na primeira frente de pareto (melhores soluções), já as soluções 2, 5, 6 e 10 ficam na segunda frente de pareto (soluções piores do que as da primeira frente), e, por fim, as soluções 3 e 8 ficam na terceira e última frente de pareto (piores soluções). A primeira frente de pareto também é chamada de grupo de soluções não-dominadas.

\subsubsection{Densidade relativa das soluções}

As frentes de pareto são capazes de separar as soluções obtidas em grupos de soluções não-dominadas entre si. No entanto, existe uma necessidade de seleção das melhores soluções dentro de uma mesma frente 


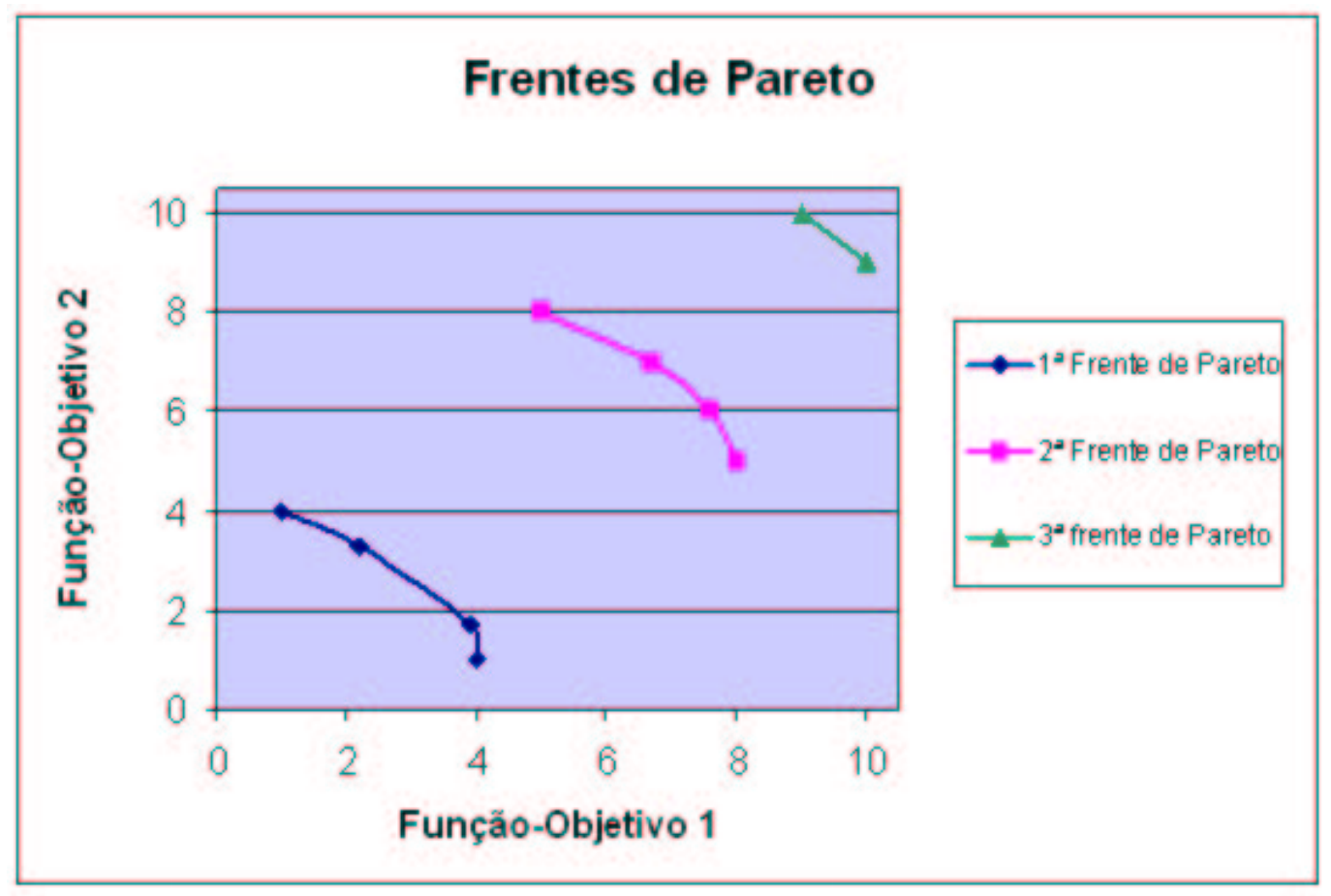

Figura 4.2: Frentes de pareto problema exemplo

de pareto. Essa necessidade é suprida considerando-se a densidade relativa de cada solução dentro da frente de pareto na qual ela se encontra.

A densidade relativa é calculada considerando a quantidade de soluções próximas de uma dada solução, no espaço das funções-objetivo. As soluções que se encontram nos extremos de cada uma das frentes de pareto, são as que possuem menor densidade relativa. Já as soluções que possuem valores intermediários de funções-objetivos têm uma maior densidade relativa dentro de sua frente de pareto.

Considera-se, então, que as melhores soluções dentro de uma frente de pareto são aquelas que possuem menor densidade relativa. Dessa forma, os extremos das frentes de pareto têm uma maior probabilidade de serem selecionados para gerar indivíduos na próxima iteração. Esse processo de seleção garante uma busca por uma boa diversidade de soluções dentro de uma mesma frente de pareto.

Um ordenamento geral de todas as soluções pode ser feito combinando-se as informações da frente de pareto, com a densidade relativa. Para o exemplo da Seção 4.3.3.1, uma densidade relativa é atribuída a cada solução e é feito o ordenamento considerando os dois critérios. A Tab. 4.2 mostra esse ordenamento. 
Tabela 4.2: Ordenamento das soluções do problema exemplo

\begin{tabular}{|c|c|c|c|c|c|}
\hline Ordem & $N^{o}$ Solução & Objetivo 1 & Objetivo 2 & Frente & Densidade \\
\hline $1^{\underline{a}}$ & 1 & 1 & 4 & 1 & 0 \\
\hline $1^{\underline{a}}$ & 9 & 4 & 1 & 1 & 0 \\
\hline $3^{\underline{a}}$ & 4 & 2,2 & 3,3 & 1 & 0,3 \\
\hline $4^{\underline{a}}$ & 7 & 3,9 & 1,7 & 1 & 0,7 \\
\hline $5 \underline{a}$ & 2 & 5 & 8 & 2 & 0 \\
\hline $5 \underline{a}$ & 10 & 8 & 5 & 2 & 0 \\
\hline $7 \underline{a}$ & 5 & 6,7 & 7 & 2 & 0,3 \\
\hline $8^{\underline{a}}$ & 6 & 7,6 & 6 & 2 & 0,8 \\
\hline $9^{\underline{a}}$ & 3 & 9 & 10 & 3 & 0 \\
\hline $9 \underline{a}$ & 8 & 10 & 9 & 3 & 0 \\
\hline
\end{tabular}

\subsubsection{Criação de novas soluções}

Considerando o ordenamento feito no processo de seleção, novas soluções são geradas a cada iteração do algoritmo evolucionário. Dessa forma, os parâmetros das novas soluções geradas possuem maior semelhança com as soluções melhor ordenadas do que com os parâmetros das outras soluções.

O processo de criação de novos indivíduos é muito diferente para os diferentes tipos de algoritmos evolucionários. Esse processo será, portanto, mais detalhado para cada um dos tipos de algoritmos evolucionários implementados.

\subsubsection{Verificação de critérios de parada}

Os critérios de parada para um algoritmo evolucionário podem ser bem variados. Um número máximo de iterações, um número máximo de soluções avaliadas, a obtenção de um valor para uma dada funçãoobjetivo ou, ainda, uma variação menor de um dado valor entre uma iteração e outra são alguns exemplos de critérios de parada.

A escolha do critério de parada é condicionada à escolha do tipo de algoritmo evolucionário implementado. Dessa forma, os critérios de parada serão especificados para cada um dos tipos de algoritmo implementados. 


\subsection{ALGORITMO GENÉTICO}

Um algoritmo genético foi um dos tipos de algoritmos evolucionários implementados. Ele baseia-se no processo de evolução natural na tentativa de realizar uma otimização. Todos os processos descritos na Seção 4.3 fazem parte do fluxo de execução de um algoritmo genético.

Quando falamos de algoritmos genéticos, as diferentes soluções podem ser chamadas de indivíduos, as iterações do algoritmo podem ser chamadas de gerações e os parâmetros otimizáveis podem ser chamados de cromossomos. O principal critério de parada de um algoritmo genético é o número máximo de gerações a serem processadas. Ao iniciar uma otimização com algoritmo genético, devemos, portanto, escolher o número de indivíduos de cada geração e o número máximo de gerações a serem processadas.

Além da nomenclatura diferente, um algoritmo genético diferencia-se dos outros tipos de algoritmos evolucionários pelo seu processo de criação de novas soluções. Esse processo é realizado em duas partes: cruzamentos e mutações (os operadores genéticos).

\subsubsection{Cruzamentos}

Os cruzamentos consistem na combinação numérica dos valores dos cromossomos de dois indivíduos pré-existentes. Para isso, faz-se necessário a escolha dos indivíduos que serão cruzados. Essa escolha é feita com base no ordenamento realizado dos indivíduos existentes. A probabilidade de escolha de um dado indivíduo para um cruzamento é maior quanto melhor ele estiver ordenado dentre os outros indivíduos.

Uma vez feita a escolha dos indivíduos a serem cruzados, 'indivíduos-pais', cada um dos cromossomos dos dois indivíduos são combinados, formando, assim, os cromossomos dos 'indivíduos-filhos'. A probabilidade de ocorrer cruzamento, e a forma como os cromossomos são combinados são variáveis.

\subsubsection{Mutações}

As mutações são o segundo processo pelo qual passa a criação de novos indivíduos nos algoritmos genéticos. Após a criação dos 'indivíduos-filhos', eles podem passar pelo processo de mutação. A mutação consiste em realizar uma variação aleatória nos cromossomos de um dado indivíduo já criado. O tamanho da variação e a probabilidade de ocorrer mutação são variáveis. 


\subsubsection{NSGA-II}

Quando se definem todos os processos presentes em um algoritmo genético, chega-se a uma implementação bem específica. A implementação realizada é a implementação descrita em [15], chamada de NSGA-II (Nondominated sorting genetic algorithm II).

O algoritmo NSGA-II tem como uma de suas grandes características a busca por soluções dispersas em sua primeira frente de pareto. Para isso, o processo de seleção de indivíduos é exatamente o descrito na Seção 4.3.3.

O processo de cruzamento utilizado é o cruzamento SBX (Simulated Binary Crossover). Ele consiste em fazer uma média ponderada de cada um dos cromossomos dos 'indivíduos-pais'. O peso do cromossomo de cada um dos 'indivíduos-pais' é definido aleatoriamente, com uma função de densidade de probabilidade polinomial de ordem variável. Dessa forma, a ordem da função de densidade de probabilidade é definida por quem realiza a otimização.

O processo de mutação utilizado é a mutação polinomial. Portanto, o tamanho da variação aplicada a cada cromossomo é definido aleatoriamente com uma função de densidade de probabilidade polinomial de ordem variável. Assim como no cruzamento, a ordem da função de densidade de probabilidade é definida por quem realiza a otimização.

\subsubsection{Interface e exemplo de otimização}

A Fig 4.3 mostra a interface gráfica implementada para a chamada do algoritmo genético NSGA-II. $\mathrm{Na}$ interface gráfica, estão todos os campos que precisam ser definidos para a execução de uma otimização: número de indivíduos, número de gerações, probabilidade de cruzamento, probabilidade de mutação, ordem da função polinomial do cruzamento e ordem da função polinomial da mutação. Além disso, existe uma caixa de texto na qual são definidos os parâmetros a serem otimizados, com suas faixas de variação, e também as funções-objetivo.

A Fig. 4.4 mostra uma topologia de amplificador projetada para ganho máximo (Fig. 4.4-a) descrita em [13] e o comportamento de $|S 21|^{2} d B$ em função da frequiência para os valores iniciais de projeto (Fig. 4.4-b).

A Fig. 4.5 apresenta os resultados da otimização, em busca de ganho na freqüência central e planura na banda de $3.8 \mathrm{GHz}$ a $4.2 \mathrm{GHz}$, do comprimento das linhas de transmissão do circuito. A primeira frente de pareto final (Fig. 4.5-a), o comportamento de $|S 21|^{2}$ para o indivíduo de maior ganho (Fig. 4.5-b), 


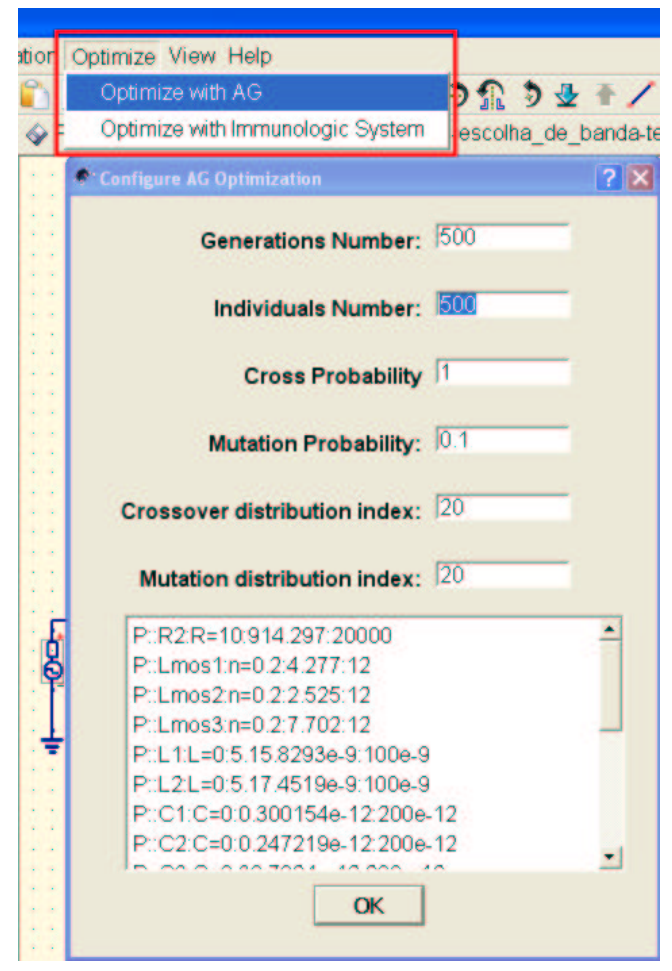

Figura 4.3: Interface implementada para a utilização do algoritmo NSGA-II

o comportamento de $|S 21|^{2}$ para o indivíduo com banda mais plana (Fig. 4.5-c) e o comportamento de $|S 21|^{2}$ para um indivíduo intermediário (Fig. 4.5-d) são mostrados.

A otimização foi realizada com 200 indivíduos por geração, 200 gerações, 100\% de probabilidade de cruzamento, $10 \%$ de probabilidade de mutação, ordem da função polinomial de cruzamento igual a 20 e ordem da função polinomial de mutação igual a 20. A frente de pareto final mostra a grande diversidade e soluções obtidas, o que é exemplificado nas simulações dos indivíduos finais mostrados.

\subsection{SISTEMAS IMUNOLÓGICOS}

Um sistema imunológico foi o outro tipo de algoritmo evolucionário implementado. Ele baseia-se num sistema imunológico natural na tentativa de realizar uma otimização. O funcionamento simplificado dos sistemas imunológicos naturais e diferentes formas de implementação dos sistemas imunológicos artificiais são explicados em [16]. Assim como no algoritmo genético, todos os processos descritos na Seção 4.3 fazem parte do fluxo de execução de um sistema imunológico.

Quando falamos de sistemas imunológicos, uma abordagem usual é: as diferentes soluções são chamadas de anticorpos, os anticorpos originados de um outro anticorpo são chamados de clones, um anticorpo que 


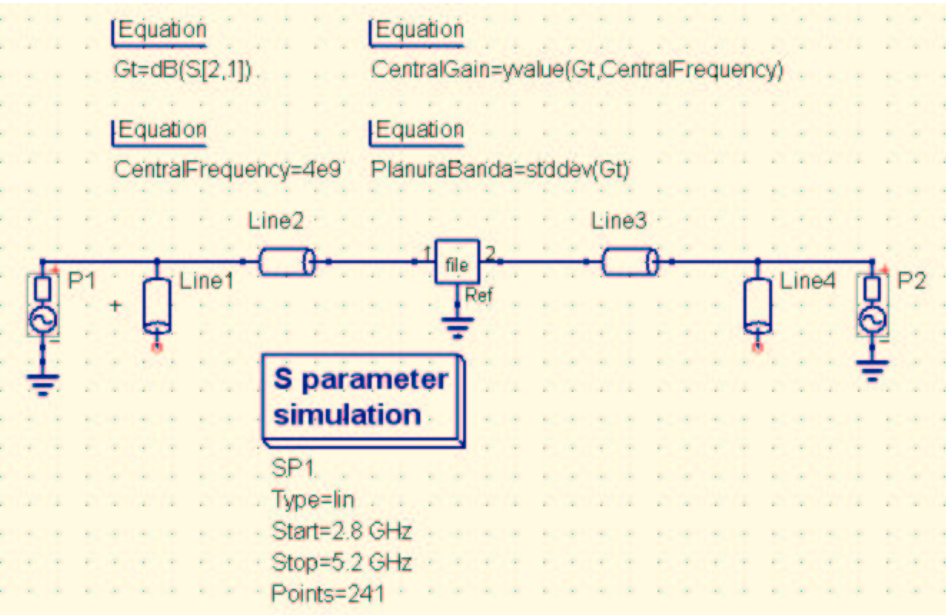

(a) Esquemático do amplificar

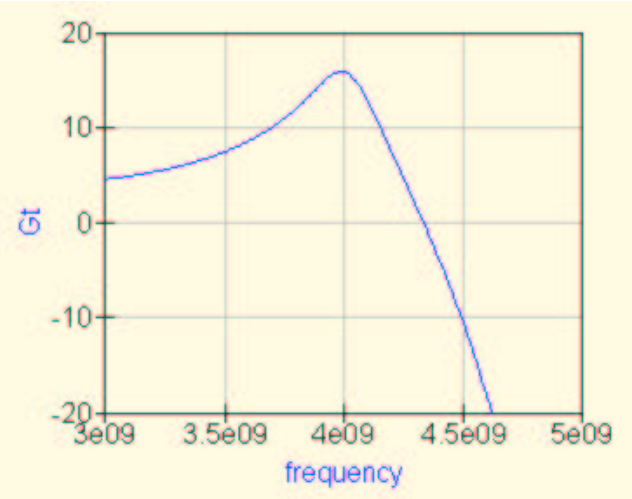

(b) $|S 21|^{2} d B$

Figura 4.4: Circuito original 


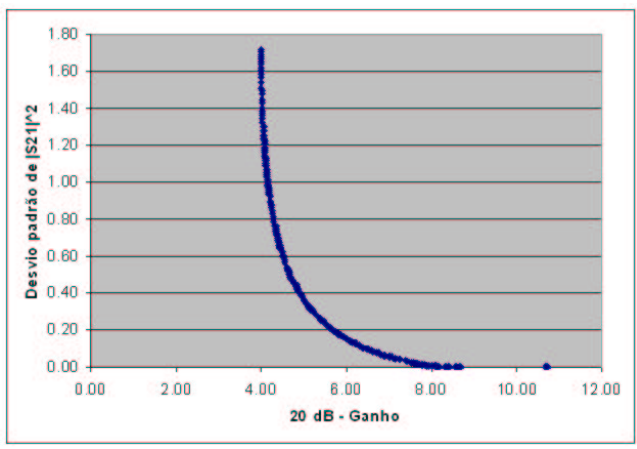

(a) Primeira frente de pareto final

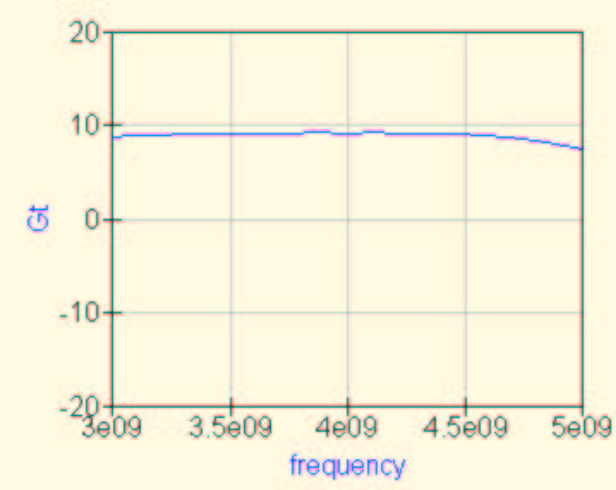

(c) $|S 21|^{2} d B$ do indivíduo de banda mais plana

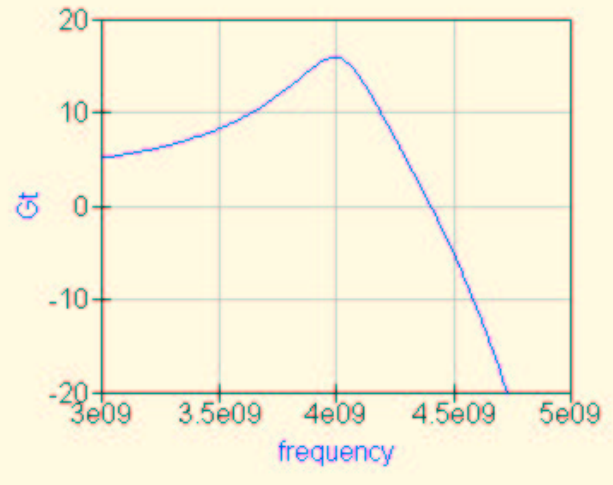

(b) $|S 21|^{2} d B$ do indivíduo de maior ganho

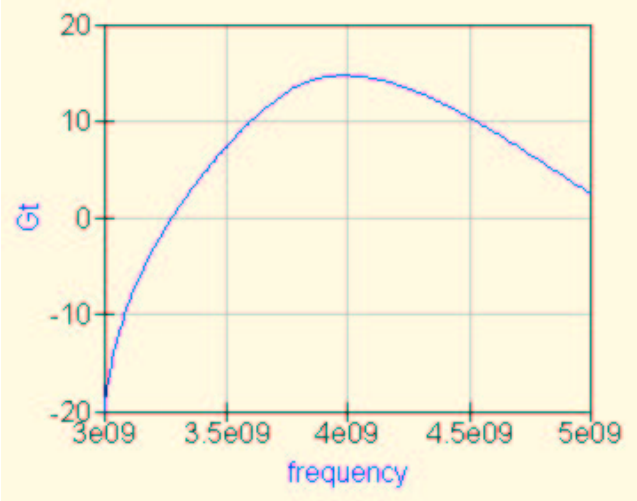

(d) $|S 21|^{2} d B$ de um indivíduo intermediário

Figura 4.5: Resultados da otimização com NSGA-II 
gera clones é chamado de célula-mãe e um grupo de clones junto com sua célula-mãe é chamado de família. Além da nomenclatura diferente, um sistema imunológico diferencia-se dos outros tipos de algoritmos evolucionários pelo seu processo de seleção de indivíduos a serem perpetuados, e pelo seu processo de criação de novas soluções.

O processo de seleção de indivíduos é semelhante ao descrito na Seção 4.3.3. No entanto, esse processo é aplicado independentemente sobre cada família de anticorpos. Dessa forma, para cada família, a cada iteração, o anticorpo com melhor ordenamento é escolhido como célula-mãe para a próxima iteração. Além disso, todos os anticorpos presentes na primeira frente de pareto de cada família são mantidos nas iterações seguintes, apesar de não serem células-mãe.

Caso ocorra após um número definido de iterações, que a célula-mãe de uma dada família se mantenha constante, essa família é considerada uma possível solução do problema de otimização. Os anticorpos da primeira frente de pareto dessa família são copiados para um apanhado de soluções gerais, e são considerados soluções globais se estiverem na primeira frente de pareto. Essa família é armazenado em um banco de memória, e uma nova família é gerada com a criação de uma nova célula-mãe.

O principal critério de parada de um sistema imunológico é o número máximo de anticorpos avaliados. Ao iniciar uma otimização com sistema imunológico, devemos, portanto, escolher o número de famílias, o número de clones por família, o número máximo de anticorpos a serem avaliados e o número de iterações com célula-mãe constante antes de uma família ser considerada solução.

Para a população global de clones não há a necessidade de se avaliar a densidade relativa de cada anticorpo. A definição da primeira frente de pareto é suficiente e constitui o resultado da otimização ao fim de sua execução. O processo de criação de novas soluções, assim como no algoritmo genético, é dividido em duas partes, os operadores imunológicos: clonagem e hypermutação.

\subsubsection{Clonagem}

O processo de clonagem consiste em criar anticorpos exatamente iguais a cada uma das células-mãe. Dessa forma, os valores dos parâmetros a serem otimizados dos anticorpos gerados são exatamente iguais aos de sua célula-mãe. Os clones gerados são exatamente iguais às células-mãe. O número de clones gerados a partir de cada uma das células-mãe é um parâmetro variável e quem realiza a otimização o define. 


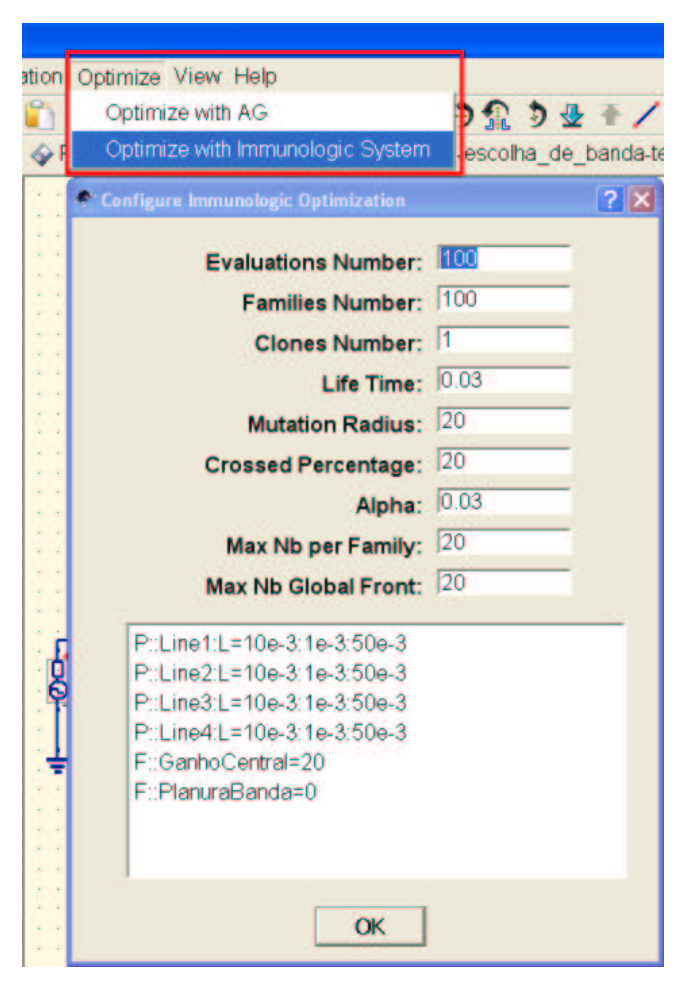

Figura 4.6: Interface implementada para a utilização do sistema imunológico

\subsection{2 hipermutação}

A hypermutação é o segundo processo para a criação dos novos anticorpos. Ela consiste em realizar uma variação aleatória nos parâmetros a serem otimizados de um dado clone criado. O tamanho da variação é definido da mesma forma que no algoritmo NSGA-II, ou seja, através de uma função de densidade e probabilidade polinomial de ordem variável. A ordem da função de densidade de probabilidade é um parâmetro definido por quem realiza a otimização.

\subsubsection{Interface e exemplo de otimização}

Assim como para o algoritmo NSGA-II, foi criada uma interface gráfica para a chamada do sistema imunológico implementado (Fig. 4.6). Essa interface possui a mesma estrutura da interface do algoritmo genético e possui todos os campos necessários para a definição da execução de uma otimização estão nela disponíveis.

A Fig. 4.7 apresenta os resultados da otimização da topologia mostrada na Fig. 4.4, utilizando o sistema imunológico. As funções-objetivo definidas foram as mesmas definidas na otimização utilizando NSGA-II. A primeira frente de pareto final (Fig. 4.7-a), o comportamento de $|S 21|^{2}$ para o anticorpo de maior ganho (Fig. 4.7-b), o comportamento de $|S 21|^{2}$ para o anticorpo com banda mais plana (Fig. 4.7-c) 


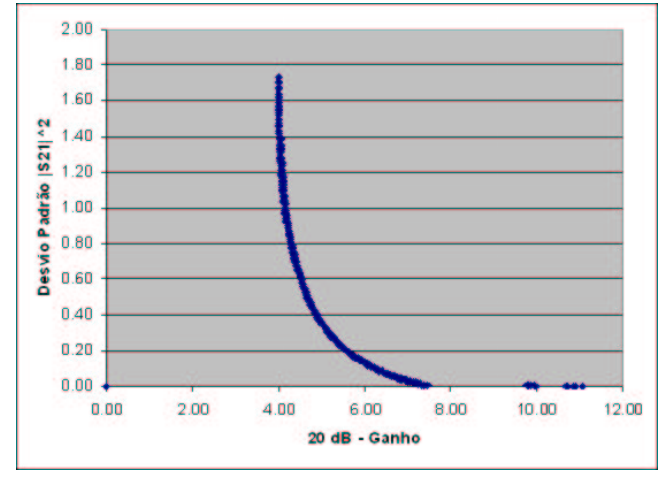

(a) Primeira frente de pareto final

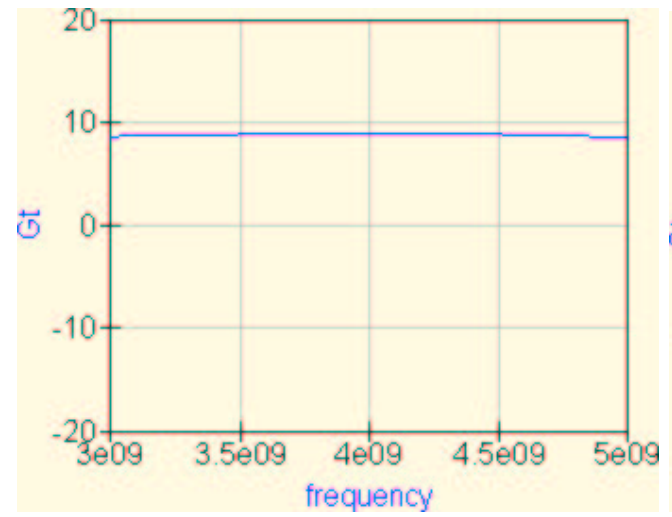

(c) $|S 21|^{2} d B$ do anticorpo de banda mais plana

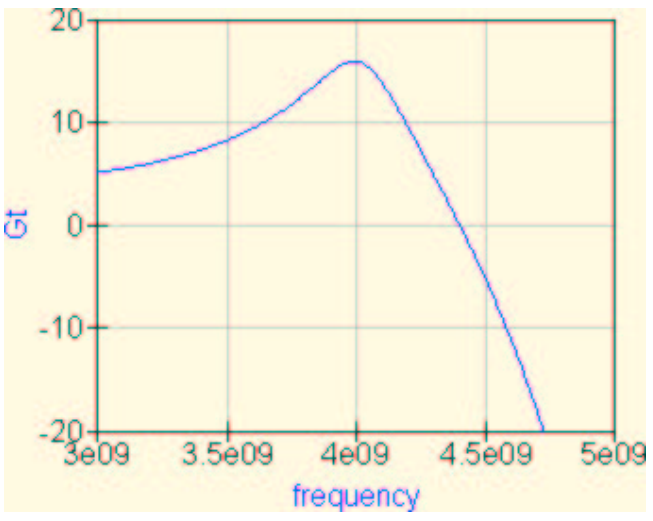

(b) $|S 21|^{2} d B$ do anticorpo de maior ganho

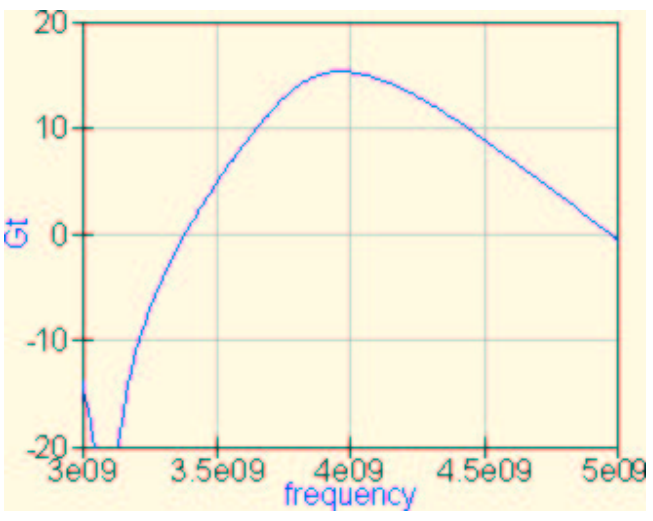

(d) $|S 21|^{2} d B$ de um anticorpo intermediário

Figura 4.7: Resultados da otimização com sistema imunológico

e o comportamento de $|S 21|^{2}$ para um anticorpo intermediário (Fig. 4.7-c) são mostrados.

A otimização foi realizada com número de clones por família igual a 4, número de famílias igual a 10, número máximo de avaliações igual a 40000, número de iterações com célula-mãe constante antes da família ser considerada solução igual a 4, e ordem da função polinomial de hypermutação igual a 20. A frente de pareto final mostra a grande diversidade e soluções obtidas, o que é exemplificado nas simulações dos anticorpos finais mostrados.

\subsection{CONSIDERAÇÕES FINAIS}

Este capítulo tratou dos algoritmos evolucionários, da teoria relacionada e de suas utilizações como métodos de otimização. A implementação de dois tipos diferentes de algoritmos evolucionários foi realizada, a interface gráfica criada para utilização desses algoritmos em conjunto com o software de simulação foi mostrada. Um exemplo de otimização de amplificador de microondas foi mostrado para cada um dos algoritmos implementados. Esses algoritmos serão utilizados na otimização de circuitos amplificadores de 
microondas, em tecnologia CMOS, considerando os elementos parasitas desta tecnologia. 



\subsection{CONSIDERAÇÕES INICIAIS}

Neste capítulo, será feita uma explanação sobre amplificadores de baixo ruído (LNA - Low Noise Amplifiers), destacando-se sua importância em sistemas de telecomunicações. As principais topologias de projetos de LNA também serão abordadas. A partir de uma das topologias apresentadas, será elaborado um projeto para a faixa de 2,4 GHz. O circuito resultante será simulado e analisado.

A partir dos resultados obtidos pelo circuito a partir de sua simulação, serão feitas otimizações para melhoria dos resultados apresentados, por meio do uso de algoritmo genético. Essa otimização dar-se-á primordialmente para o circuito com valores ideais e posteriormente será feita a simulação com a adição de parasitas característicos da tecnologia MOS no circuito.

\subsection{AMPLIFICADORES DE BAIXO RUÍDO}

Os amplificadores de baixo ruído são de fundamental importância em sistemas de telecomunicações, pois devem produzir um ganho razoável a partir de sinais que apresentam baixos níveis de potência (a fim de que estes sejam detectados por estágios a frente, que detêm menor sensibilidade) e, ao mesmo tempo, contribuir com a menor quantidade de ruído possível para o sinal de entrada. Isso se deve porque geralmente o LNA é o primeiro estágio após a antena receptora. Algumas vezes, um filtro pode ser inserido entre a antena e o amplificador para eliminação de espúrios que podem afetar o funcionamento do sistema de recepção.

Assim, o projeto de um amplificador de baixo ruído tem como metas minimizar ao máximo a figura de ruído (F), gerar ganho linear e satisfazer os critérios de impedância de entrada de $50 \Omega$ para casamento com a antena, além de necessitar, para dispositivos portáteis, de baixo consumo de potência. O casamento em $50 \Omega$ ocorre para que aja máxima transferância de potência entre antena e LNA. Devido aos baixos níveis de sinal na entrada do amplificador, deve haver, portanto, a obtenção de um bom ganho, uma alta linearidade e uma baixa figura de ruído. 
O LNA é um circuito de natureza não linear que recebe excitações fracas em sua entrada produzindo diferentes efeitos não desejados. A linearidade é uma consideração importante porque um LNA deve fazer mais do que simplesmente amplificar sinais sem somar muito ruído, deve também permanecer linear quando receber sinais fortes. Portanto, o LNA deve manter uma operação linear ao receber um sinal fraco na presença de um sinal forte, caso contrário pode gerar componentes indesejáveis como mostra a Fig.5.1.

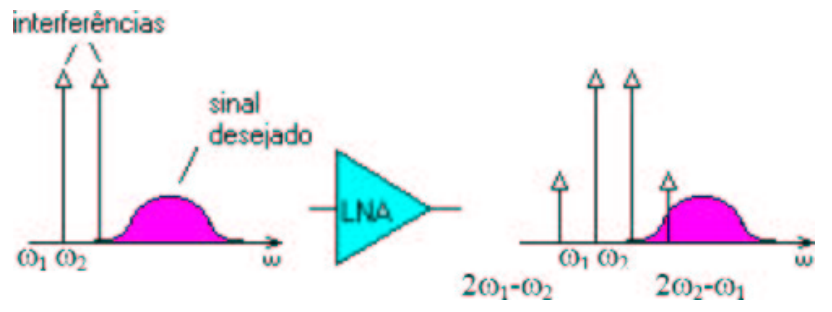

Figura 5.1: Corrupção do sinal devido à intermodulação de duas interferências [3]

\subsubsection{Topologias de Amplificadores de Baixo Ruído}

Existem basicamente quatro configurações distintas para projeto de amplificadores de baixo ruído, conforme indicado na Fig.5.2. Cada uma dessas arquiteturas pode ser utilizada em sua forma simples ou diferencial, sendo que a última não é muito aconselhável quando se tem restrições quanto à potência do dispositivo[3].

A técnica de projeto ilustrada na Fig.5.2 circuito A), usa uma terminação resistiva no pólo de entrada. Essa é uma forma de aproximação direta para casamento de $50 \Omega$ em banda larga. Como efeito deletério, o uso de resistores reais para realização do casamento influencia de maneira negativa tanto o ruído quanto o ganho, devido à adição de ruído térmico.

Na Fig.5.2 circuito B) utiliza-se a fonte de um estágio porta comum como entrada. Como a resistência vista do terminal é dada por $1 / g_{m}$, com a escolha apropriada da relação $W / L$ e da corrente de polarização, pode-se obter $50 \Omega$ como valor de impedância de entrada, realizando-se assim o casamento com a antena. Mas essa arquitetura apresenta-se instável quanto ao casamento devido à não-linearidade do transistor e a figura de ruído ficará pior para frequências altas e para canais curtos.

A topologia ilustrada na Fig.5.2 circuito C) faz uso da alimentação série-paralelo para fixação das impedâncias de entrada e saída do amplificador. Dispositivos que utilizam essa configuração apresentam banda larga, porém uma maior dissipação de potência se comparados a outros amplificadores com desempenho de ruído semelhante. Além disso, o resistor usado na realimentação gera ruído térmico, o que degrada a figura de ruído. Assim, implementações desse tipo requerem resistores com alto índice de 


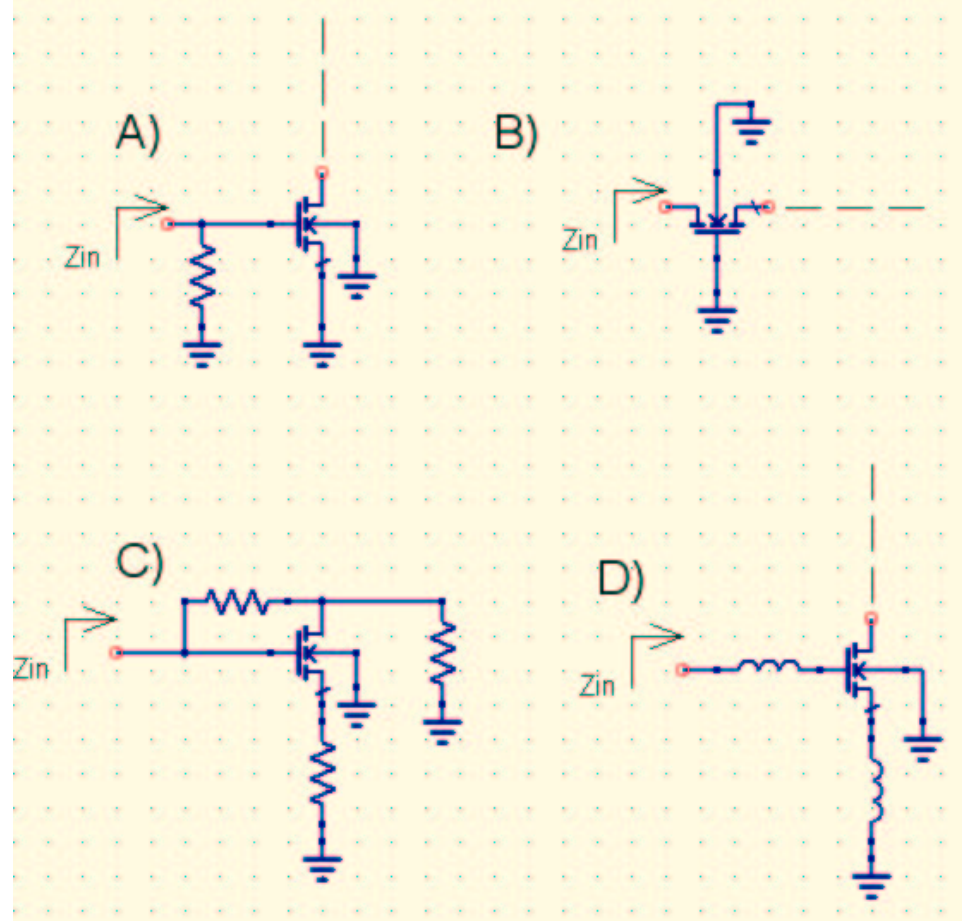

Figura 5.2: Topologias utilizadas no projeto de LNAs [3]

qualidade, geralmente não disponíveis em CMOS[3].

A quarta topologia, Fig.5.2 circuito D), emprega a degeneração indutiva na fonte para gerar um termo real de impedância, sintonizando indutores para que $50 \Omega$ sejam alcançados como valor de impedância de entrada. Esse método é largamente utilizado por projetistas MOS para o design de amplificadores de baixo ruído. A configuração cascode com degeneração indutiva na fonte, Fig.5.3, permite garantir que o estágio de LNA tenha ganho suficiente para que se despreze o ganho dos estágios subsequentes. O Transistor $M_{2}$, visto na Fig.5.3, aumenta a impedância de saída do circuito, protegendo a entrada de variações de tensão devido à saída.

\subsection{PROJETO LNA}

Foi escolhida a faixa de 2,4 GHz para o projeto do LNA na tecnologia CMOS, utilizando-se a topologia espelho de corrente/cascode com degeneração indutiva na fonte. A escolha desta topologia (Fig.5.2) é justificada pelo bom isolamento adquirido pelo uso do estágio cascode, pela facilidade de controle da corrente de polarização, devido ao espelho de corrente, e à utilização de indutores para casamento na entrada do dispositivo, que causam menos prejuízo à figura de ruído. A configuração espelho de corrente 


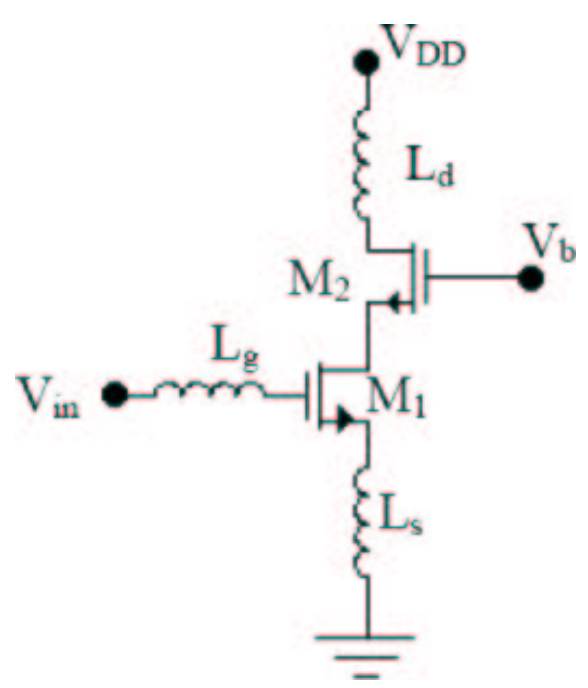

Figura 5.3: Configuração cascode com degeneração indutiva na fonte [3]

foi utilizada para, além de obter-se maior controle sobre a corrente de polarização, ter-se ganho na mesma, devido a sua interação com $I_{R E F}$ (Fig.5.5).

A foundry utilizada para este projeto pertence à TSMC. Será utilizado um modelo de transistor de tecnologia MOS $0,25 \mu \mathrm{m}$. Esses dados foram obtidos através do sítio de serviço para fabricação de circuito integrado MOSIS ${ }^{1}$. A alimentação do circuito será de 1,2 V, em busca de diminuir o consumo de potência do amplificador. Visa-se com esse projeto, após a otimização, atingir uma banda maior que $40 \mathrm{MHz}$, um ganho maior que $15 \mathrm{~dB}$ dentro de toda a banda e a menor figura de ruído possível para o circuito ( $\mathrm{F}<3$ $\mathrm{dB})$.

\subsubsection{Otimização da figura de ruído, caracterização do transistor e projeto da rede de polarização}

De acordo com [2] e com anexo I, o valor de W para que se consiga a menor figura de ruído possível é dado pela Eq.5.1.

$$
W_{o p t} \approx \frac{1}{3 \omega L C_{o x} R_{s}}
$$

Sabendo-se que $\omega=2 \pi \cdot 2,4 \cdot 10^{9} \mathrm{rps}, \mathrm{L}=0,25 \mu \mathrm{m}, C_{o x}=6,055 \cdot 10^{-3} \mathrm{~F} / \mathrm{m}$ e $R_{s}=50 \Omega$, temos que:

$W_{\text {opt }} \approx 292 \mu m$

Com W ótimo encontrado em 5.3.1, traça-se a curva $I_{d} \mathrm{X} V g s$, Fig. 5.4, que irá descrever o compor-

\footnotetext{
${ }^{1}$ Sítio: www.mosis.org
} 
tamento do transistor adotado. A partir desta curva, delimita-se o ponto de operação do circuito.

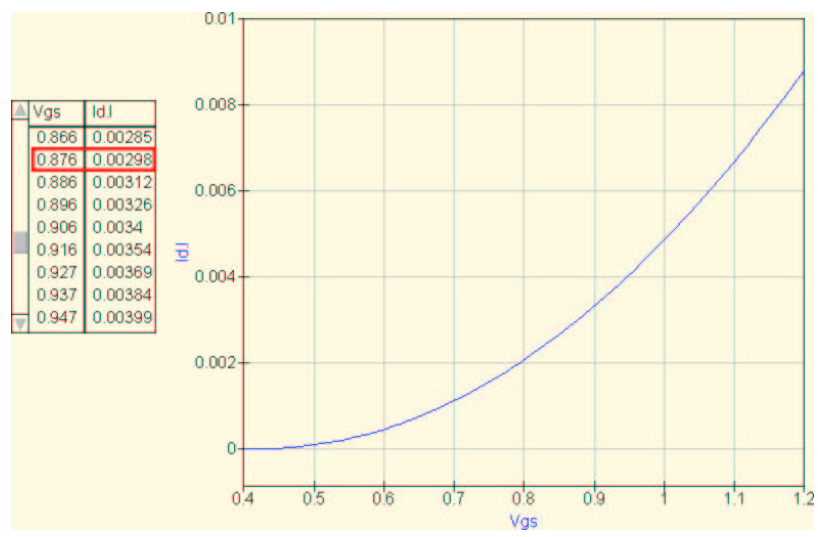

Figura 5.4: Característica $I_{d} \mathrm{X} V g s$

Na Fig.5.4, escolhe-se o ponto em que a corrente tem valor de aproximadamente $2.9 \mathrm{~mA}$, para o qual $V_{g s}$ assume um valor igual a $0,87 \mathrm{~V}$. A partir da adoção deste valor para $V_{g s}$, dimensionou-se $W_{\text {ref }}$ do transistor M0, de maneira que o ganho de corrente em M1 fosse igual a 10. Portanto, a corrente em M0 será igual a 0,29 mA (vide Eq.5.2). Na Fig.5.5, pode-se visualizar como será a configuração do circuito.

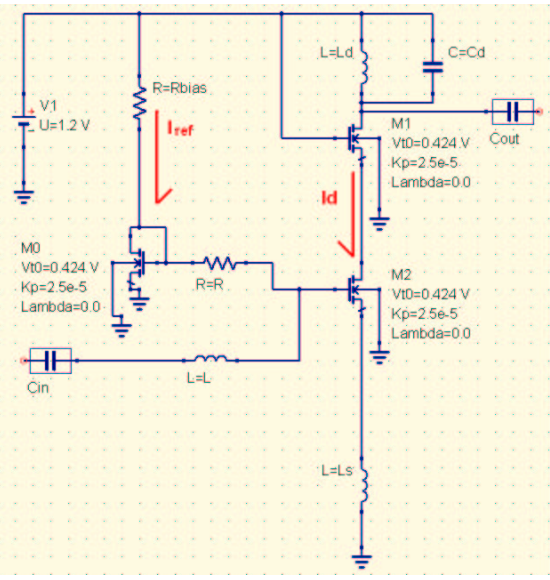

Figura 5.5: Circuito do LNA

$$
W_{\text {opt }} / W_{\text {ref }}=10, \text { portanto }, W_{\text {ref }} \approx 29 \mu m
$$

Para que a queda de tensão entre porta e fonte em M0 seja igual a $0,87 \mathrm{~V}$, deve-se projetar $R_{\text {bias }}$ conforme mostrado na Eq.5.3. O resistor $R$ deve ser projetado de maneira a impedir que o sinal de entrada flua para o gate M0. Isso é conseguido adotando-se um valor alto para essa resistência. Assim, adotou-se $R=2 k \Omega$. 


$$
R_{\text {bias }}=\frac{V_{D D}-V_{M 0}}{I_{R E F}}=\frac{1,2-0,87}{0,29.10^{-3}}=1138
$$

\subsubsection{Estimativa das Capacitâncias Parasitas e Cálculo das indutâncias do circuito}

A Fig.5.6 ilustra o modelo de um transistor MOS, no qual podem ser visualizadas as capacitâncias parasitas presentes no mesmo. As Eqs. 5.4, 5.5 e 5.7, ilustram o cálculo das capacitâncias parasitas presentes no modelo MOS level-1. O cálculo dessas capacitâncias é de fundamental importância para dimensionamento dos indutores no circuito do amplificador.

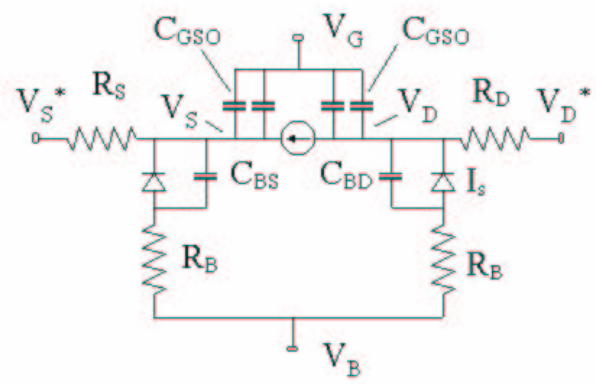

Figura 5.6: Modelo - Transistor MOS - Capacitâncias parasitas

$$
C_{g s}=C G S 0 . W_{O P T}=6,2 \cdot 10^{-10} \cdot 292 \cdot 10^{-6}=1,81 \cdot 10^{-13} \mathrm{~F}
$$

$$
C_{d s}=C D S 0 . W_{O P T}=6,2 \cdot 10^{-10} \cdot 292 \cdot 10^{-6}=1,81 \cdot 10^{-13} \mathrm{~F}
$$

$$
C_{g b}=C G B 0 . W_{O P T}=1,1.10^{-10} .0,25.10^{-6}=2,75.10^{-17} \mathrm{~F}
$$

$$
C_{d b}=\frac{W_{o p t} \cdot L \cdot C J}{\left(1+\frac{V}{P B}\right)^{M J}}+\frac{2 \cdot\left(W_{o p t}+L\right) \cdot C J S W}{\left(1+\frac{V}{P B}\right)^{M J S W}}=1 \cdot 91 \cdot 10^{-13} F
$$

A função de transferência do estágio cascode é dada pela Eq.5.8. Analisando-se seus termos verifica-se que a única parte real é dada por $\omega_{\tau} . L_{s}$. Portanto, esse termo deve ser igual a $50 \Omega$ [6] .

$$
Z_{\text {in }}=s L+\frac{1}{s C_{g s}}+\omega_{\tau} \cdot L_{s}
$$


A transcondutância de M1 ( $g m 1)$ é calculada a partir da Eq.2.10, com $V_{g s}=0,87 \mathrm{~V}$ e de parâmetros de tecnologia presentes no anexo I. O valor de $g m 1$ encontrado foi igual a $0,13456 \Omega^{-1}$. A frequência de ganho unitário $\left(\omega_{\tau}\right)$ obtido foi, aproximadamente, 305 Grps. Sabendo que $L_{s}=50 / \omega_{\tau}$, tem-se que o valor de Rs é igual a aproximadamente $0.164 \mathrm{nH}$. Para sintonização do circuito, a malha de entrada deve obedecer à Eq.5.9.

$$
\omega=\frac{1}{\sqrt{L_{\text {total }} \cdot C_{g s}}}
$$

Onde,

$$
L_{\text {total }}=L_{s}+L_{g}
$$

Para $\omega$ igual a 15,08 Gprs, frequência central de operação, $L_{\text {total }}$ é igual a 9,9 nH. Logo, $L_{g}$ é igual a aproximadamente $9,83 \mathrm{nH}$.

O indutor $L_{d}$ em conjunto com $C_{d}$ formam o circuito de ressonância (Fig.5.5), ou seja, esse circuito faz a sintonização para a faixa de frequência desejada e aumenta a impedância de saída do amplificador. Seu funcionamento pode ser visto na Eq.5.11. Para esse cálculo, como tem-se duas incógnitas ( $L_{d}$ e $\left.C_{d}\right)$, fixa-se $C_{d}=0,82 \mathrm{pF}$. Assim, o valor obtido para $L_{d}$ é 4,35 $\mathrm{nH}$.

$$
\omega=\frac{1}{\sqrt{L_{d} \cdot\left(C_{d b}+C_{d}\right)}}
$$

\subsubsection{Resultados do Projeto}

O circuito projetado pode ser visto em Fig.5.7. Foi adotada como entrada, simulando uma antena, uma fonte senoidal com $1 \mathrm{mV}$ de tensão e impedância interna de $50 \Omega$. Nesse circuito, foi obtido um ganho de tensão igual a 72,6 dB em torno de 2,41 Ghz, como visto na Fig.5.8. Como pode ser percebido, esse circuito apresenta-se muito seletivo em relação a sua faixa de atuação. A solução para criação de uma maior banda seria buscar diminuir o grau de comprometimento da estrutura do circuito para com a frequência de 2,41 GHz, para assim obter ganho nas frequências vizinhas. Além disso, essa estrutura para casamento em banda larga pode ser utilizada como transformadora de impedância, trazendo a impedância de saída do estágio cascode, de alto valor, para a impedância padrão de $50 \Omega$. 


\subsubsection{Casamento com $50 \Omega$}

Para que o circuito adquira uma impedância de saída de $50 \Omega$, foi utilizado o estágio de transformação de impedância ilustrado na Fig.5.9. Esse estágio tem como intuito, além da transformação de impedância, o alcance de uma maior banda de operação para o circuito.

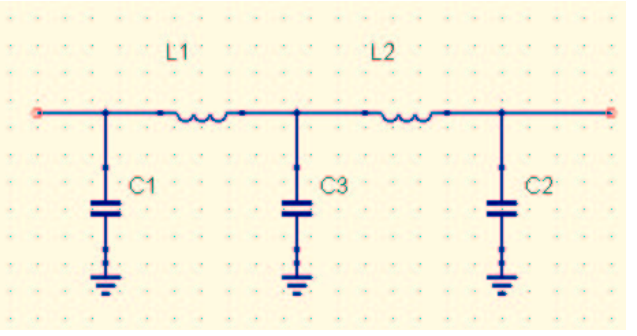

Figura 5.9: Circuito utilizado para transformação de impedância

Além disso, essa estrutura vem facilitar as análises da teoria de microondas sobre o circuito, pois, assim, serão mais facilmente visualizados os parâmetros de espalhamento do circuito e sua figura de ruído. $\mathrm{O}$ cálculo dessa rede de casamento será feito via algoritmo genético, pois essa estrutura deve ser 'levemente' descasada na frequência central para que possa gerar um ganho maior nas frequências adjacentes.

\subsubsection{Otimização Ganho/Banda/Figura de Ruído}

Em busca de obter melhores resultados e casamento da saída para a impedância de $50 \Omega$, foi utilizado o circuito descrito na Fig.5.10.

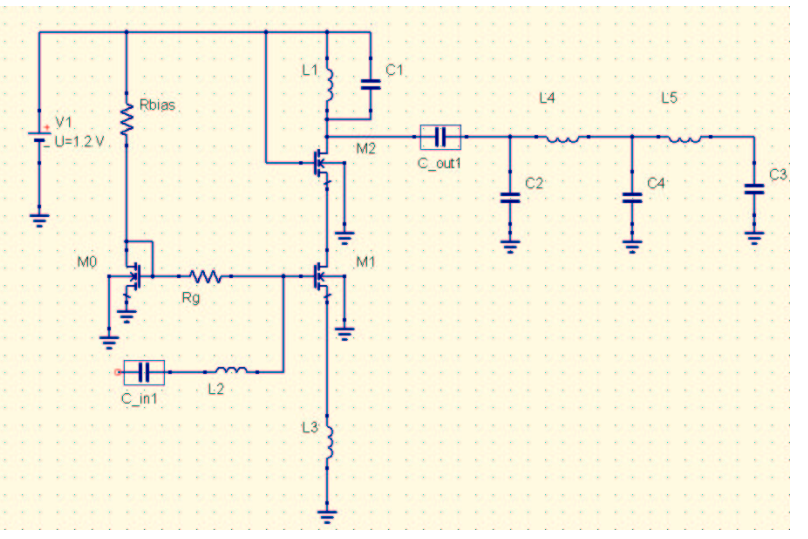

Figura 5.10: Circuito a ser otimizado

A otimização do circuito foi realizada de maneira que as seguintes funções objetivos fossem alcançadas:

-Maximização do ganho na frequência de $2,43 \mathrm{GHz}$ 
-Maximização do ganho na frequência de $2,39 \mathrm{GHz}$

-Minimização da Figura de Ruído

-Minimização entre a diferença de ganho nas frequências 2,39 - 2,43 GHz

-Minimização do desvio padrão de $S_{21}$ na banda compreendida entre 2,39/2,43 GHz

Para a realização das metas descritas, foram otimizadas as seguintes variáveis:

-Rbias - Valor inicial: $1138 \Omega$-Variação: 10 a $2000 \Omega$

-L1 - Valor inicial: 4,35 nH -Variação: 0 a $100 \mathrm{nH}$

-L2 - Valor inicial: 9,83 nH -Variação: 0 a $100 \mathrm{nH}$

-L3 - Valor inicial: 0,164 nH -Variação: 0 a $100 \mathrm{nH}$

-L4 - Valor inicial: 13,03 nH -Variação: 0 a $100 \mathrm{nH}$

-L5 - Valor inicial: 0,202 nH -Variação: 0 a $100 \mathrm{nH}$

-C1 - Valor inicial: 0.82 pF -Variação: 0 a 200 pF

-C2 - Valor inicial: 0.25 pF -Variação: 0 a 200 pF

-C3 - Valor inicial: 27,31 pF -Variação: 0 a 200 pF

-C4 - Valor inicial: 59 pF -Variação: 0 a 200 pF

-M0 (W)- Valor inicial: $29 \mu \mathrm{m}$-Variação: 0,25 a $1000 \mu \mathrm{m}$

-M1 (W)- Valor inicial: $292 \mu \mathrm{m}$-Variação: 0,25 a $1000 \mu \mathrm{m}$

-M2 (W)- Valor inicial: $292 \mu \mathrm{m}$-Variação: 0,25 a $1000 \mu \mathrm{m}$

Para a otimização, foi adotada a configuração para o algoritmo genético de modo que fossem feitas 300 gerações com 300 indivíduos cada uma. Os valores utilizados apresentaram grande espaço de variação, para que fosse possível testar como as variáveis convergiriam, já que algumas otimizações para esse circuito, com parâmetro tendo poucas variações, já haviam sido feitas. Assim, tinha-se, de antemão, uma idéia de quais seriam os valores ideais para o funcionamento do circuito. Deve-se portanto, salientar que os resultados obtidos por essa simulação foram excelentes, pois, apesar do grande campo de busca, as soluções se cristalizaram em torno dos valores obtidos em outras otimizações realizadas a efeito de teste.

Os valores obtidos após a otimização do circuito ideal, foram:

-Rbias - Valor: $842,34 \Omega$ 
-L2 - Valor: 3,27 nH

-L3 - Valor: 33,88 nH

-L4 - Valor: $15,83 \mathrm{nH}$

-L5 - Valor: 0,17 nH

-C1 - Valor: $0,18 \mathrm{pF}$

-C2 - Valor: $0,29 \mathrm{pF}$

-C3 - Valor: $39,78 \mathrm{pF}$

-C4 - Valor: 67,41 pF

-M0 (W)- Valor: 5,25 $\mu \mathrm{m}$

-M1 (W)- Valor: 582,5 $\mu \mathrm{m}$

-M2 (W)- Valor: $435 \mu \mathrm{m}$

Assim, os resultados obtidos foram: ganho máximo na banda em torno de $21 \mathrm{~dB}$, banda em torno de $67 \mathrm{MHz}$, como visto na Fig.5.11, perda por retorno em torno $\left(S_{11}\right)$ de $0.12(-18,4 \mathrm{~dB})$, figura de ruído em torno de 1,9 dB (Fig.5.11). Também pode ser visualizado, na Fig.5.12, o ótimo isolamento reverso presente no circuito, devido ao baixo valor de $S_{12}$ e ainda, pode ser visto o comportamento de $S_{22}$.

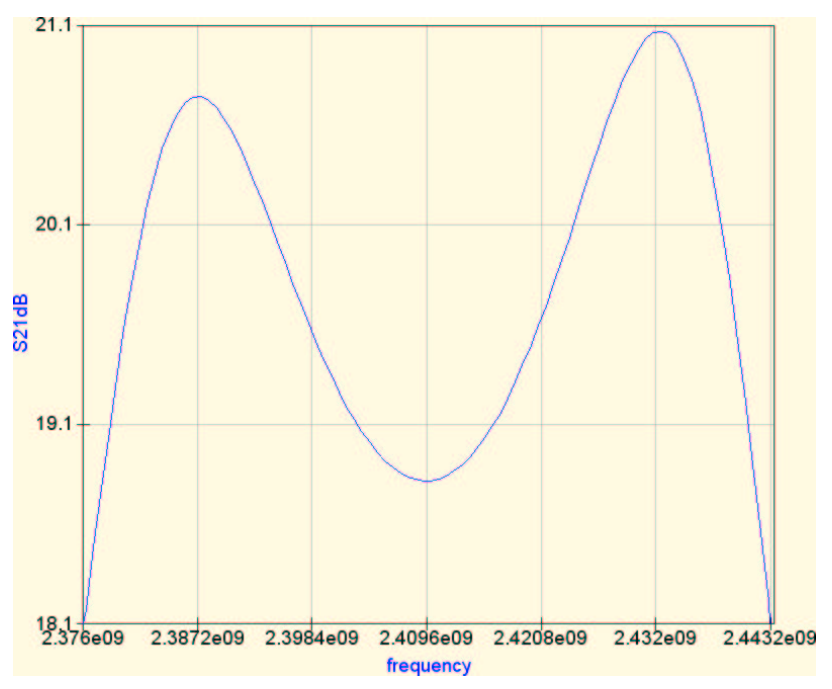

Figura 5.11: Otimização - Ganho em potência/Banda do Amplificador

Na Fig.5.13, pode ser analisado a comportamento do amplificador para as frequências adjacentes. Dessa figura pode-se concluir que o funcionamento da amplificador não será sujeito a interferências exter- 

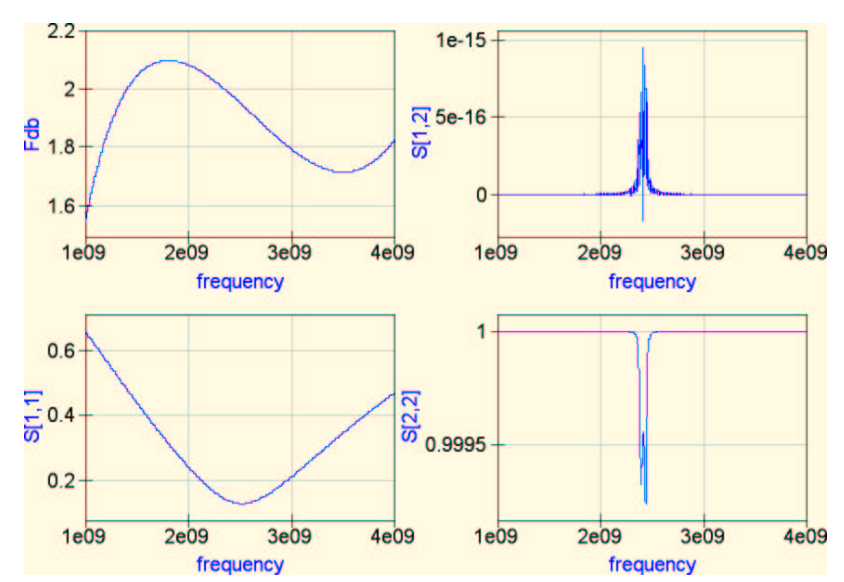

Figura 5.12: F(figura de ruído) em $\mathrm{dB}, S_{12}, S_{11}$ e $S_{22}$

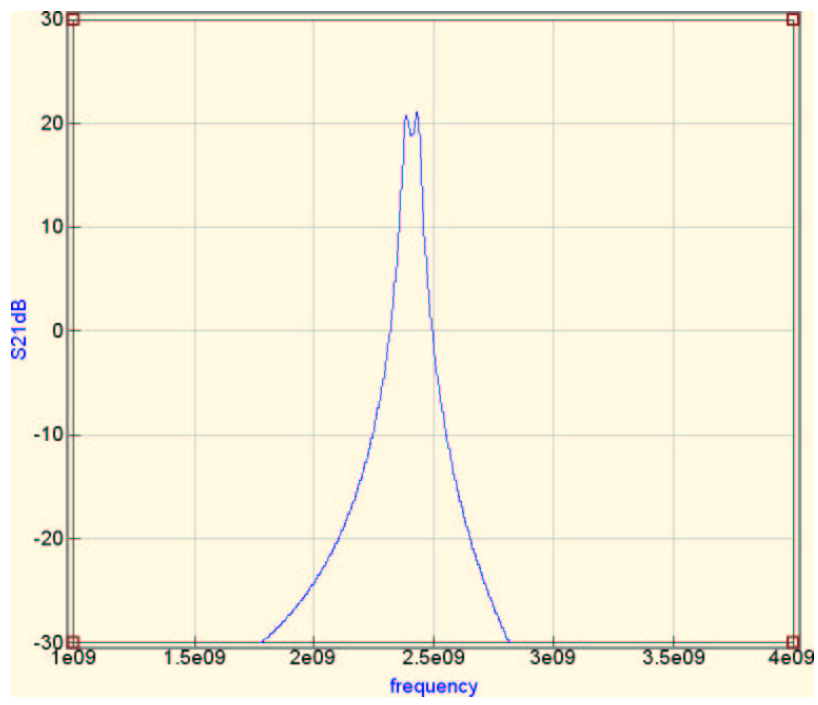

Figura 5.13: Comportamento do amplificador levando em consideração as frequências adjacentes

nas.

\subsubsection{Simulações otimizadas para circuito com parasitas}

Parasitas advindos da fabricação de indutores são sérios limitantes de desempenho para circuitos MOS operando em altas frequências. Com o intuito de ilustrar a diferença entre resultados obtidos com um circuito ideal e outro que apresentasse tais limitação da tecnologia, foram adotadas na seção 5.4.2.1 as mesmas funções objetivo utilizadas na seção 5.4.1.2. 
Em busca de obter resultados para comparação com a simulação ideal, foi utilizado o circuito descrito na Fig.5.14. A inserção de indutores parasitas foi feita para os indutores L1, L2 e L3. Os valores base, utilizados na inserção desses parasitas, não foram os mesmos dados da foundry de $0,25 \mu \mathrm{m}$, devido à falta de informações para sua obtenção. Portanto, foi feita uma adaptação do cálculo de parasitas utilizados na tecnologia MOS de 0,35 $\mu \mathrm{m}$. Assim, os valores aqui encontrado devem ser encarados como um exemplo de degradação gerada por elementos parasitários no circuito.

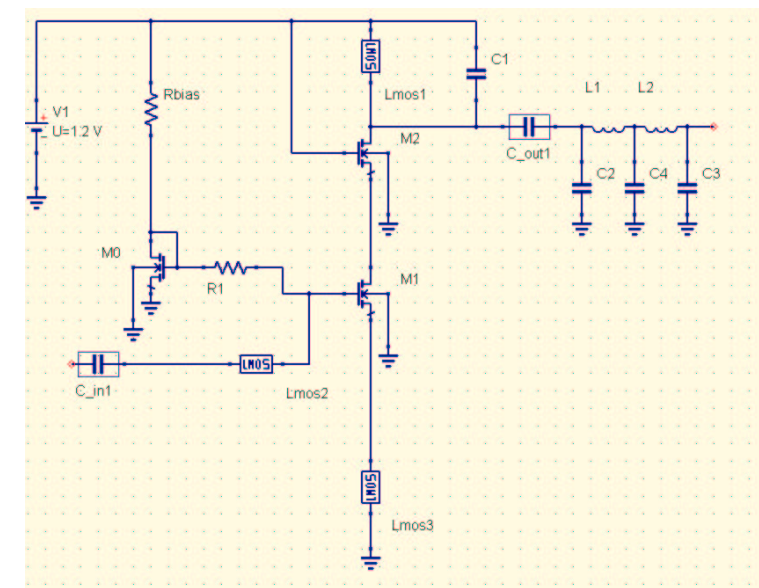

Figura 5.14: Circuito a ser otimizado, incluindo parasitas

A otimização do circuito foi realizada de maneira que as seguintes funções objetivos fossem alcançadas:

-Maximização do ganho na frequência de 2,43 GHz

-Maximização do ganho na frequência de 2,39 GHz

-Minimização da Figura de Ruído

-Minimização entre a diferença de ganho nas frequências 2,39 - 2,43 GHz

-Minimização do desvio padrão de $S_{21}$ na banda compreendida entre 2,39/2,43 GHz

Para a realização das metas descritas, foram otimizados as seguintes variáveis:

-Rbias - Valor inicial: $1138 \Omega$-Variação: 10 a $2000 \Omega$

-Lmos1 - Valor inicial ( $N$ de voltas): 4,277 - Variação: 0.1 a 20

-Lmos2 - Valor inicial ( $N$ de voltas): 4,277 -Variação: 0.1 a 20

-Lmos3 - Valor inicial ( $N$ de voltas): 4,277 -Variação: 0.1 a 20 
-L4 - Valor inicial: 13,03 nH -Variação: 0 a $100 \mathrm{nH}$

-L5 - Valor inicial: 0,202 nH -Variação: 0 a $100 \mathrm{nH}$

-C1 - Valor inicial: 0.82 pF -Variação: 0 a 200 pF

-C2 - Valor inicial: 0.25 pF -Variação: 0 a 200 pF

-C3 - Valor inicial: 27,31 pF -Variação: 0 a 200 pF

-C4 - Valor inicial: 59 pF -Variação: 0 a 200 pF

-M0 (W)- Valor inicial: $29 \mu \mathrm{m}$-Variação: 0,25 a $1000 \mu \mathrm{m}$

-M1 (W)- Valor inicial: $292 \mu \mathrm{m}$-Variação: 0,25 a $1000 \mu \mathrm{m}$

-M2 (W)- Valor inicial: $292 \mu \mathrm{m}$-Variação: 0,25 a $1000 \mu \mathrm{m}$

Para a otimização, foi configurado o algoritmo genético de modo que fossem feitas 500 gerações com 500 indivíduos cada uma. Os valores dos componentes utilizados são os mesmos descritos para o circuito ideal, pois assim busca-se observar melhor quais as diferenças entre a convergência do circuito ideal e a do circuito com parasitas. Deve-se observar que, como esperado, a performance do circuito foi degradada pela inserção de elementos parasitários ao circuito.

Os valores obtidos após a otimização do circuito com parasitas, foram:

-Rbias - Valor: 14433,30 $\Omega$

-Lmos1 - Valor ( $N$ de voltas): 5,37

-Lmos2 - Valor ( $N$ de voltas): 3,15

-Lmos3 - Valor ( $N$ de voltas): 5,59

-L4 - Valor: $12,58 \mathrm{nH}$

-L5 - Valor: 0,32 nH

-C1 - Valor: 0,04 pF

-C2 - Valor: 0,22 pF

-C3 - Valor: 17,53 pF

-C4 - Valor: 57,58 pF

-M0 (W)- Valor: 1,25 $\mu \mathrm{m}$ 
-M2 (W)- Valor: 824,50 $\mu \mathrm{m}$

Os resultados obtidos foram: ganho máximo na banda em torno de $18,8 \mathrm{~dB}$, banda em torno de $52 \mathrm{MHz}$, como visto na Fig.5.15, perda por retorno em torno $\left(S_{11}\right)$ de 0.37 (-8,64 dB), figura de ruído em torno de 1,3 dB (Fig.5.15). Vale ressaltar que o ruído gerado pelos indutores com parasitas não foi considerado e por isso a figura de ruído obtida é menor do que deveria ter sido obtida. Também pode ser visualizado, na Fig.5.12, o ótimo isolamento reverso presente no circuito, devido ao baixo valor de $S_{12}$ e ainda, pode ser visto o comportamento de $S_{22}$.

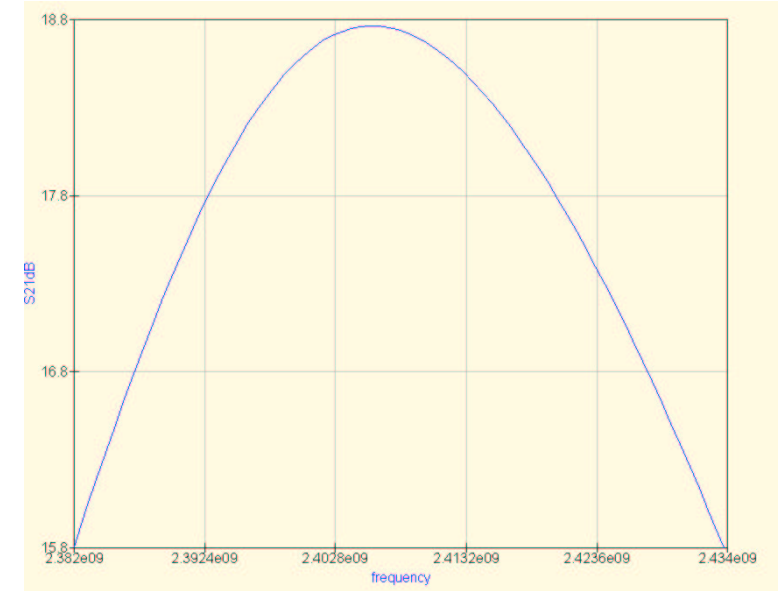

Figura 5.15: Otimização - Ganho em potência/Banda do Amplificador
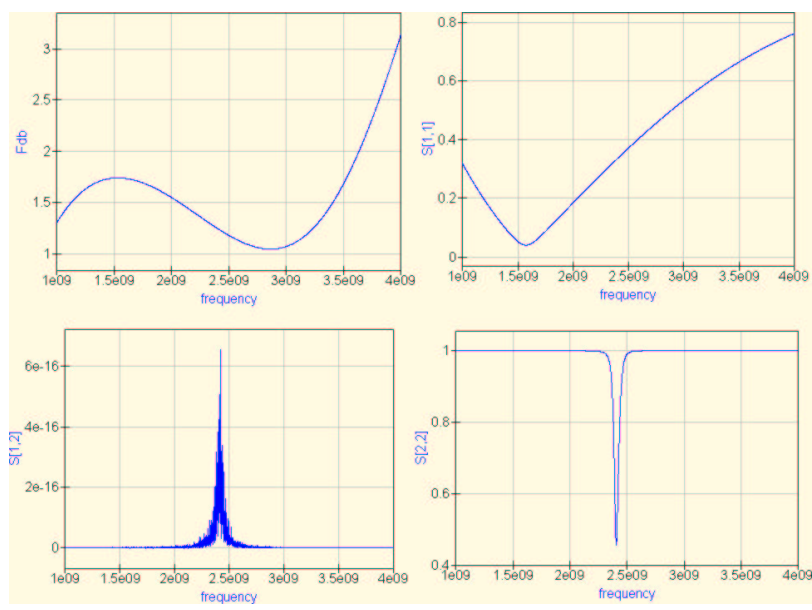

Figura 5.16: F(figura de ruído) em $\mathrm{dB}, S_{12}, S_{11}$ e $S_{22}$

Na Fig.5.17, pode ser analisado a comportamento do amplificador para as frequências adjacentes. Dessa figura pode-se concluir que o funcionamento da amplificador não será sujeito a interferências externas. 


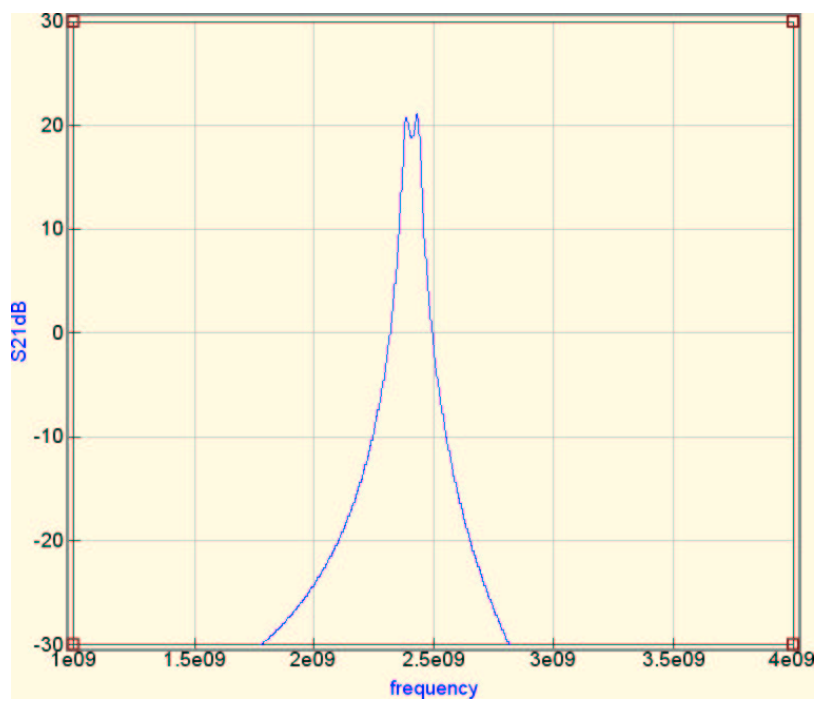

Figura 5.17: Comportamento do amplificador, incluindo parasitas, levando em consideração as frequências adjacentes 


\section{CONCLUSÕES}

Este trabalho focou-se na implementação de uma ferramenta de otimização de circuitos elétricos e no projeto de um amplificador de baixo ruído (LNA). A implementação da ferramenta foi feita em um software livre, QUCS - Quite Universal Circuit Simulator. Com essa escolha, objetivou-se criar um ambiente amigável para o usuário e bem integrado ao programa. O projeto do LNA é tanto uma maneira de verificar o funcionamento do módulo de otimização implantado, quanto uma contribuição para as tecnologias móveis mais modernas como Bluetooth, Wi-Fi e WiMAX.

O otimizador foi desenvolvido com base no algoritmo NSGA-II e em sistemas imunológicos. Esses algoritmos são estruturados com base na teoria genética e nos sistemas imunológicos naturais e apresentam suporte para realização de múltiplas funções-objetivo. A integração dos algoritmos ao programa foi bem sucedida, devido aos resultados atingidos em várias simulações para otimização de funções teste. No menu do software de análise de circuitos foi feita a inclusão do ente Optimize, onde podem ser feitas as configurações para cada otimização.

O amplificador projetado deveria obter, com uma fonte de alimentação de 1,2 V, os seguintes resultados: ganho de potência $\left(S_{21}\right)>15 \mathrm{~dB}$, banda $>10 \mathrm{MHz}$ e F $<3 \mathrm{~dB}$, para frequência central em torno de 2,4 GHz. Com a utilização do algoritmo de otimização, os resultados obtidos foram: ganho de potência igual a aproximadamente $21 \mathrm{~dB}$, banda igual a 67,2 MHz e F igual a 1,9 dB, com frequência central em 2,41 GHz. Pela confrontação entre os dados esperados e os dados obtidos, pode-se afirmar que o LNA resultante da otimização atendeu às demandas instituídas. É importante frisar que esses resultados foram obtidos tanto para o circuito ideal, quanto ao circuito com inclusão de parasitas. Para o circuito com parasitas os resultados obtidos foram: ganho de potência igual a aproximadamente $18,8 \mathrm{~dB}$, banda igual a $50 \mathrm{MHz}$ e F igual a 1,3 dB, com mesma frequência central.

As maiores dificuldades encontradas para realização desta monografia foram: encontrar modelos adequados para transistores e a integração dos algoritmos de otimização ao simulador de circuitos. O material disponibilizado para simulação de transistores é bastante restrito. Outro limitante, em relação à simulação de transistores, é a grande quantidade de modelos disponíveis e o fato dos mesmos não serem conversíveis entre si. Basicamente, foi encontrada uma única fonte ${ }^{1}$ com dezenas de transistores que, infelizmente,

\footnotetext{
${ }^{1}$ Sítio: www.mosis.org
} 
apresentavam um modelo diferente do utilizado pelo QUCS. Nesse sítio, felizmente, existe uma parte dedicada a modelos de transistor para propósitos educacionais, de onde foi possível obter dados do transistor utilizado no LNA projetado.

A maior dificuldade de integração dos algoritmos de otimização deveu-se à sua interface gráfica. Essa interface foi desenvolvida originalmente para sistemas Linux, e apesar de já existirem distribuições Windows do simulador, compilar o mesmo para ambientes Windows tornou-se uma tarefa complicada. A solução encontrada foi a utilização de um emulador de sistemas Linux para Windows(MSys), em conjunto com o IDE (Integrated Development Environment) para criações de interface gráficas QT e o compilador MingW32. Dessa forma, uma complilação cross-plataforma foi realizada (compilação em ambiente Linux com resultados para ambiente Windows).

Uma proposta para trabalhos futuros seria a prototipagem do circuito otimizado. Um circuito otimizado com a ferramenta desenvolvida, implementado em CMOS, poderia ser a prova final do funcionamento do otimizador. Seria imensamente enriquecedor verificar se o que foi atingido via software também se verificaria na forma de circuito integrado. Outra proposta interessante seria agregar ao analisador de circuitos modelos de simulação mais robustos para os transistores. O nível do modelo de transistor utilizado no simulador não leva em consideração uma ampla quantidade de efeitos que podem modificar completamente o comportamento desse dispositivo. 
[1] RAZAVI, B. Design of AnAlog CMOS. [S.1.]: McGraw-Hill, 2001.

[2] LeE, T. H. The Design of CMOS Radio-Frequency Integrated Circuits. [S.1.]: PrenticeHall, 2004.

[3] BARONCini, V. H. V. Projeto de Amplificadores de Baixo Ruído de RF em TeCnologia CMOS usando um modelo baseado em corrente. Departamento de Engenharia Elétrica, Setor de Tecnologia: [s.n.], 2004.

[4] GOEl, A.; KAlia, A. Comparison of nMos, CMO and GaAs Technologies. IEEE, P. $1238-1241$.

[5] EGELS, M. et al. Design Method for fully integrated CMOS RF LNA. ELECTRONICS LETTERS, v. 24, P. 97-99, 2004.

[6] Allstot, D. J. et al. Design Considerations for CMOS Low-Noise Amplifiers. IEEE Radio Frequency Integrated Circuits Symposium, P. 97-99.

[7] ABIDI, A. A. RF CMOS COMES of Age. IEEE JOURNAL OF SOLID-STATE CIRCUITS, v. 39, P. 559-561, 2004.

[8] PARK, S.; KIM, W. Design of A 1.8GHz Low-Noise Amplifier fOr RF Front-End IN A 0.8 $\mu \mathrm{M}$ CMOS TEChNology. IEEE Transactions on Consumer Electronics, v. 47, P. 10-15, 2001.

[9] AMARAL, W. A. do. AmpliCAdor de baixo Ruído a 900 MHz em TeCnologia CMOS para TRANSCEPTOR DE RF EM SOC. Departamento de Engenharia Elétrica: [s.n.], 2004.

[10] ROHDE, U. L.; NEWKIRK, D. P. RF/MicroWAVE Circuit Design fOR Wireless ApplicATIONS. [S.1.]: John Wiley \& Sons, 2000.

[11] CARSON, R. S. High-Frequency Amplifiers. [S.1.]: John Wiley \& Sons, 1982.

[12] AlbUlet, M. RF Power Amplifiers. [S.1.]: Noble Publishing, 2001.

[13] M, P. D. Microwave Engineering. [S.1.]: John Wiley \& Sons, 2005. 
[14] CONRADO, L. F. M. Estudo sobre AMPLifiCAdores De Microondas. Departamento de Engenharia Elétrica: [s.n.], 1979.

[15] DEB, K. et al. IEEE Transactions on Evolutionary Computation.

[16] CAStRo, L. N. de. Fundamentals of natural computing: Basic Concepts, AlgoRITHMS, AND APPLICATIONS. [S.1.]: Chapman \& Hall/CRC Taylor \& Francis Group, 2006. 
ANEXOS 

Tabela I.1: Parâmetros de caracterização de transistores - Level 1

\begin{tabular}{|c|l|}
\hline Parâmetro & Valor \\
\hline Vt0 & 0,4238252 \\
\hline Kp & $2,501048 \mathrm{E}-4$ \\
\hline Gamma & 0,431731 \\
\hline Phi & 0,7 \\
\hline Lambda & 0 \\
\hline Is & Corrente de saturação na junção \\
\hline Rd & 0 \\
\hline Rs & 0 \\
\hline Rg & 0 \\
\hline $\mathrm{N}$ & 1 \\
\hline Ld & $3,162278 \mathrm{E}-11$ \\
\hline Tox & $5,7 \mathrm{E}-9$ \\
\hline Cgso & $6,2 \mathrm{E}-10$ \\
\hline Cgdo & $6,2 \mathrm{E}-10$ \\
\hline Cgbo & $1 \mathrm{E}-10$ \\
\hline Pb & 0,5 \\
\hline $\mathrm{Mj}$ & 0,3282553 \\
\hline Fc & 0,5 \\
\hline Cjsw & $5,341337 \mathrm{E}-10$ \\
\hline Mjsw & 0,5 \\
\hline Nsub & $1 \mathrm{E} 17$ \\
\hline Uo & 425,6466519 \\
\hline Rsh & $4,062439 \mathrm{E}-3$ \\
\hline $\mathrm{Cj}$ & $1,81211 \mathrm{E}-3$ \\
\hline Tpg & 1 \\
\hline & \\
\hline
\end{tabular}

